\title{
Handbook on the Material Properties of FeCrAl Alloys for Nuclear Power Production Applications
}

(FY18 Version: Revision 1.1)

\section{Nuclear Technology}

Research and Development

Approved for public release. Distribution is unlimited.
Prepared for

U.S. Department of Energy Nuclear Technology R\&D Advanced Fuels Campaign FY18 version author(s): Kevin G. Field ${ }^{1}$ FY17 version author(s) Kevin G. Field ${ }^{1}$, Mary A. Snead ${ }^{2}$, Yukinori Yamamoto", Kurt A. Terrani ${ }^{1}$

1Oak Ridge National Laboratory ${ }^{2}$ Brookhaven National Laboratory

August 2018 M2NT-18OR020202091 



\section{DISCLAIMER}

This information was prepared as an account of work sponsored by an agency of the U.S. Government. Neither the U.S. Government nor any agency thereof, nor any of their employees, makes any warranty, expressed or implied, or assumes any legal liability or responsibility for the accuracy, completeness, or usefulness, of any information, apparatus, product, or process disclosed, or represents that its use would not infringe privately owned rights. References herein to any specific commercial product, process, or service by trade name, trade mark, manufacturer, or otherwise, does not necessarily constitute or imply its endorsement, recommendation, or favoring by the U.S. Government or any agency thereof. The views and opinions of authors expressed herein do not necessarily state or reflect those of the U.S. Government or any agency thereof. 



\section{FOREWARD TO FY18 REVISION}

The "Handbook on the Materials Properties of FeCrAl Alloys for Nuclear Power Production Applications" was published in its first version in United States Fiscal Year August 2017 with the intention to begin the process of collecting, distilling, and then disseminating the current knowledgebase on cast and wrought $\mathrm{FeCrAl}$ alloys intended for use in both fission and fusion based nuclear power production [1]. The handbook was broken into two primary sections, the first being on unirradiated material properties and the second being on irradiated properties. It was expected at the time of publication that the document would exist as a "living" document and updates would be made when additional findings, results, and publications regarding nuclear-focused $\mathrm{FeCrAl}$ alloys became available. The revision of the original handbook contained within and monikered: FY18 Version: Revision 1 serves as the first update based on new or newly discovered findings.

The FY18 revision contains 10+ pages of new content, with a significant focus on providing the first findings from integral irradiation testing completed within the United States and abroad. The result is over 45 new citations, 6 new figures, and 1 additional table are included in the provided revision. The quantity and quality of additional studies completed within a one-year time span signals the fact the $\mathrm{FeCrAl}$ alloys still remain a strongly relevant alloy class for nuclear power applications and one of the most important metallic alloys for consideration as an accident tolerant fuel (ATF) cladding. The table below quickly summarizes the significant updates made within the contained revision. Data provided within is available upon request from the primary author. It is intended that the handbook will remain a living document with additional updates provided in the future.

Summary of updates made between the FY17 and FY18 versions of the FeCrAl handbook

\begin{tabular}{|c|c|c|}
\hline Section & Sub-section & Updates made: \\
\hline \multirow[t]{3}{*}{1} & 1.1 & - Updated to indicate current version is a revision \\
\hline & 1.2 & - $\quad$ Added comments regarding depth of material covered \\
\hline & $1.3-1.4$ & ( \\
\hline \multirow[t]{2}{*}{2} & 2.1 & None \\
\hline & 2.2 & $\begin{array}{l}\text { - Updated to include importance of inter-pass annealing on tube fabrication } \\
\text { - Updated to include recent friction stir welding studies }\end{array}$ \\
\hline \multirow[t]{4}{*}{3} & $3.1-3.2$ & None \\
\hline & 3.3 & $\begin{array}{l}\text { - Updated to include dynamic strain aging effects } \\
\text { - } \text { Updated property-property relationship } \\
\text { - Added discussion on microstructure role on fracture properties } \\
\text { - } \text { Added recent nanohardness results } \\
\text { - Adated creep properties with C26M data } \\
\text { - Udded new sub-section on fatigue from newly found data } \\
\text { - Updetting and wear to include new study on APMT }\end{array}$ \\
\hline & 3.4 & - Updated to include section on low-temperature oxidation in air \\
\hline & 3.5 & 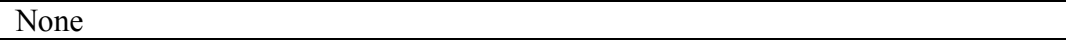 \\
\hline \multirow[t]{6}{*}{4} & 4.1 & $\begin{array}{l}\text { - Added discussion on techniques for dislocation loop characterization } \\
\text { - } \quad \text { Added discussion on comparison of ions to neutrons under irradiation }\end{array}$ \\
\hline & $4.2-4.3$ & None \\
\hline & 4.4 & $\begin{array}{ll}\text { - } & \text { Updated to include irradiation temperature trends } \\
\text { - } & \text { Updated to include recent nanohardness study } \\
\end{array}$ \\
\hline & 4.5 & - $\quad$ Updated to include corrosion study under irradiation \\
\hline & 4.6 & - $\quad$ Added to Section 4 \\
\hline & 4.7 & - $\quad$ Added to Section 4 \\
\hline 5 & & None \\
\hline 6 & & - Updated based on body content \\
\hline Appendix A & & $\begin{array}{ll}\text { - } & \text { Added alloys derived from KTH } \\
\text { - } & \text { Added additional ORNL Generation II alloys }\end{array}$ \\
\hline
\end{tabular}


Handbook on the Material Properties of FeCrAl Alloys for Nuclear Power Production Applications 


\section{SUMMARY}

FeCrAl alloys are a class of alloys that have seen increased interest for nuclear power applications including accident tolerant fuel cladding, structural components for fast fission reactors, and as first wall and blanket structures for fusion reactors. $\mathrm{FeCrAl}$ alloys are under consideration for these applications due to their inherent corrosion resistance, stress corrosion cracking resistance, radiation-induced swelling resistance, and high temperature oxidation resistance. A substantial amount of research effort has been completed to design, develop, and begin commercial scaling of $\mathrm{FeCrAl}$ alloys for nuclear power applications over the past half a century. These efforts have led to the development of an extensive database on material properties and process knowledge for $\mathrm{FeCrAl}$ alloys but not within a consolidated format. The following report is the first revision of a materials handbook to consolidate the current state of knowledge on $\mathrm{FeCrAl}$ alloys for nuclear power applications. This centralized database focuses solely on wrought $\mathrm{FeCrAl}$ alloys; oxide dispersion strengthened alloys, although discussed in brief, are not covered. Where appropriate, recommendations for applications of the data is provided and current knowledge gaps are identified. 
Handbook on the Material Properties of FeCrAl Alloys for Nuclear Power Production Applications 


\section{CONTENTS}

FOREWARD TO FY18 REVISION. iii

SUMMARY $\mathrm{v}$

ACRONYMS xii

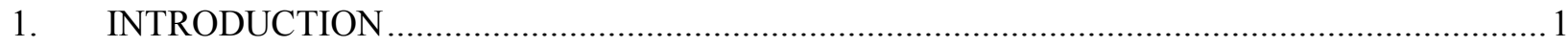

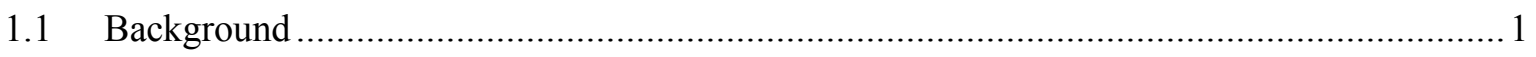

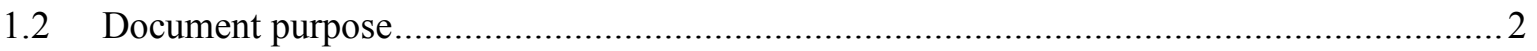

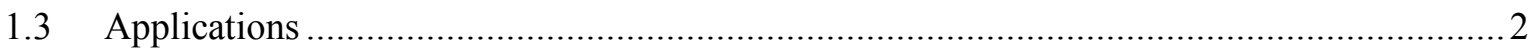

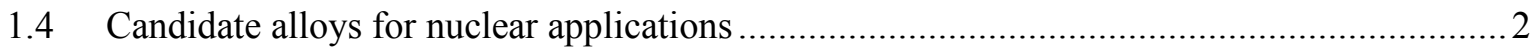

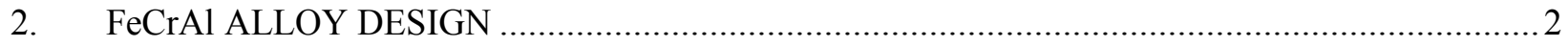

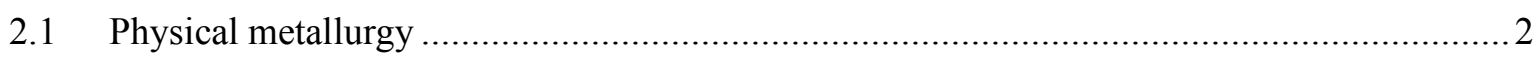

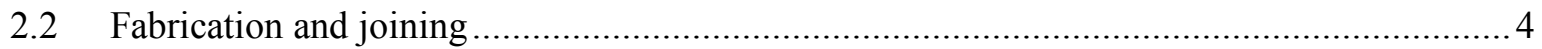

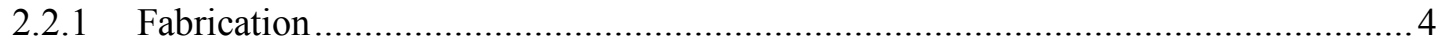

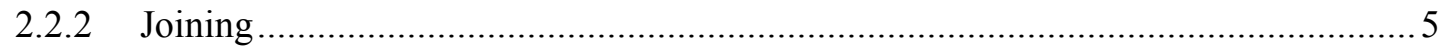

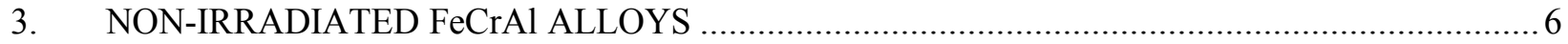

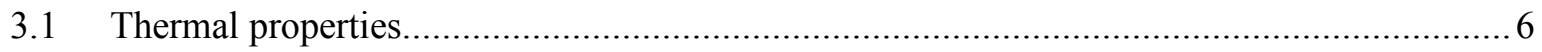

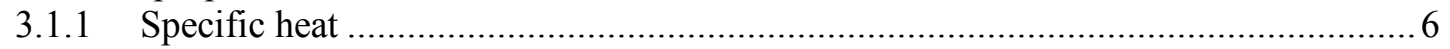

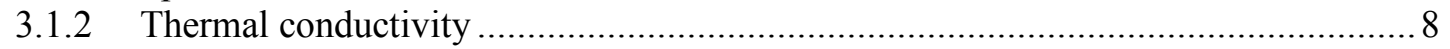

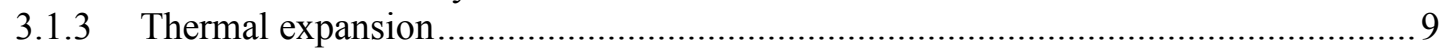

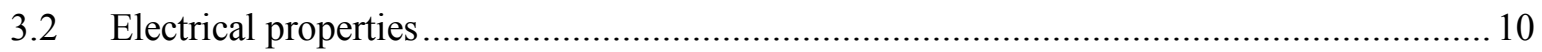

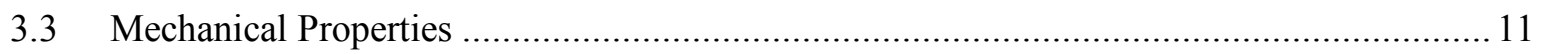

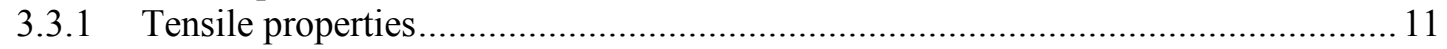

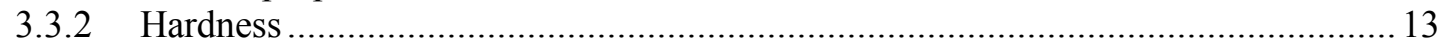

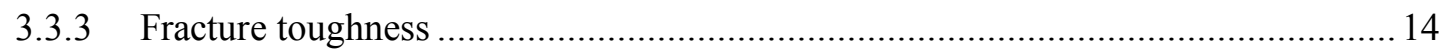

3.3.4 Elastic modulus, Poisson's ratio, and Shear modulus .............................................. 15

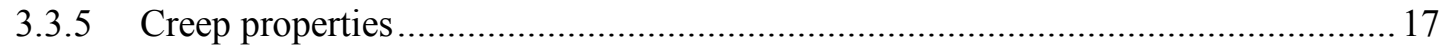

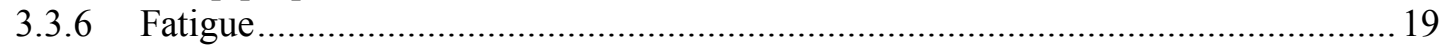

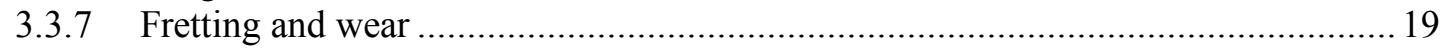

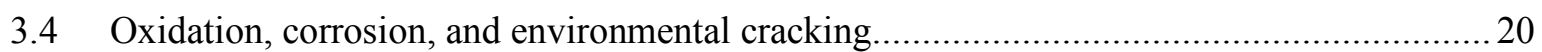

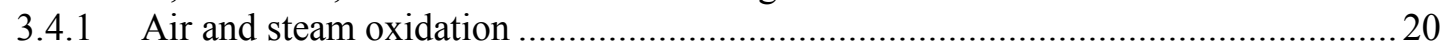

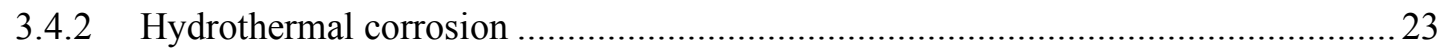

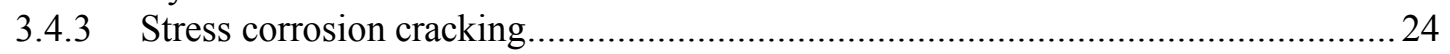

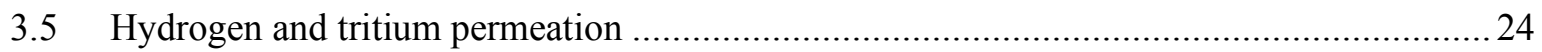

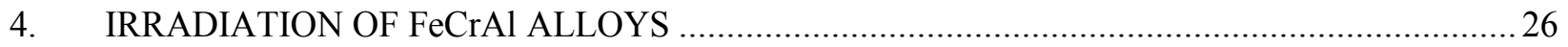

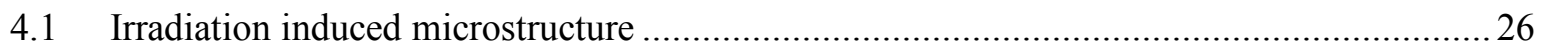

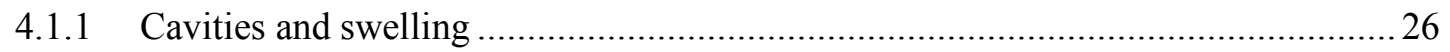

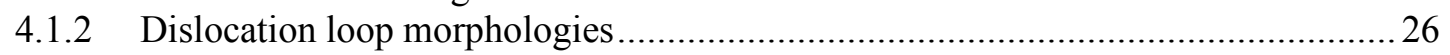

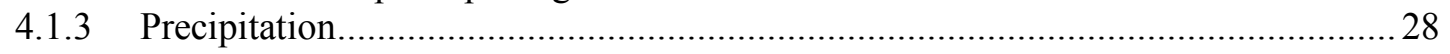

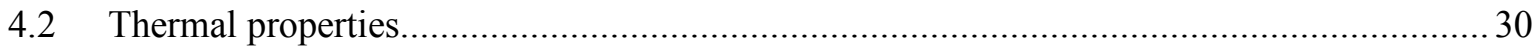

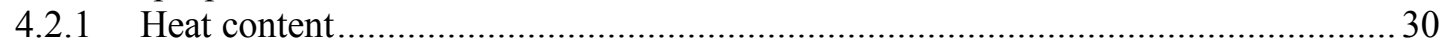




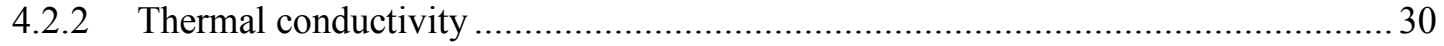

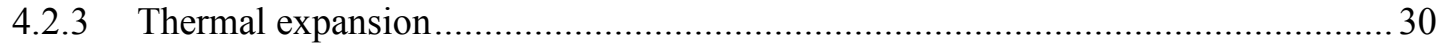

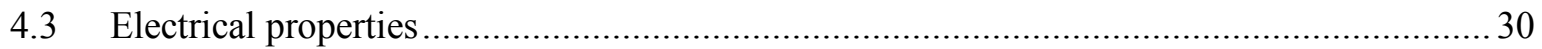

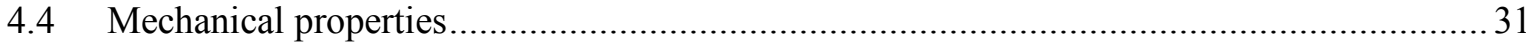

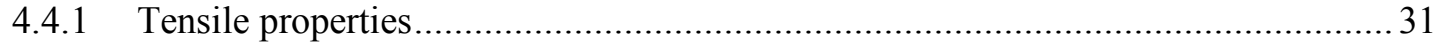

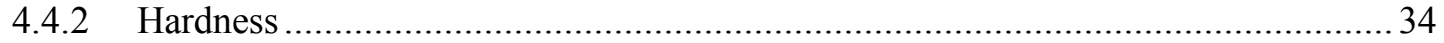

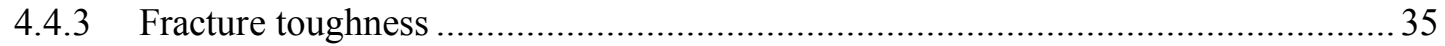

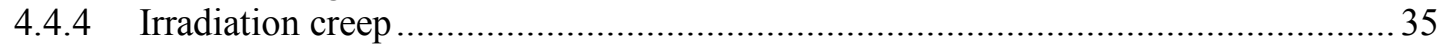

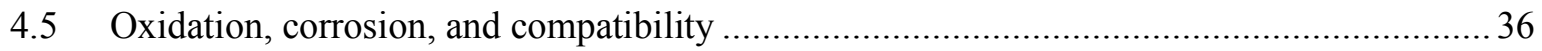

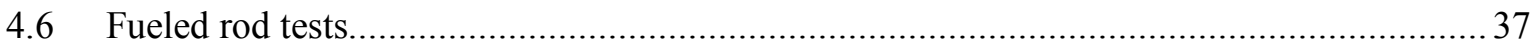

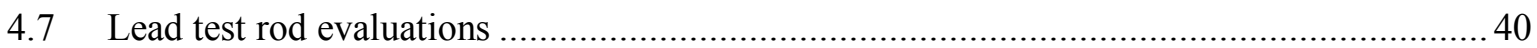

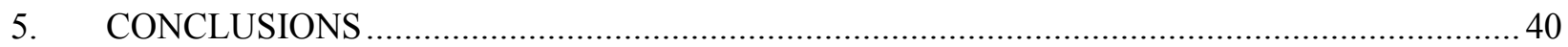

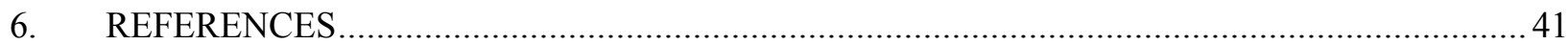

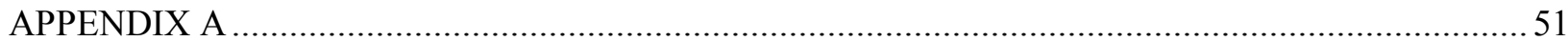

\section{FIGURES}

Figure 1: Fe-Cr binary alloy phase diagram showing phase boundaries of $\alpha-\mathrm{Fe}, \alpha^{\prime}-\mathrm{Cr}$, and $\sigma-\mathrm{FeCr}$. The effect of $\mathrm{Al}$ additions on the $\alpha-\alpha^{\prime}$ phase boundary is also shown; $4 \mathrm{wt} . \%$ boundary shown as example [23] 3

Figure 2: Tube production flow chart for thin walled cladding [35]. .5

Figure 3: Cracking susceptibility map for weld overlays in FeCrAl alloys. Reproduced from [39].

Dashed line is extrapolation of the fitted spline function. 6

Figure 4: Specific heat capacity of select FeCrAl alloys at elevated temperatures. Symbols are experimental data points while solid lines are empirical fits using Eqn. 3.1-3.2.......

Figure 5: Thermal conductivity of select $\mathrm{FeCrAl}$ alloys at elevated temperatures. Error bars represent a $7 \%$ error due to the assumed experimental variability in the heat capacity, thermal diffusivity, and density.

Figure 6: Thermal expansion coefficients of select $\mathrm{FeCrAl}$ alloys at elevated temperatures.

Figure 7: Yield strength and total elongation properties for select $\mathrm{FeCrAl}$ alloys as a function of temperature.

Figure 8: Room temperature tensile properties of model FeCrAl alloys as a function of $\mathrm{Al}$ content

(a) and $\mathrm{Cr}$ content (b). Open symbols correspond to total elongation; closed symbols correspond to yield strength [38].

Figure 9: Room temperature hardness values for model $\mathrm{FeCrAl}$ alloys. (a) $\mathrm{Cr}$ and $\mathrm{Al}$ effect on microhardness [63] and (b) simple property-property correlation between ultimate tensile strength and microhardness for unirradiated $\mathrm{FeCrAl}$ alloys [5,65-67].

Figure 10: DBTT as a function of $\mathrm{Al}$ content in 23-25 wt.\% $\mathrm{Cr} \mathrm{FeCrAl}$ alloys [34]. 
Figure 11: Elastic moduli (a) and Poisson's ratio (b) of various ORNL wrought FeCrAl alloys [68] and Kanthal APMT [70] as a function of temperature. Fits for wrought data provided within figure.

Figure 12: Creep rates versus applied stress for varying $\mathrm{FeCrAl}$ alloys (a) and Arrhenius plot of compiled creep data for given $\mathrm{FeCrAl}$ alloys where the ordinate axis is normalized to the creep exponent (b). Symbols for given alloys are identical in both plots [5,71-74]....

Figure 13: Creep rupture for varying FeCrAl alloys. Legend is identical to Figure 12a.

Figure 14: Cyclic stress response curves of a Fe-23.85Cr-3.89Al in wt.\% alloy tested (a) at $400^{\circ} \mathrm{C}$ at various strain amplitudes and (b) at a strain amplitude of $0.3 \%$ at various test temperatures. Reproduced from [58].

Figure 15: Effect of $\mathrm{Cr}$ and $\mathrm{Al}$ alloy content on steam oxidation resistance at $1200^{\circ} \mathrm{C}$ in $\mathrm{FeCrAl}$ alloys. (a) green, up-triangle symbols showing compositions which form a protective alumina scale and red, down-triangle symbols are those that are not protective [88], dashed line is arbitrary boundary separating the two regimes. Where kinetic data is available [21] circles are scaled with the scaling factor (S) presented to the Kanthal APMT parabolic oxidation rate as shown in inset, $k p C r, A l=S \cdot k p A P M T: 1200^{\circ} \mathrm{C}$. (b) maximum use temperature determined via "ramp" testing, green circles are alloys with maximum use above $1200^{\circ} \mathrm{C}$ [89].....

Figure 16: Arrhenius plot of the fitted hydrogen permeability for several FeCrAl alloys [109114]. Closed symbols are for samples with limited to no oxidation, open symbols are for oxidized specimens, (D): deuterium permeability, (T): tritium permeability. .25

Figure 17: On-[100] zone STEM-BF images showing dislocation loops in ORNL model and commercial FeCrAl alloys irradiated to 1.8 dpa at $364-382^{\circ} \mathrm{C}$. (a) F1C5AY [24], (b) B125Y [24], (c) B154Y-2 [24], (d) B183Y-2 [24], (e) C35M, (f) Alkrothal 720 [117], (g) Kanthal APMT [118]. .28

Figure 18: Atom probe tomography $\mathrm{Cr}$ atom maps showing precipitation of $\alpha^{\prime}$ after neutron irradiation [96]. B183Y-2 as-received, $0.8 \mathrm{dpa}$ at $355^{\circ} \mathrm{C}, 1.8 \mathrm{dpa}$ at $382^{\circ} \mathrm{C}$, and $7.0 \mathrm{dpa}$ at $320^{\circ} \mathrm{C}$, (a-d) respectively. FeCrAl alloys irradiated to 7.0 dpa at $320^{\circ} \mathrm{C}$, (e) $\mathrm{F} 1 \mathrm{C} 5 \mathrm{AY}$, (f) B125Y, (g) B154Y-2, (h) B183Y-2. All maps taken with a $20 \mathrm{~nm}$ z-axis (in-page) slice.

Figure 19: Bubble plot indicating change in $0.2 \%$ offset yield strength $(\Delta \sigma y 0.2 \%)$ as a function of damage dose (dpa) and alloy $\mathrm{Cr}$ content for tensile tests performed at (a) room temperature $\left(\mathrm{T}_{\text {test }}=24^{\circ} \mathrm{C}\right)$ and $(\mathrm{b})$ elevated temperature $\left(\mathrm{T}_{\text {test }}=320^{\circ} \mathrm{C}\right)$. Open symbols for Kanthal APMT and B183Y-2 represent tests that failed in a brittle manner. Symbol " $\times$ " represents data points where the brittle failure stress occurred below the unirradiated yield stress. Legends in (a) and (b) are valid for both plots. Reproduced from [62].

Figure 20: Mechanical properties - yield (YS) and ultimate tensile (UTS) strength, uniform (UE) and total (TE) elongation of C35M SS-J and SS-2E type specimens in the as-received (AR, e.g. non-welded) and the as-welded (AW) states irradiated at varying temperatures in the dose range of $1.8 \mathrm{dpa}$ to $1.9 \mathrm{dpa}$. Baseline data shown on the left portion of each plot for comparison. Reproduced from [138].

Figure 21: Scatter plot indicating change in nanohardness as a function of damage dose (dpa) and alloy for nanohardness tests performed at room temperature $\left(\mathrm{T}_{\text {test }}=24^{\circ} \mathrm{C}\right)$. Averages and standard deviations (error bars) come from a total of 8-27 tests for each data point. Reproduced from [120]. 
Figure 22: Normalized creep data using the Zenner-Holloman parameter for 1541 [5] and C35M alloys [71] irradiated to low dose $(<1 \mathrm{dpa})$ at temperatures of $50^{\circ} \mathrm{C}$ and $350^{\circ} \mathrm{C}$, respectively...... 36

Figure 23: Optical images of FeCrAl specimens after peak irradiation fluence of $1.21 \times 10^{21} \mathrm{n} / \mathrm{cm}^{2}$ (E $>0.1 \mathrm{MeV}$ - dpa was not reported) in PWR-like water conditions; (a) Kanthal AF, (b) C36M3, and (c) C06M. Images courtesy of Y. Katoh (ORNL). .37

Figure 24: Images of capsule and rodlet assembly for FCA-L3 rodlet from the ATF-1 irradiation in the ATR. (a) optical image of capsule assembly, (b) neutron radiography of capsule and rodlet assemblies, (c) optical image of rodlet assembly. Reproduced from [154].

Figure 25: Cladding elongation (EC, in $\mathrm{mm}$ ) in $\mathrm{C} 06 \mathrm{M} 2$ after two cycles of neutron irradiation near $300^{\circ} \mathrm{C}$ in the Halden Reactor as a function of full power days (FPD). Results provided courtesy of K. Terrani (ORNL), first cycle data (blue) presented in [156].

Figure 26: Fueled rodlets for a full length rodlet (red label) and segmented rods (blue and purple labels) for C06M2 and C36M3 after one cycle $\left(1.4 \mathrm{MWd} / \mathrm{kgUO}_{2}\right)$ in the IFA-796 experiment. Results provided courtesy of K. Terrani (ORNL).

\section{TABLES}

Table 1: Coefficients of empirical formulas for the specific heat capacity of various FeCrAl alloys.

Table 2: Coefficients of second-order polynomial fit for the thermal conductivity coefficient of various $\mathrm{FeCrAl}$ alloys.

Table 3: Coefficients of third-order polynomial fit for the thermal expansion coefficient of various $\mathrm{FeCrAl}$ alloys.

Table 4: Estimated creep parameters for varying FeCrAl alloys based on Eqn. (3.9)

Table 5: Parabolic oxidation $\left(k_{1}\right)$ and dissolution $\left(k_{2}\right)$ rate constants for various $\mathrm{FeCrAl}$ alloys [103].

Table 6: Estimated permeability parameters for varying $\mathrm{FeCrAl}$ alloys.

Table 7: Comparison of two electron microscopy approaches to quantify the dislocation loop population in $\mathrm{C} 06 \mathrm{M} 2$ and $\mathrm{C} 36 \mathrm{M} 3$ after heavy ion irradiations at $300^{\circ} \mathrm{C}$. Reproduced from [120]. 
Handbook on the Material Properties of FeCrAl Alloys for Nuclear Power Production Applications

August 2018 


\section{ACRONYMS}

\begin{tabular}{|c|c|c|c|}
\hline Acronym & Description & Acronym & Description \\
\hline $\mathrm{Al}$ & Aluminum & LWR & Light water reactor \\
\hline APT & Atom probe tomography & MA-ODS & $\begin{array}{l}\text { Mechanically alloyed oxide dispersion } \\
\text { strengthening }\end{array}$ \\
\hline ASTM & $\begin{array}{l}\text { American society for testing and } \\
\text { materials }\end{array}$ & $\mathrm{MeV}$ & Mega electron volt \\
\hline ATF & Accident tolerant fuel & $\min$ & Minute \\
\hline ATR & Advanced Test Reactor & MIT & Massachusetts Institute of Technology \\
\hline $\mathrm{BCC}$ & Body-centered-cubic structure & MITR & $\begin{array}{l}\text { Massachusetts Institute of Technology } \\
\text { reactor }\end{array}$ \\
\hline BWR & Boiling water reactor & $\mathrm{mm}$ & Millimeter \\
\hline CERT & Constant extension rate tensile & Mo & Molybdenum \\
\hline $\mathrm{cm}$ & Centimeter & MOX & Mixed oxide fuel \\
\hline $\mathrm{Cr}$ & Chromium & $\mathrm{MPa}$ & Megapascal \\
\hline DBTT & Ductile brittle transition temperature & $\mathrm{n}$ & Neutrons \\
\hline Dpa & Displacements per atom & $\mathrm{Nb}$ & Niobium \\
\hline DSA & Dynamic strain aging & NWC & Normal water chemistry \\
\hline DSC & Differential scanning calorimetry & ${ }^{\circ} \mathrm{C}$ & Degree Celsius \\
\hline EBW & Electron beam welding & ODS & Oxide dispersion strengthened \\
\hline EDS & Energy dispersive X-ray spectroscopy & ORNL & Oak Ridge National Laboratory \\
\hline ETR & Engineering test reactor & PCMI & Pellet cladding mechanical interaction \\
\hline FCC & Face-centered-cubic structure & PM & Powder metallurgy \\
\hline FSW & Friction stir welding & PRW & Pressure resistance welding \\
\hline $\mathrm{Fe}$ & Iron & PWR & Pressurized water reactor \\
\hline $\mathrm{FeCrAl}$ & Iron-chromium-aluminum & RUS & Resonant ultrasound spectroscopy \\
\hline FMDP & Fissile Materials Disposition Program & SANS & Small angle neutron scattering \\
\hline GE & General Electric & SBO & Station black out \\
\hline GMAW & Gas metal arc welding & SCC & Stress corrosion cracking \\
\hline GTAW & Gas tungsten arc welding & STEM-BF & $\begin{array}{l}\text { Scanning transmission electron } \\
\text { microscope - Bright field }\end{array}$ \\
\hline GTRF & Grid to grid fretting & TE & Total elongation \\
\hline HAZ & Heat affected zone & TGA & Thermogravimetric Analysis \\
\hline HIP & Hot-isostatic press & TMT & Thermo-mechanical treatment \\
\hline $\mathrm{hr}$ & Hour & UE & Uniform elongation \\
\hline $\mathrm{Hv}$ & Micro-hardness & $\mathrm{UO}_{2}$ & Uranium di-oxide \\
\hline HWC & Hydrogen water chemistry & UOKV & $\begin{array}{l}\text { Umantsev-Olson-Kuehmann- } \\
\text { Voorhees }\end{array}$ \\
\hline IASCC & $\begin{array}{l}\text { Irradiation assisted stress corrosion } \\
\text { cracking }\end{array}$ & UTS & Ultimate tensile strength \\
\hline IFA & Instrumented Fuel Assembly & VIM & Vacuum induction melt process \\
\hline IFE & Institutes for Energy Technology & wt.\% & Weight percentage \\
\hline $\mathrm{K}$ & Kelvin & $\mathrm{Y}$ & Yttrium \\
\hline LBW & Laser beam welding & $\mathrm{Zr}$ & Zirconium \\
\hline LOCA & Loss of coolant accident & $\mu \mathrm{m}$ & micrometer \\
\hline
\end{tabular}


Handbook on the Material Properties of FeCrAl Alloys for Nuclear Power Production Applications

August 2018 



\section{HANDBOOK ON THE MATERIAL PROPERTIES OF FECRAL ALLOYS FOR NUCLEAR POWER PRODUCTION APPLICATIONS}

\section{INTRODUCTION}

\subsection{Background}

Iron-chromium-aluminum ( $\mathrm{FeCrAl})$ alloys are an alloy class typically deployed within industrial applications where high temperature oxidation resistance is needed. $\mathrm{FeCrAl}$ alloys have been primarily used as heating elements and components in high temperature furnaces due to their superior oxidation resistance over many other common materials. Over the past half a century, FeCrAl alloys have also been considered for structural applications for varying industrial applications including for the nuclear power industry. The earliest large-scale effort within the nuclear industry was completed as part of the High-Temperature Materials and Reactor Component Development Program which is documented in a series of publicly available reports published by General Electric (GE) Corporation [2-10]. The large-scale program was focused on developing fuel elements for elevated temperature nuclear applications that included coolants of steam, air, and carbon dioxide. A series of different $\mathrm{FeCrAl}$ alloys with varying Cr content (typically 515 wt.\%) and Al content (typically 3-6 wt.\%) were developed and evaluated. Evaluations included fuelclad compatibility, high-temperature exposure in both air and steam, aging, welding/formability, and radiation effects, among several other topics. Processing routes included wrought and powder metallurgy techniques with final form factors of both plate and tube. Most alloys were simple systems with only Fe, $\mathrm{Cr}, \mathrm{Al}$, and Y used to form the alloy; these alloys are deemed "GE model" alloys herein.

Publicly available program reports on the GE model alloys exist into the late 1960s, although some studies were present later including the swelling study nearly a decade later by Little and Stow [11]. Limited details on the extinction of FeCrAl alloys within the program are given but indications are that the lack of hightemperature mechanical properties [12] and lower temperature embrittlement [13] were significant reasons for not considering further pursuit past the last available report of the program [5].

Forty years later, the nuclear accident in Japan in 2011 served as the catalyst for the recent boom in interest of FeCrAl alloys for nuclear power applications. The accident that occurred in Japan spawned considerable research devoted to identifying light water reactor (LWR) fuel systems that tolerate severe accident scenarios (i.e. beyond design basis accidents) [14-17]. The objective is to provide larger safety margins, i.e. delay the onset of severe core degradation by reducing the rate of $\mathrm{H}_{2}$ and heat generated by the rapid oxidation of Zr-based alloy cladding and increase the coping time after an accident [14-18]. Development of nuclear grade, iron-based wrought $\mathrm{FeCrAl}$ alloys has been initiated for LWR fuel cladding to serve as a substitute for Zr-based alloys with enhanced accident tolerance.

Significant efforts on developing FeCrAl alloy(s) have been conducted by commercial entities, national laboratories, and universities, many times with significant cross collaborations between the different research sectors. Again, both wrought $\mathrm{FeCrAl}$ and powder-metallurgy based $\mathrm{FeCrAl}$ alloys are currently under development. The most systematic efforts have been focused on the development of wrought FeCrAl alloys which are to be considered "nuclear grade." In this context, "nuclear grade" means an optimized composition to perform in both normal and off-normal conditions. Much of these wrought FeCrAl alloy studies are on Oak Ridge National Laboratory (ORNL) developed compositions including two different generations of alloys. "Generation I" alloys are simple alloys, similar in composition and structure to the GE Model alloys, while "Generation II" alloys are derived from Generation I alloys but include minor 
alloying additions to increase specific performance factors [14]. Herein, both generations of alloys are grouped together as "ORNL model" alloys unless directly specified.

FeCrAl alloys as a class of materials can demonstrate a wide range of properties depending on their structure, chemistry, and processing. Through combining the databases produced on the GE and ORNL model alloys, as well as other significant commercial and model alloy systems, the first edition of a comprehensive handbook on $\mathrm{FeCrAl}$ alloys for nuclear power applications was developed. This handbook served to draw from nearly half a century of scientific research. Since the publication of the first edition, significant gains have been made on a range of topics for $\mathrm{FeCrAl}$ alloys. As such, recent findings have been incorporated into the first edition resulting in the present second edition. It is intended that this edition will be updated as more results and data are presented throughout the available literature.

\subsection{Document purpose}

This document is an effort to identify and describe all of the available physical, mechanical, thermal, and performance property data for $\mathrm{FeCrAl}$ alloys in nuclear power applications. This includes newly developed (i.e. ORNL model alloys) and historical materials (i.e. GE model alloys). Where appropriate, the detailed trends on composition and/or microstructure are provided to guide the user towards an optimized composition and microstructure space for any specific application. This document includes fabrication data (as-manufactured data) as well as available irradiation and accident data. The sections contained within are developed to frame specific topics but does not provide an exhaustive discussion of any one topic. Readers should look towards the cited references for additional discussion on any given topic. This handbook is intended for use by researches, modelers, and reactor designers.

\subsection{Applications}

The excellent oxidation and corrosion resistance of $\mathrm{FeCrAl}$ alloys means wide-scale applicability to nuclear power generation. FeCrAl alloys are currently under consideration as accident tolerant fuel (ATF) cladding, structural components for advanced reactor designs including fast reactors, and as first wall and blanket structures for fusion reactors.

\subsection{Candidate alloys for nuclear applications}

FeCrAl alloys span a wide range of compositions and microstructures. Several commercial alloys are under consideration for nuclear applications, but a vast array of studies have been completed on model alloys or simple alloy systems. Appendix A provides a list of common candidate alloys used throughout the remainder of this work.

\section{FeCrAI ALLOY DESIGN}

\subsection{Physical metallurgy}

FeCrAl alloys mainly consist of iron $(\mathrm{Fe})$, chromium $(\mathrm{Cr})$, and aluminum $(\mathrm{Al})$, together with minor alloying additions for various purposes, such as solid-solution hardening, precipitate hardening, grain size control, oxidation resistance, and so on. The matrix is fully ferritic (body-centered-cubic structure, BCC) phase with typically no phase transformation to/from austenite (face-centered-cubic structure, FCC) in the range from liquidus temperature to room temperature. This is due to a strong $\mathrm{BCC}$ stabilizing effect of $\mathrm{Cr}$ and $\mathrm{Al}$ additions on $\mathrm{Fe}$ base alloys [19]. Additions of $\mathrm{Cr}$ and $\mathrm{Al}$ are essential for improving oxidation resistance at 
elevated temperatures by forming protective, continuous alumina (aluminum oxide, $\alpha-\mathrm{Al}_{2} \mathrm{O}_{3}$ ) scales on the surface [20]. The effect of oxidation resistance on FeCrAl alloys increases with the amounts of $\mathrm{Cr}$ and $\mathrm{Al}$ additions [21]. The $\mathrm{Cr}$ addition is also known to reduce the required amount of the $\mathrm{Al}$ addition to form aluminum oxide scale, which is a so-called third element effect [22]. The amounts of $\mathrm{Cr}$ and $\mathrm{Al}$ additions need to be balanced for not only the surface protection effect but also the property control purpose; e.g. avoiding brittle $\sigma-\mathrm{FeCr}$ or $\alpha^{\prime}$-Cr phase formation by minimizing the $\mathrm{Cr}$ content. $\mathrm{FeCrAl}$ alloys typically contain some portion of reactive element additions.

The Fe-Cr binary phase diagram in Figure 1 [23] indicates the formation of Cr-rich $\alpha$ phase in the binary alloy at relatively low temperature range (below $\sim 500^{\circ} \mathrm{C}$ ) where LWRs would be operated, and it is known that such Cr-rich $\alpha^{\prime}$ formation typically makes the material brittle [24]. Note, the $\alpha-\alpha^{\prime}$ boundary shown in Figure 1 does not take into account recent studies, the currently proposed boundary is shifted toward higher $\mathrm{Cr}$ for $\mathrm{FeCr}$ alloys, see Ref. [25]. The $\mathrm{Al}$ addition, however, increases the solubility limit of $\mathrm{Cr}$ in $\alpha$-Fe matrix significantly, as shown in Figure 1, and reduces the driving force of Cr-rich $\alpha$ phase formation even with relatively high $\mathrm{Cr}$ containing alloys. Further details on the low temperature phase stabilities in $\mathrm{FeCrAl}$ alloys are discussed in detail elsewhere [26-28].

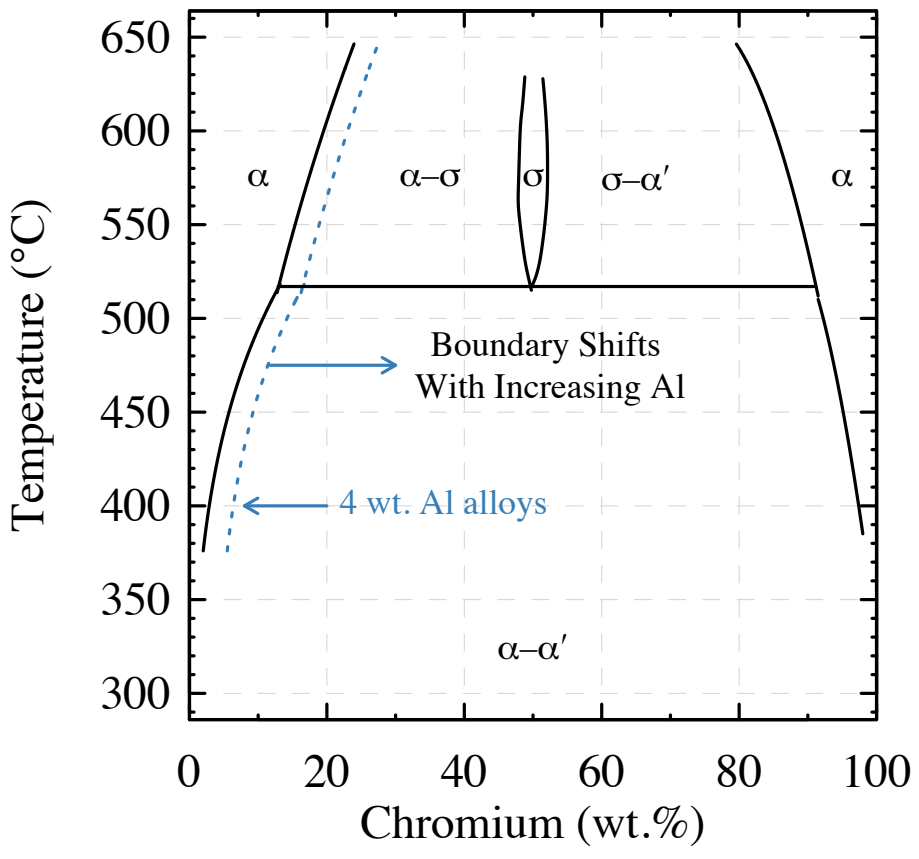

Figure 1: Fe-Cr binary alloy phase diagram showing phase boundaries of $\alpha-\mathrm{Fe}, \alpha^{\prime}-\mathrm{Cr}$, and $\sigma-\mathrm{FeCr}$. The effect of $\mathrm{Al}$ additions on the $\alpha-\alpha^{\prime}$ phase boundary is also shown; 4 wt.\% boundary shown as example [23].

Reactive element additions have shown to reduce the growth rate of the alumina scale and increase the adherence of the scale during oxidation trials and thermal cycling [29,30]. The typical reactive element of choice is yttrium. Small yttrium additions can significantly increase the oxidation resistance of the alloy(s). The solubility of yttrium in the ferritic matrix is quite low $(<0.1 \mathrm{wt} . \%)$ leading to a fine dispersion of the intermetallic $\mathrm{YFe}_{9}$ compound [23]. Fine dispersions of the $\mathrm{YFe}_{9}$ compound lends itself towards better mechanical properties.

The vacuum melt process is suggested for nuclear grade FeCrAl alloy heat production to obtain the target alloy composition and avoid potential contamination of unintended/undesired elemental additions, such as 
nitrogen. High nitrogen content in $\mathrm{FeCrAl}$ alloy leads to a coarse aluminum nitride particle formation during the solidification process, which typically degrades both mechanical properties and oxidation resistance [31]. The as-cast ingot typically exhibits a dendritic structure with compositional segregation at the dendrite arm spacing. Homogenization treatment is required either thermally or thermo-mechanically to eliminate such compositional segregation. Thermo-mechanical treatment (TMT, e.g. extrusion, forging, rolling, etc.) at elevated temperatures is also necessary to break the solidification microstructure (e.g. coarse columnar grains) prior to any production process, because such coarse grain structure limits the deformability of FeCrAl alloys. Careful control of TMT process pathways and parameters is required to avoid unnecessary grain coarsening, since grain coarsening also occurs rapidly during exposure at elevated temperature. Powder metallurgy (PM) is one of the approaches to avoid macroscopic segregation and grain coarsening, although its main trade off is the production cost due to additional process routes (powder production, consolidation, etc.) and potential oxygen contamination. Mechanically alloyed oxide dispersion strengthening (MA-ODS) is also used for PM-FeCrAl alloys [32], but further details will not be discussed here.

Product forms of nuclear grade FeCrAl alloys include, but are not limited to, plates (e.g. grid assemblies), bars (e.g. supportive rods), and seamless thin-wall tubes (e.g. fuel cladding). Because of limited deformability of $\mathrm{FeCrAl}$ alloys at room temperature (up to $\sim 5-20 \%$ thickness reduction, depending on alloy compositions and grain structure [33]), the component production requires either hot-work or cold-work combined with re-heating process to achieve sufficient deformation for producing the final products [34]. Generally, increasing the $\mathrm{Cr}$ and/or Al content reduces the components ability to be hot- or cold-worked into final product forms [34]. The production routes also include surface machining. The process parameters need to be selected for introducing sufficient deformability through recovery/recrystallization [35], as well as the property requirement of the final products, such as microstructure, mechanical properties, surface finish quality, size tolerance, and so on. To meet such requirements, especially the microstructure, the design of the process routes and control of the process parameters, from the heat production to the final machining, is very important.

\section{$2.2 \quad$ Fabrication and joining}

\subsubsection{Fabrication}

As one of the examples of $\mathrm{FeCrAl}$ alloy component fabrication, the commercial tube production for LWR fuel cladding process flow is illustrated in Figure 2 [35]. The process can be divided into three major steps: (1) heat production, (2) master bar production, and (3) tube reduction (by drawing). The target tube size for LWR fuel cladding applications is $\sim 10 \mathrm{~mm}$ in outer diameter and $\sim 0.4 \mathrm{~mm}$ in wall thickness, and the tube length through this batch process would be in a range from several feet to 500-1000 ft.

A columnar shape cast ingot is made by a vacuum induction melt (VIM) process, followed by hot-isostatic pressing (HIP) to ensure the compositional homogenization and eliminate potential internal defects that may have formed during the solidification process. The ingot is machined into a necessary size for the master bar production step, either through a hot-extrusion process (shown in the figure) or hot-forging. The process parameters (e.g. process temperatures, area reduction ratio, etc.) need to be defined to control the microstructure (e.g. refined grain structure) and supply sufficient deformability of the material in the following tube reduction process. The master bars are gun-drilled to make master tubes, and then either tube drawing or pilgering is applied in either a cold- or warm-condition (up to $\sim 300^{\circ} \mathrm{C}$ ) [36]. The size of die and mandrel are selected to control the area reduction in each pass not to exceed the limit of the material deformability, in order to avoid premature failure (e.g. cracks, necking, etc.). Application of an inter-pass annealing step after each reduction step is needed to provide reasonable deformability in the following reduction steps [37]. The inter-pass annealing step is required due to the work-hardenability of FeCrAl alloys [38]. By combining with the inter-pass annealing, the reduction process targets to exceed more than 
$80 \%$ total wall-thickness reduction to expect sufficiently homogeneous deformation and control uniform grain structure in the final tube products.

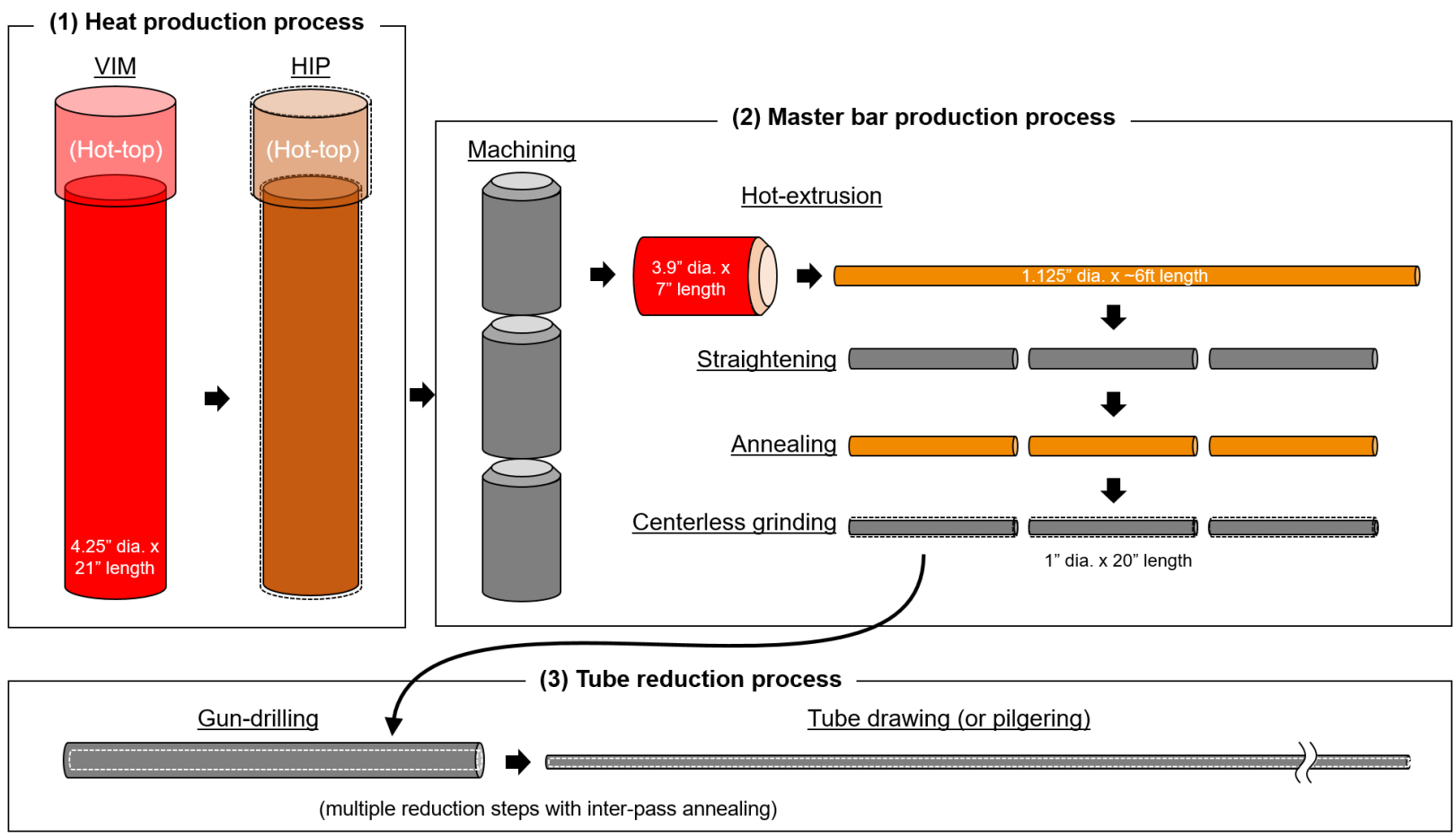

Figure 2: Tube production flow chart for thin walled cladding [35].

\subsubsection{Joining}

Joining of FeCrAl alloys has been studied using gas tungsten arc welding (GTAW) [39,40], gas metal arc welding (GMAW) [39], laser beam welding (LBW) [41-45], electron beam welding (EBW), and pressure resistance welding (PRW) [46,47]. Friction stir welding (FSW) and PRW has also been completed on the powder metallurgy derived Kanthal APMT alloy [48,49]. A majority of the studies have been focused on welding in laboratory trial conditions but preliminary welding trails at an industrial fuel manufacturing plant have shown success in welding thin walled tubes of FeCrAl alloys to caps made of the same material [49].

In general, it has been demonstrated that composition plays a strong role in the weld performance of FeCrAl alloys. For example, Regina et al. showed significant additions of $\mathrm{Cr}$ and $\mathrm{Al}$ lead to cracking in weld overlays of FeCrAl alloys applied using either GTAW or GMAW techniques, Figure 3 [39]. Similar embrittlement has been demonstrated moving from 5 to $7 \mathrm{wt} . \% \mathrm{Al}$ in a $13 \mathrm{wt} . \% \mathrm{Cr} \mathrm{FeCrAl}$ alloy using autogenous bead-on-plate LBW [42]. For alloys which reside within the crack-free deposit regime, Figure 3 , no cracks or other superficial defects have been observed using any of the described techniques. Fusionbased welding techniques typically reduces the yield strength but increases the ductility of the weldments. Weldments tend to fail within the fusion zone of tensile specimens which contain the fusion zone, heataffect zone(s) (HAZ), and the parent material [41,42]. Noticeable softening in weldments can be attributed to the large grain sizes observed in the fusion zone as well as softening in the HAZ due to recrystallization and grain growth.

Several alloy design strategies have been pursued to increase the weldability of FeCrAl alloys. Dupont et al. [40] introduced $\mathrm{TiC}$ additions into $\mathrm{FeCrAl}$ weld overlays as a means to include hydrogen trapping sites. 
Their study showed that FeCrAl alloys can be highly susceptible to hydrogen induced cracking, and hence all fusion-based welding techniques should be completed in an inert cover gas or under vacuum. The TiC additions were also found to be beneficial in decreasing the susceptibility of FeCrAl alloys to hydrogen embrittlement during GTAW. Gussev et al. [42] also explored the addition of TiC and Nb-based additions for Laves formation to increase the weldability of $\mathrm{FeCrAl}$ alloys. In both cases, the dispersions of $\mathrm{TiC}$ or Laves phase lead to reduced grain sizes in the fusion zone which in-turned promoted less softening of the weldment compared to alloys without dispersions [42]. Overall, issues regarding the weldability of FeCrAl alloys has been demonstrated to be insignificant as long as the alloy and process parameters are properly optimized.

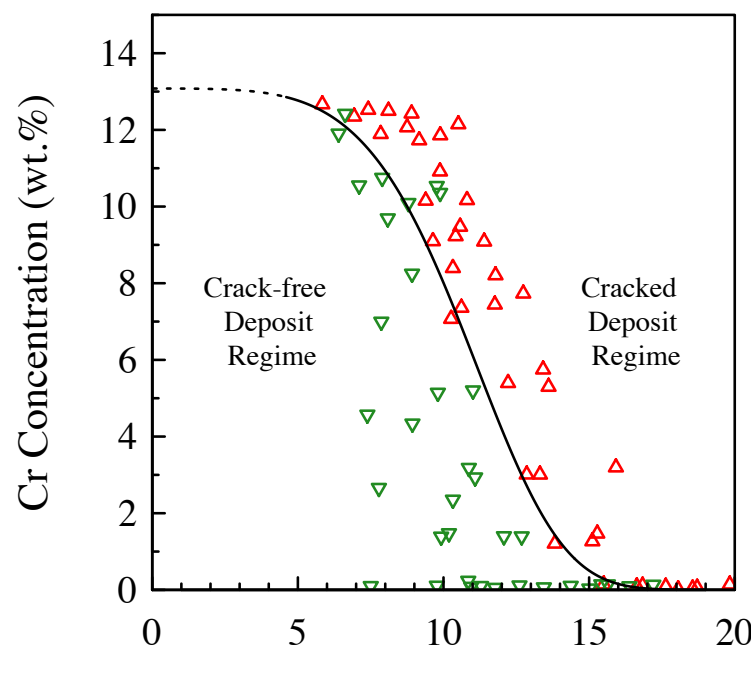

Al Concentration (wt.\%)

Figure 3: Cracking susceptibility map for weld overlays in FeCrAl alloys. Reproduced from [39]. Dashed line is extrapolation of the fitted spline function.

\section{NON-IRRADIATED FeCrAI ALLOYS}

\subsection{Thermal properties}

Limited studies on the thermal properties of non-commercial $\mathrm{FeCrAl}$ alloys, especially lean-Cr content $(<15$ wt.\%) has been completed. Furthermore, limited empirical derived relationships exist. Thus, a series of the ORNL model alloys' thermal properties were investigated and empirical fitting functions were applied within the temperature range relevant for reactor and fuel modeling efforts. Kanthal APMT was also tested to provide a baseline assessment to the commercial database. The following sections briefly outline the resulting study, further thermal property data is widely available from commercial manufactures of specific alloys.

\subsubsection{Specific heat}

The specific heat of ORNL model alloys and the commercial Kanthal APMT alloy have been measured using a Netzsch Differential Scanning Calorimetry (DSC) $404 \mathrm{C}$. Samples were heated at $20 \mathrm{~K} / \mathrm{min}^{-1}$ followed by cooling to room temperature at $20 \mathrm{~K} / \mathrm{min}^{-1}$. The resulting data upon cooling is shown in Figure 4.

The sharp peaks seen in the vicinity of $750-900 \mathrm{~K}$ are from the magnetic contribution to the specific heat capacity as the alloy(s) undergo a second order phase transition from the ferromagnetic to the paramagnetic 
state [50]. As a first trial, the simple expression for heat capacity of ferritic-martensitic steels proposed by Raju et al. [51] was initially applied to capture the full temperature dependence of $c_{p}$,

$$
c_{p}=a T+b T^{2}+C T^{3}+\frac{D}{T}+E \ln \left(\frac{a b s\left(T-T_{c}\right)}{T_{c}}\right), \quad T>T_{c}
$$

where $c_{p}$ is the specific heat capacity $\left(\mathrm{J} \mathrm{kg}^{-1} \mathrm{~K}^{-1}\right), \mathrm{a}, \mathrm{b}, \mathrm{C}, \mathrm{D}$, and $\mathrm{E}$ are fitting constants, $\mathrm{T}$ is the temperature in $\mathrm{K}$, and $\mathrm{T}_{\mathrm{c}}$ is the Curie temperature in $\mathrm{K}$. The last term on the right-hand side of the expression is a simplified expression for the magnetic contribution to the total value for specific heat. It was found that the above expression severely overestimates the specific heat capacity in the vicinity of the Curie temperature as well as showed poor fitting below the Curie temperature. The expression, when fitted to the full data, did show reasonable fitting to the data above the Curie temperature for each alloy. Therefore, to obtain a better expression the heat capacity was separated into two expressions, one being the above expression by Raju et al. [51] which was deemed valid in the temperature ranges above the Curie temperature but below the melting point (fitted to the entire dataset) while a simple third-order polynomial was applied towards the datasets below the Curie temperature,

$$
c_{p}=a T+b T^{2}+C T^{3}, \quad T \leq T_{c}
$$

where the symbols retain the same identity as those in the expression above it. It was found that partitioning the data into two regimes provided reasonable fits to the experimental data, as seen by the solid lines in Figure 4. The fitting constants for the two regimes for each alloy are provided in Table 1. Similar, but inherently more complex schemes, could be used to obtain better fits such as the one proposed by Chen and Sundman [52] but were not applied here to keep the expressions within an easily consumable format.

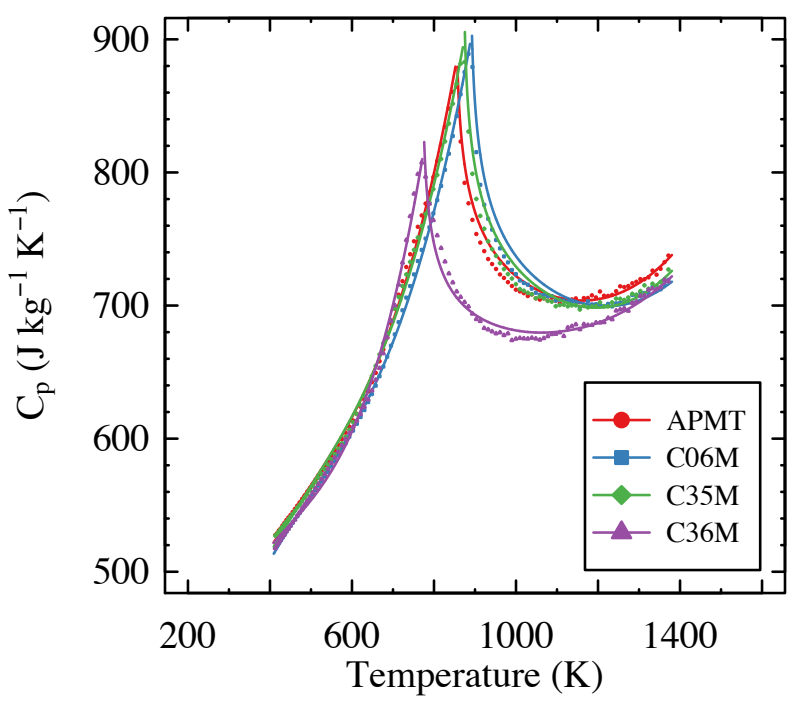

Figure 4: Specific heat capacity of select FeCrAl alloys at elevated temperatures. Symbols are experimental data points while solid lines are empirical fits using Eqn. 3.1-3.2. 
Table 1: Coefficients of empirical formulas for the specific heat capacity of various FeCrAl alloys.

\begin{tabular}{|c|c|c|c|c|c|c|c|c|}
\hline $\begin{array}{l}\text { Alloy } \\
\text { ID }\end{array}$ & $\begin{array}{l}\text { Cr, Al } \\
\text { (wt.\%) }\end{array}$ & $\begin{array}{c}\text { Valid } \\
\text { Temp. } \\
\text { Range } \\
\text { (K) }\end{array}$ & $\begin{array}{c}a \\
\left(J \mathrm{~kg}^{-1}\right)\end{array}$ & $\begin{array}{c}\mathbf{b} \\
\left(\mathrm{J} \mathrm{K} \mathrm{kg}^{-1}\right. \\
\left.\times \mathbf{1 0}^{-3}\right)\end{array}$ & $\begin{array}{c}\mathrm{C} \\
\left(\mathrm{J} \mathrm{K}^{2} \mathbf{k g}^{-1}\right. \\
\left.\times 10^{-6}\right)\end{array}$ & $\begin{array}{c}\text { D } \\
\left(\mathrm{J} \mathrm{K}^{-2} \mathrm{~kg}^{-1}\right. \\
\left.\times 10^{3}\right)\end{array}$ & $\begin{array}{c}\mathbf{E} \\
\left(\mathbf{J ~ K}^{-1}\right. \\
\left.\mathrm{kg}^{-1}\right)\end{array}$ & $\begin{array}{r}\mathbf{T}_{\mathbf{c}} \\
(\mathbf{K})\end{array}$ \\
\hline \multirow{2}{*}{$\begin{array}{l}\text { Kanthal } \\
\text { APMT }\end{array}$} & \multirow{2}{*}{21,5} & $300<\mathrm{T}<\mathrm{T}_{\mathrm{c}}$ & $\begin{array}{l}2.540 \pm \\
0.003\end{array}$ & $\begin{array}{l}-4.311 \pm \\
0.011\end{array}$ & $\begin{array}{l}2.982 \pm \\
0.009\end{array}$ & - & - & \multirow{2}{*}{852} \\
\hline & & $\mathrm{T}_{\mathrm{m}}>\mathrm{T}>\mathrm{T}_{\mathrm{c}}$ & $\begin{array}{l}1.840 \pm \\
0.015\end{array}$ & $\begin{array}{l}-1.843 \pm \\
0.024\end{array}$ & $\begin{array}{l}0.643 \pm \\
0.001\end{array}$ & $\begin{array}{l}-5.712 \pm \\
1.485\end{array}$ & $\begin{array}{l}-50.38 \pm \\
0.36\end{array}$ & \\
\hline \multirow{2}{*}{ C06M } & \multirow{2}{*}{10,6} & $300<\mathrm{T}<\mathrm{T}_{\mathrm{c}}$ & $\begin{array}{l}2.430 \pm \\
0.002\end{array}$ & $\begin{array}{l}-3.957 \pm \\
0.006\end{array}$ & $\begin{array}{l}2.656 \pm \\
0.004\end{array}$ & - & - & \multirow{2}{*}{888} \\
\hline & & $\mathrm{T}_{\mathrm{m}}>\mathrm{T}>\mathrm{T}_{\mathrm{c}}$ & $\begin{array}{l}1.827 \pm \\
0.016\end{array}$ & $\begin{array}{l}-1.807 \pm \\
0.025\end{array}$ & $\begin{array}{l}0.6134 \pm \\
0.011\end{array}$ & $\begin{array}{l}-9.419 \pm \\
1.551\end{array}$ & $\begin{array}{l}-54.54 \pm \\
0.39\end{array}$ & \\
\hline \multirow{2}{*}{$\mathrm{C} 35 \mathrm{M}$} & \multirow{2}{*}{13,5} & $300<\mathrm{T}<\mathrm{T}_{\mathrm{c}}$ & $\begin{array}{l}2.450 \pm \\
0.003\end{array}$ & $\begin{array}{l}-4.002 \pm \\
0.010\end{array}$ & $\begin{array}{l}2.720 \pm \\
0.008\end{array}$ & - & - & \multirow{2}{*}{870} \\
\hline & & $\mathrm{T}_{\mathrm{m}}>\mathrm{T}>\mathrm{T}_{\mathrm{c}}$ & $\begin{array}{l}1.946 \pm \\
0.016\end{array}$ & $\begin{array}{l}-2.002 \pm \\
0.026\end{array}$ & $\begin{array}{l}0.698 \pm \\
0.011\end{array}$ & $\begin{array}{l}-1.652 \pm \\
0.159\end{array}$ & $\begin{array}{l}-53.93 \pm \\
0.39\end{array}$ & \\
\hline \multirow{2}{*}{$\mathrm{C} 36 \mathrm{M}$} & \multirow{2}{*}{13,6} & $300<\mathrm{T}<\mathrm{T}_{\mathrm{c}}$ & $\begin{array}{l}2.995 \pm \\
0.006\end{array}$ & $\begin{array}{l}-5.953 \pm \\
0.021\end{array}$ & $\begin{array}{l}4.516 \pm \\
0.018\end{array}$ & - & - & \multirow{2}{*}{771} \\
\hline & & $\mathrm{T}_{\mathrm{m}}>\mathrm{T}>\mathrm{T}_{\mathrm{c}}$ & $\begin{array}{l}1.456 \pm \\
0.012 \\
\end{array}$ & $\begin{array}{l}-1.296 \pm \\
0.017\end{array}$ & $\begin{array}{l}0.438 \pm \\
0.007\end{array}$ & $\begin{array}{l}26.45 \pm \\
1.09\end{array}$ & $\begin{array}{l}-46.89 \pm \\
0.01^{*}\end{array}$ & \\
\hline
\end{tabular}

\subsubsection{Thermal conductivity}

The thermal conductivity $(\kappa)$ of the FeCrAl alloys was calculated using,

$$
\kappa=\alpha c_{p} d
$$

where $\alpha$ is the thermal diffusivity, $c_{p}$ is the specific heat capacity, and $\mathrm{d}$ is the specimen density. The density was determined via the sample geometry and mass at room temperature. It was assumed the density remained constant across the temperature range investigated. The thermal diffusivity was measured using the laser flash technique and values near the Curie temperatures of the alloys was excluded from the results. Figure 5 shows the temperature dependence of the thermal conductivity of select FeCrAl alloys.

In the range studied, the thermal conductivity of all alloys increased monotonically with increasing temperature, an observation consistent with other high-Cr ferritic/martensitic steels $[50,53,54]$. The thermal conductivity $(\kappa-\mathrm{W} / \mathrm{m}-\mathrm{K})$ can be expressed for each alloy using a second order polynomial,

$$
\kappa=A_{1} T^{2}+A_{2} T+A_{3}
$$

where $\mathrm{A}_{1-3}$ are fitting constants and $\mathrm{T}$ is the temperature in $\mathrm{K}$. The constants for each alloy are provided in Table 2 and the fits are provided in Figure 5. No systematic trends based on composition could be determined.

\footnotetext{
${ }^{*}$ This value was updated from the incorrect value of 77.09 to the correct value of -46.89 in the FY18: Revision 1.1 version of this document.
} 


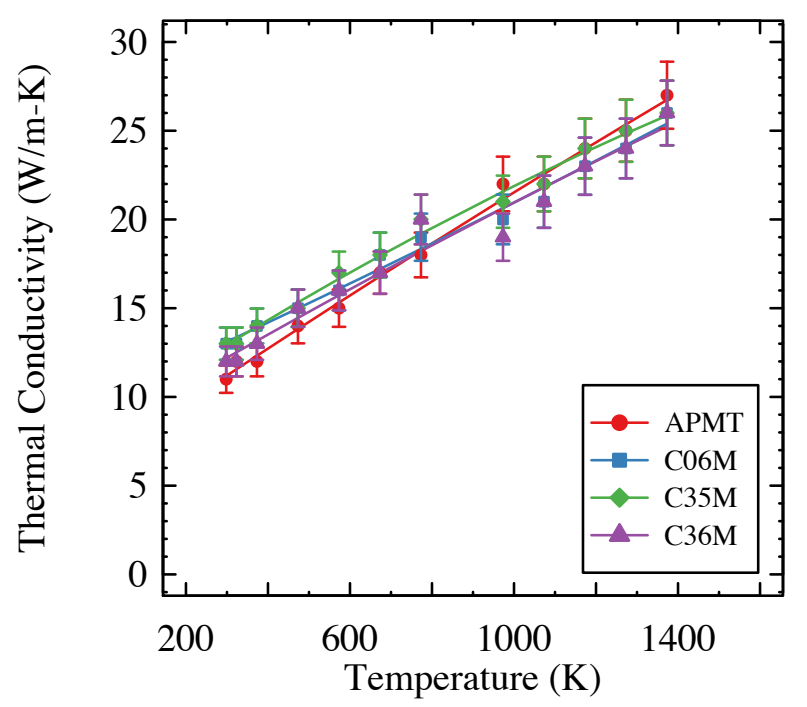

Figure 5: Thermal conductivity of select FeCrAl alloys at elevated temperatures. Error bars represent a $7 \%$ error due to the assumed experimental variability in the heat capacity, thermal diffusivity, and density.

Table 2: Coefficients of second-order polynomial fit for the thermal conductivity coefficient of various FeCrAl alloys.

\begin{tabular}{|c|c|c|c|c|c|}
\hline Alloy ID & $\begin{array}{c}\text { Cr, Al } \\
(\mathbf{w t . \%})\end{array}$ & $\begin{array}{c}\mathbf{A}_{\mathbf{1}} \\
\left(\times \mathbf{1 0}^{-\mathbf{7}}\right)\end{array}$ & $\begin{array}{c}\mathbf{A}_{\mathbf{2}} \\
\left(\times \mathbf{1 0}^{-\mathbf{2}}\right)\end{array}$ & $\mathbf{A}_{\mathbf{3}}$ & $\mathbf{R}^{\mathbf{2}}$ \\
\hline Kanthal APMT & 21,5 & $-7.223 \pm 0.128$ & $1.563 \pm 0.211$ & $6.569 \pm 0.738$ & 99.35 \\
\hline C06M & 10,6 & $6.762 \pm 0.155$ & $1.032 \pm 0.256$ & $9.956 \pm 0.895$ & 98.48 \\
\hline C35M & 13,5 & $-19.860 \pm 12.980$ & $1.537 \pm 0.214$ & $8.502 \pm 0.747$ & 99.06 \\
\hline C36M & 13,6 & $-9.184 \pm 26.50$ & $1.368 \pm 0.437$ & $8.187 \pm 1.526$ & 96.19 \\
\hline
\end{tabular}

\subsubsection{Thermal expansion}

For each FeCrAl alloy studied, measurements were taken twice each in the rolling and the transverse direction. Minimal variation was found between the two directions, and hence the data presented in Figure 6 are the mean values of all four measurements with the error bars reporting one standard deviation of the mean. At lower temperatures $(<1000 \mathrm{~K})$, variation in the thermal expansion coefficient can be observed with composition. The thermal expansion coefficient can be expressed for each alloy using a third order polynomial,

$$
\alpha=A_{1} T^{3}+A_{2} T^{2}+A_{3} T+A_{4}
$$

where $\mathrm{A}_{1-4}$ are fitting constants and $\mathrm{T}$ is the temperature in $\mathrm{K}$. The constants for each alloy are provided in Table 3 and the fits are provided in Figure 6. 


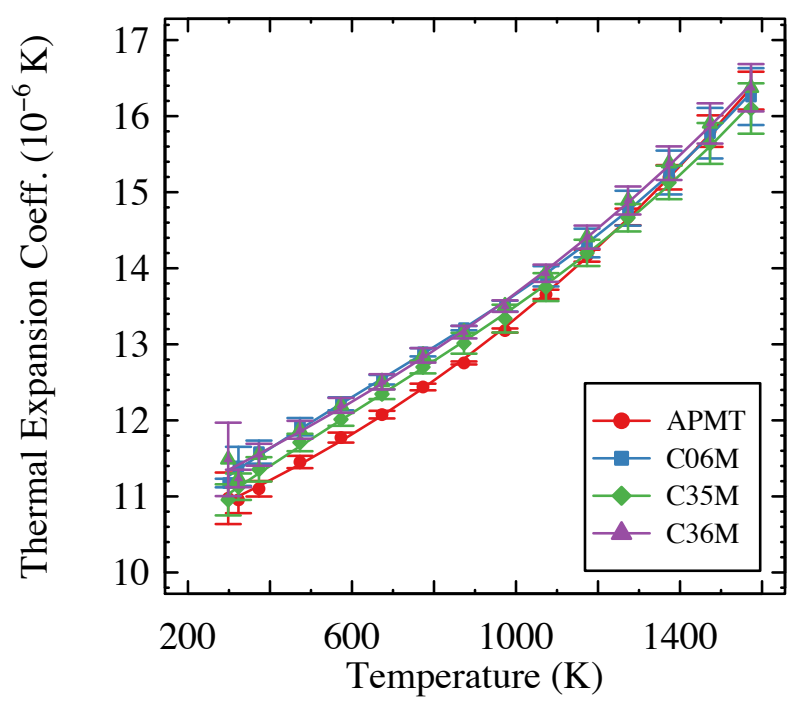

Figure 6: Thermal expansion coefficients of select $\mathrm{FeCrAl}$ alloys at elevated temperatures.

Table 3: Coefficients of third-order polynomial fit for the thermal expansion coefficient of various FeCrAl alloys.

\begin{tabular}{|c|c|c|c|c|c|c|}
\hline $\begin{array}{c}\text { Alloy } \\
\text { ID }\end{array}$ & $\begin{array}{c}\text { Cr, Al } \\
\text { (wt.\%) }\end{array}$ & $\begin{array}{c}A_{1} \\
\left(\times 10^{-10}\right) \\
\end{array}$ & $\begin{array}{c}\mathbf{A}_{2} \\
\left(\times \mathbf{1 0}^{-7}\right) \\
\end{array}$ & $\begin{array}{c}A_{3} \\
\left(\times \mathbf{1 0}^{-3}\right) \\
\end{array}$ & $\mathbf{A}_{4}$ & $\mathbf{R}^{2}$ \\
\hline $\begin{array}{l}\text { Kanthal } \\
\text { APMT }\end{array}$ & 21,5 & $\begin{array}{c}1.771 \pm \\
2.171 \\
\end{array}$ & $9.558 \pm 6.056$ & $\begin{array}{l}1.937 \pm \\
0.5089 \\
\end{array}$ & $\begin{array}{l}10.27 \pm \\
0.1234 \\
\end{array}$ & 99.95 \\
\hline $\mathrm{C} 06 \mathrm{M}$ & 10,6 & $\begin{array}{c}10.74 \pm \\
2.560 \\
\end{array}$ & $-21.36 \pm 7.142$ & $\begin{array}{c}4.694 \pm \\
0.6001 \\
\end{array}$ & $\begin{array}{l}10.03 \pm \\
0.1455 \\
\end{array}$ & 99.92 \\
\hline $\mathrm{C} 35 \mathrm{M}$ & 13,5 & $\begin{array}{c}9.095 \pm \\
2.594 \\
\end{array}$ & $-17.46 \pm 7.236$ & $\begin{array}{c}4.530 \pm \\
0.6080 \\
\end{array}$ & $\begin{array}{c}9.810 \pm \\
0.1474 \\
\end{array}$ & 99.92 \\
\hline $\mathrm{C} 36 \mathrm{M}$ & 13,6 & $\begin{array}{c}3.079 \pm \\
4.297 \\
\end{array}$ & $\begin{array}{c}2.719 \pm \\
0.1199 \\
\end{array}$ & $2.535 \pm 1.007$ & $\begin{array}{c}10.56 \pm \\
0.2442 \\
\end{array}$ & 99.78 \\
\hline
\end{tabular}

\subsection{Electrical properties}

The electrical properties of FeCrAl alloys have been primarily based on studies of FeCrAl wires for hightemperature strain gage applications. Studies in general have shown alloys to have favorable electrical properties including high temperature resistivity and low-temperature coefficient of resistance. Studies such as the one presented by Metcalfe [55] have shown a dependence on these properties as a function of both $\mathrm{Cr}$ and $\mathrm{Al}$ content. Additionally, the electrical properties have been found to stabilize after several thermal cycles during cyclic thermal loading [56]. 


\subsection{Mechanical properties}

The base mechanical properties of varying $\mathrm{FeCrAl}$ alloys have been evaluated in a wide range of studies. By far, the mechanical properties database for $\mathrm{FeCrAl}$ alloys is the most robust database for FeCrAl alloys. Here, selected results are presented to highlight specific aspects within the mechanical property database.

\subsubsection{Tensile properties}

The tensile properties of wrought, ferritic FeCrAl alloys show strong dependencies on test temperature, alloy composition, and microstructure. Figure 7 demonstrates the general trends as a function of test temperature for select alloy groups. Note, data is derived from non-tube product. Data presented in Figure 7 represent a wide range of alloys with various major (chromium and aluminum) and minor (Mo, $\mathrm{Nb}$, etc.) content. Given the wide range of $\mathrm{FeCrAl}$ alloys, all alloys show a similar trend with temperature; tensile properties remain fairly constant up to $\sim 400^{\circ} \mathrm{C}$ and then an inflection point is observed and the alloys' yield strength decreases and the total elongation increases significantly. For the ORNL Model alloys, these trends are attributed to recovery of cold work (10\%) and recrystallization [57]. It should be noted the strength parameters can be beneficially increased via oxide, precipitate, or reactive element particle dispersions within the matrix, as observed for Kanthal APMT and C35MN compared to the non-dispersion alloys such as $\mathrm{C} 35 \mathrm{M}$ in Figure 7.
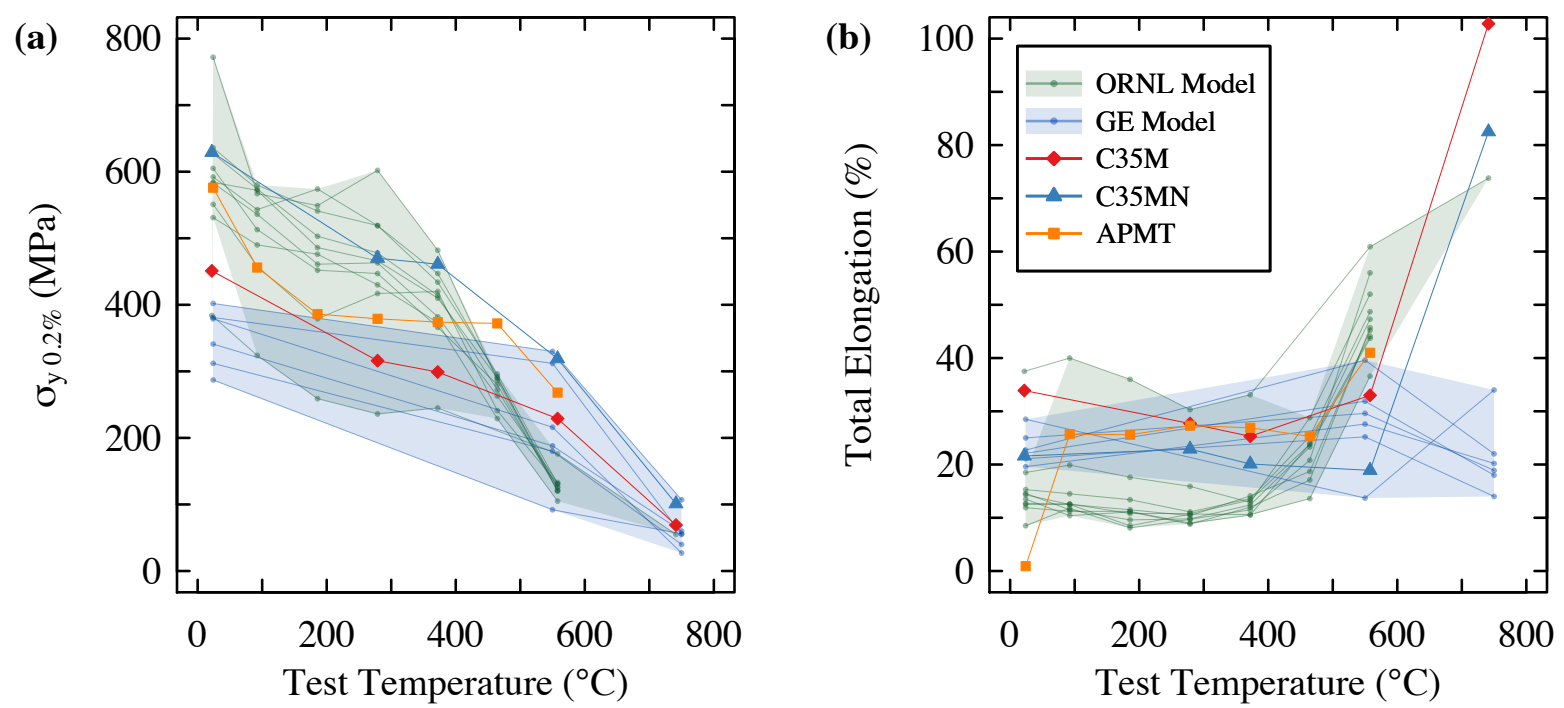

Figure 7: Yield strength and total elongation properties for select $\mathrm{FeCrAl}$ alloys as a function of temperature.

The largest variability in tensile properties is observed below $\sim 400^{\circ} \mathrm{C}$ for wrought $\mathrm{FeCrAl}$ alloys. The variability can be attributed to several different compositional or microstructural variations within the alloy. For example, Figure 8 shows the yield strength and total elongation of different model FeCrAl alloys as a function of $\mathrm{Cr}$ and $\mathrm{Al}$ content when tested at room temperature [38]. Yield strengths are observed to increase at roughly a rate of $35 \mathrm{MPa} / \mathrm{wt} . \% \mathrm{Al}(\sim 100 \mathrm{MPa} / \mathrm{wt} . \% \mathrm{Al}$ for the ultimate tensile strength) with a correlated decrease in total elongation. The $\mathrm{Al}$ effect is especially sensitive for higher $\mathrm{Cr}(>13$ wt.\%) alloys. The $\mathrm{Cr}$ effect is not nearly as significant as seen in Figure $8 \mathrm{~b}$ compared to the Al effect. Similar results have been presented on GE model alloys [5] and showed the $\mathrm{Cr}$ and $\mathrm{Al}$ effect to occur at room temperature and 
elevated temperatures up to $600^{\circ} \mathrm{C}$ but no strong effect was seen at temperatures near $750^{\circ} \mathrm{C}$. The results on ORNL model and GE model alloys indicate that Al addition increases the deformation resistance significantly, and thus the strong $\mathrm{Al}$ dependence on the fabricability of $\mathrm{FeCrAl}$ alloys.
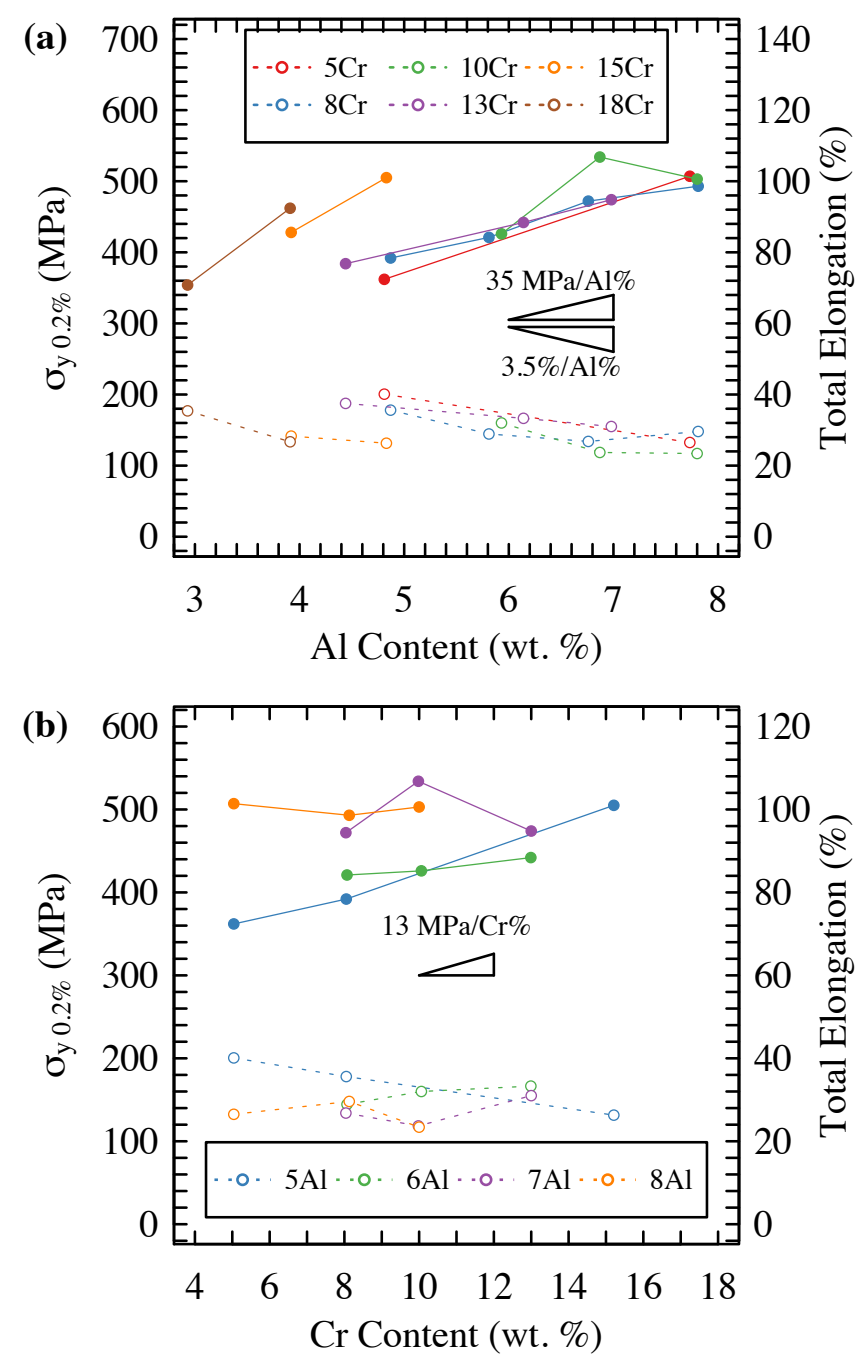

Figure 8: Room temperature tensile properties of model $\mathrm{FeCrAl}$ alloys as a function of $\mathrm{Al}$ content (a) and $\mathrm{Cr}$ content (b). Open symbols correspond to total elongation; closed symbols correspond to yield strength [38].

Minor alloying additions have also been studied for both ORNL model and GE model FeCrAl alloys. Common solid solution strengthening elements, such as Mo, have been shown to increase the strength of FeCrAl alloys. In general, Mo additions have been observed to increase the high temperature strength of FeCrAl alloys. Other alloying additions, such as $\mathrm{Nb}$, Ti, and $\mathrm{C}$, have also been shown to increase the strength and decrease the ductility of FeCrAl alloys via a precipitate hardening mechanism.

Grain size effects have also been evaluated in regard to tensile properties. Yamamoto et al. [14] showed that small grained $\mathrm{FeCrAl}$ alloys (average grain size: $\sim 10-40 \mu \mathrm{m}$ ) showed higher strengths than large grain variants $(\sim 250-900 \mu \mathrm{m})$. Within a limited composition range (1-3 wt.\%), grain size was found to be a more 
significant factor on the tensile properties than composition. Additionally, application of cold work has been shown to increase strength and reduce plastic elongations in model $\mathrm{FeCrAl}$ alloys. Application of 10\% cold working introduces a high density of dislocations that appear as dislocation tangles and distinct cell walls [24] causing the yield stress in the material to be comparable if not higher than the ultimate tensile strength of non-cold work samples. Additionally, $10 \%$ cold work leads to limited to no load bearing capacity after yield.

Dynamic strain aging (DSA) has been observed in a range of $\mathrm{FeCrAl}$ alloys including wrought alloys [58,59] and within the PM-based APMT alloy [60-62]. DSA manifests itself in the form of serrated flow, negative strain-rate sensitivity, and plateaus in the variations of yield strength and ultimate tensile strength in $\mathrm{FeCrAl}$ alloys [58]. DSA has been observed to be strongly dependent on the temperature range and strain rate studied. Typically, a reduction in strain rate leads to a shift in the DSA temperature regime towards lower test temperatures. The observed DSA affect has been attributed towards the solute additions in wrought alloys and thus the presence of DSA is also strongly dependent on alloy composition.

In summary, the tensile properties of $\mathrm{FeCrAl}$ alloys can be directly modified by applying traditional metallurgical techniques including varying TMT processes to introduce varying grain size, through compositional modifications including both major and minor alloying additions, through hardening mechanisms such as precipitate/particle/oxide dispersions and through processing techniques such as cold working. Given this, variations in tensile properties were observed to decrease at elevated temperatures $\left(>600^{\circ} \mathrm{C}\right)$.

\subsubsection{Hardness}

Microhardness has been found to mirror tensile properties for wrought FeCrAl alloys. For example, the compositional variations observed in Figure 8 have also been observed for hardness by Kornilov [63] and on ORNL Model alloys, Figure 9a. In lower Cr content (8-15 wt.\% Cr) FeCrAl alloys, small variations in hardness are seen as a function of composition but a strong, $13 \mathrm{Hv} / \mathrm{wt} . \%$ addition of $\mathrm{Al}$ is observed. For higher $\mathrm{Cr}$ content alloys $(>15 \mathrm{wt} . \% \mathrm{Cr}$ ), both $\mathrm{Al}$ and $\mathrm{Cr}$ have a significant effect on the room temperature microhardness of the FeCrAl alloys studied. The similar observations between the uniaxial tensile properties and the microhardness on composition can be concluded to be due to the relationship between the tensile properties and hardness measurements.

Busby et al. [64], evaluated the relationship between tensile and hardness properties for six separate datasets on ferritic steels and showed that the change in yield strength is $3.06 \times$ greater than a change in Vickers microhardness. Similar relationships can be drawn exclusively for ferritic $\mathrm{FeCrAl}$ alloys. Figure $9 \mathrm{~b}$ shows the compiled data and resulting correlation between the ultimate tensile strength $\left(\sigma_{U T S}\right)$ and $\mathrm{Hv}$ for ORNL model, GE model [5,65,66], and Kanthal APMT alloys [67]. The resulting relationship ${ }^{\dagger}$ was found as

$\sigma_{U T S}(\mathrm{MPa})=2.55 \cdot \mathrm{Hv}\left(\frac{\mathrm{kg}}{\mathrm{mm}^{2}}\right)$. Note, the relationship is in regard to absolute values and the ultimate tensile strength, unlike the reported and widely used relationship on relatives and the yield stress reported by Busby et al. [64]. A correlation between the yield stress could not be completed here due to the lack of reported values for the GE model alloys, particularly the lower strength $(<400 \mathrm{MPa})$ alloys reported in Figure 9b.

A variety of studies have been completed on using hardness values to report aging effects in wrought FeCrAl alloys $[5,8,26,27]$. Many of these studies are derived from studies evaluating $\alpha^{\prime}$ precipitation within The relationship was updated from $\sigma_{U T S}(\mathrm{MPa})=2.7 \cdot \mathrm{Hv}\left(\frac{\mathrm{kg}}{\mathrm{mm}^{2}}\right)$ to $\sigma_{U T S}(M P a)=2.55 \cdot \mathrm{Hv}\left(\frac{\mathrm{kg}}{\mathrm{mm}^{2}}\right)$ in the FY18: Revision 1 version of this
document based on additional data from [52]. 
this alloy class. For example, GE model alloys [65] were aged up to $10,000 \mathrm{hr}$ at $450^{\circ} \mathrm{C}$. Lower $\mathrm{Cr}$ variants, such as 0561 and 1041 (5 wt. \% and 10 wt.\% Cr, respectively) showed little variation in Rockwell 15-N hardness while higher $\mathrm{Cr}$ variants (15 wt.\% and higher) showed significant increases in hardness above $1000 \mathrm{hr}$. The recent and influential study of Kobayahsi and Takasugi [26] have shown these significant increases in hardness can be directly correlated to the miscibility gap in the Fe-rich corner of the Fe-Cr-Al phase diagram, Figure 1. Aging within this miscibility gap leads to the precipitation of the Cr-rich $\alpha$ phase which through a dispersed barrier model [24], has been shown to harden FeCrAl alloys. The result is simple aging studies conducted below $\sim 500^{\circ} \mathrm{C}$ in excess of 1000 to $10000 \mathrm{hrs}$ followed by hardness measurements, such as the ones completed on GE Model alloys, can be used to pre-screen a given FeCrAl alloy's susceptibility to $\alpha^{\prime}$ precipitation.

(a)

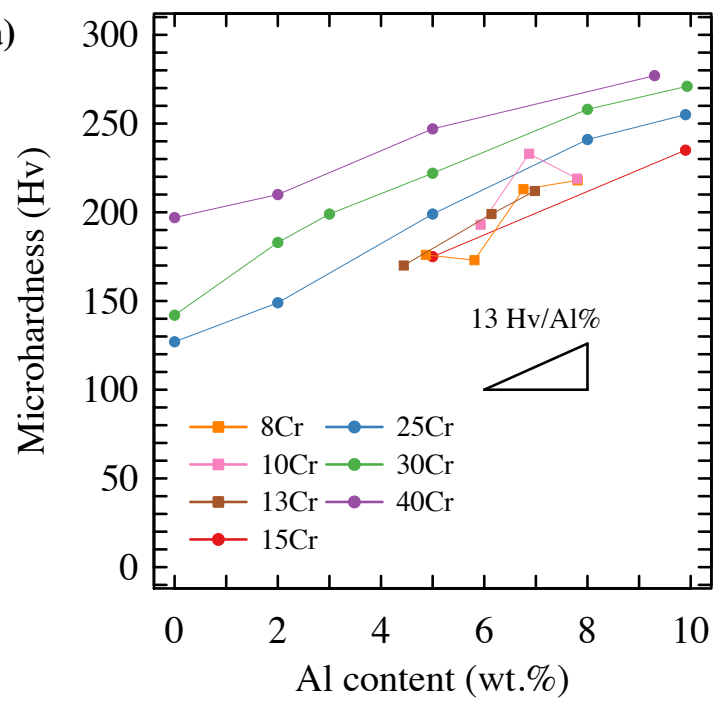

(b)

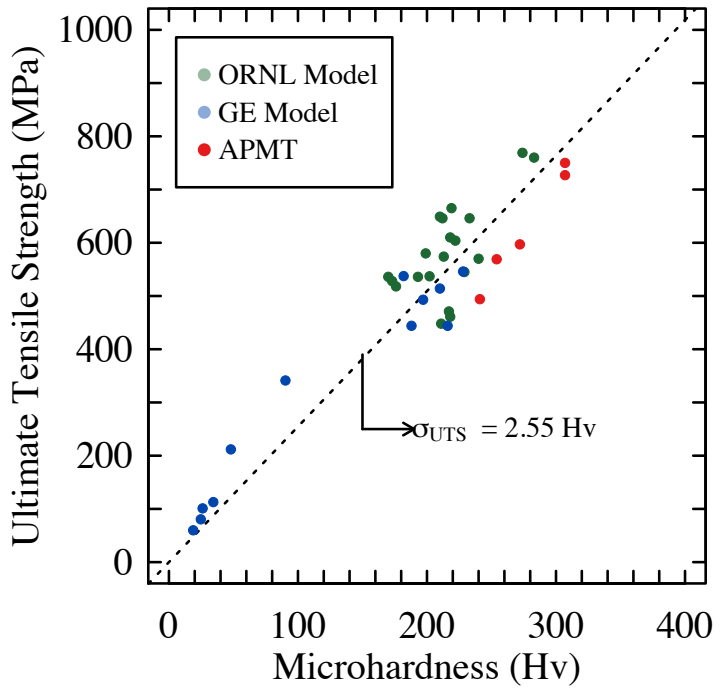

Figure 9: Room temperature hardness values for model FeCrAl alloys. (a) $\mathrm{Cr}$ and $\mathrm{Al}$ effect on microhardness [63] and (b) simple property-property correlation between ultimate tensile strength and microhardness for unirradiated FeCrAl alloys [5,65-67].

\subsubsection{Fracture toughness}

A limited amount of studies regarding the fracture properties of $\mathrm{FeCrAl}$ alloys have been completed to date. All data summarized here have been completed using ASTM or sub-size Charpy V-notch specimens to determine the impact properties and the ductile-to-brittle transition temperature (DBTT) of select alloys. Alloying effects have been primarily derived from the studies of Kornilov [63] and Chubb et al. [34]. Figure 10 shows the effect of $\mathrm{Al}$ on the transition temperature in high $\mathrm{Cr}$ content $\mathrm{FeCrAl}$ alloys [34]. The results show doubling the $\mathrm{Al}$ content from $3 \mathrm{wt} . \%$ to $6 \mathrm{wt} \% \%$ leads to a nearly $100-150^{\circ} \mathrm{C}$ increase in the DBTT. The detrimental impact of $\mathrm{Al}$ on the ductile behavior of FeCrAl alloys could be a driving factor for the reduced fabricability of higher $\mathrm{Al}$ content $\mathrm{FeCrAl}$ alloys. Cr effect has also been studied in higher $\mathrm{Cr}$ content (23-25 wt.\% Cr) alloys and shown limited composition effect on the transition temperature, a stark contrast to the Al effect shown in Figure 10. It should be noted no systematic and published study has been completed on the effect of $\mathrm{Cr}$ or $\mathrm{Al}$ for lean $\mathrm{Cr}$ content $\mathrm{FeCrAl}$ alloys.

Determination of the role of $\mathrm{C}$ on the DBTT in $25 \mathrm{wt} . \% \mathrm{Cr}-5 \mathrm{wt} \% \mathrm{Al} \mathrm{FeCrAl}$ alloys showed mixed and difficult to interpret results. The clearest indication made by Chubb et al. [34] was that $\mathrm{C}$ contents greater than 600-700 ppm lead to significant embrittlement of $\mathrm{FeCrAl}$ alloys. $\mathrm{O}$ has been shown to decrease the 
DBTT in 23-26 wt.\% Cr alloys where a nearly $140 \mathrm{ppm}$ increase in $\mathrm{O}$ resulted in $\sim 100-150^{\circ} \mathrm{C}$ decrease in the DBTT [34]. No direct indications on the mechanisms behind the observed $\mathrm{O}$ or $\mathrm{C}$ effect was derived. Other minor alloying additions such as $\mathrm{Mn}, \mathrm{Ti}$, and $\mathrm{V}$ have shown no significant effect on the DBTT of FeCrAl alloys [34].

Microstructural and processing effects on the DBTT of FeCrAl alloys was recently studied by Sun et al. [67]. Wrought $\mathrm{FeCrAl}$ alloys with nominal compositions of $\mathrm{Fe}-(10-13) \mathrm{Cr}-6 \mathrm{Al}-2 \mathrm{Mo}$ (in wt.\%) and varying heats of the APMT alloy were investigated using half-size V-notch Charpy specimens. Key results include the determination that all of the $\mathrm{FeCrAl}$ specimens showed fully brittle characteristics at room temperature due to the DBTT of the investigated alloys being between 119 to $318^{\circ} \mathrm{C}$ which is consistent with the much earlier obtained results presented in Figure 10. In addition, it was found that alloys that exhibited a fine, uniform grain structure had greater impact toughness compared to course grained materials of the same composition. Residual strain apparent in the alloys were found to also impact the absorbed energy in the studied FeCrAl alloys. The resulting conclusion is that TMT can be used in conjunction with chemical composition to produce alloy variants with decreased DBTT [67].

Aging studies on the DBTT of FeCrAl alloys have been completed on Alloy 1361 DS, a GE derived 13 wt. $\% \mathrm{Cr}-6 \mathrm{wt} \% \mathrm{Al}$ oxide dispersion strengthened (ODS) FeCrAl alloys. At the time of this report, no systematic aging studies on the impact properties of wrought $\mathrm{FeCrAl}$ alloys were found. Aging for $50 \mathrm{hr}$ at 550 and $800^{\circ} \mathrm{C}$ showed no appreciable difference in the impact properties for $1361 \mathrm{DS}$. Aging at $450^{\circ} \mathrm{C}$ showed significant difference, a result which was attributed to a fine dispersion of $\alpha$ '. No microstructural observations were completed to confirm the presence of $\alpha^{\prime}$ in the aged 1361 DS alloy. The results on 1361 DS provide alarm on the embrittling effect of $\alpha^{\prime}$ on $\mathrm{FeCrAl}$ alloys. Given this, more systematic studies are needed, especially towards leaner alloy compositions currently under consideration for nuclear power applications.

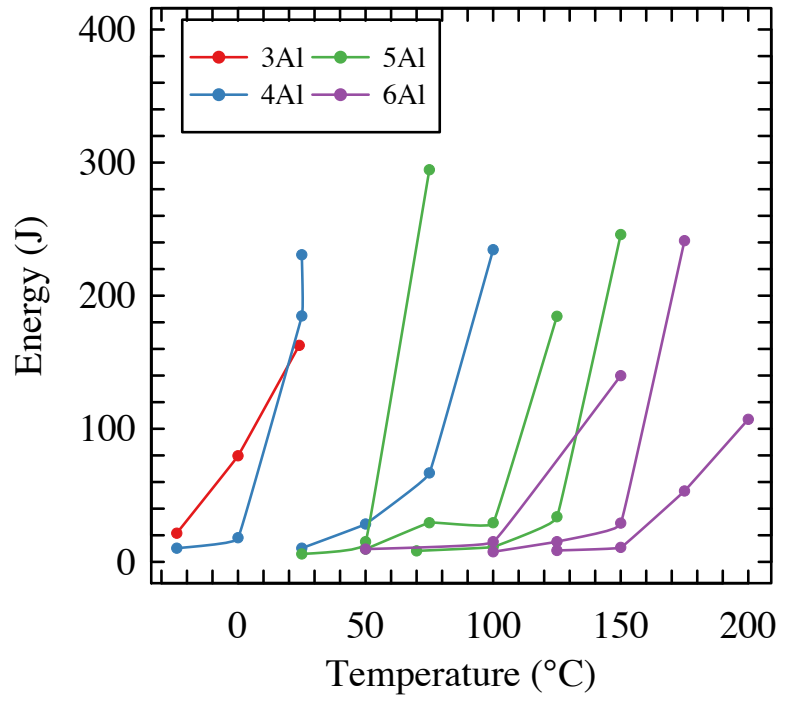

Figure 10: DBTT as a function of Al content in 23-25 wt.\% Cr FeCrAl alloys [34].

\subsubsection{Elastic modulus, Poisson's ratio, and Shear modulus}

Resonant ultrasound spectroscopy (RUS) has been completed to determine the elastic modulus of ORNL model FeCrAl alloys and Kanthal APMT [68]. Additional studies using nanoindentation have been used to 
determine the elastic modulus of ORNL model FeCrAl alloys in the welded and non-welded state [69]. Figure 11 summarizes the elastic moduli and Poisson's ratio of various ORNL-based alloys and Kanthal APMT using the RUS technique. The study concluded almost no variation is observed in the moduli of the alloys as a function of major alloying elements, but alloys with $2 \mathrm{wt}$ \% Mo appeared to have slightly higher elastic moduli. The finding of additional $2 \mathrm{wt} . \%$ Mo increasing the elastic moduli is in agreement with the room temperature nanoindentation studies on Mo contained ORNL model FeCrAl alloys [69]. The elastic modulus of the wrought $\mathrm{FeCrAl}$ alloys at elevated temperatures determined using RUS can be empirically generalized as,

$$
E=-5.46 \times 10^{-5} T^{2}-3.85 \times 10^{-2} T+199
$$

where $\mathrm{E}$ is the elastic modulus and $\mathrm{T}$ is the temperature in ${ }^{\circ} \mathrm{C}[68]$.

The Poisson's ratio was found to have minor temperature dependence, Figure 11b. Cr and/or Al content of the $\mathrm{FeCrAl}$ alloys did not have a significant effect on Poisson's ratio. The generalized empirical relationship with temperature can be described by,

$$
v=4.46 \times 10^{-5} T+0.27
$$

where the temperature is expressed in ${ }^{\circ} \mathrm{C}$.

The shear modulus, $G$, can be determined using the relationship,

$$
G=E / 2(1+v) \text {. }
$$

The temperature dependence of the shear modulus can be determined by substituting in Eqn. (3.6) and (3.7) into Eqn. (3.8). Based on the relationship, and the elastic modulus and Poisson's ratio, limited composition effects should be present in the shear modulus of wrought FeCrAl alloys.
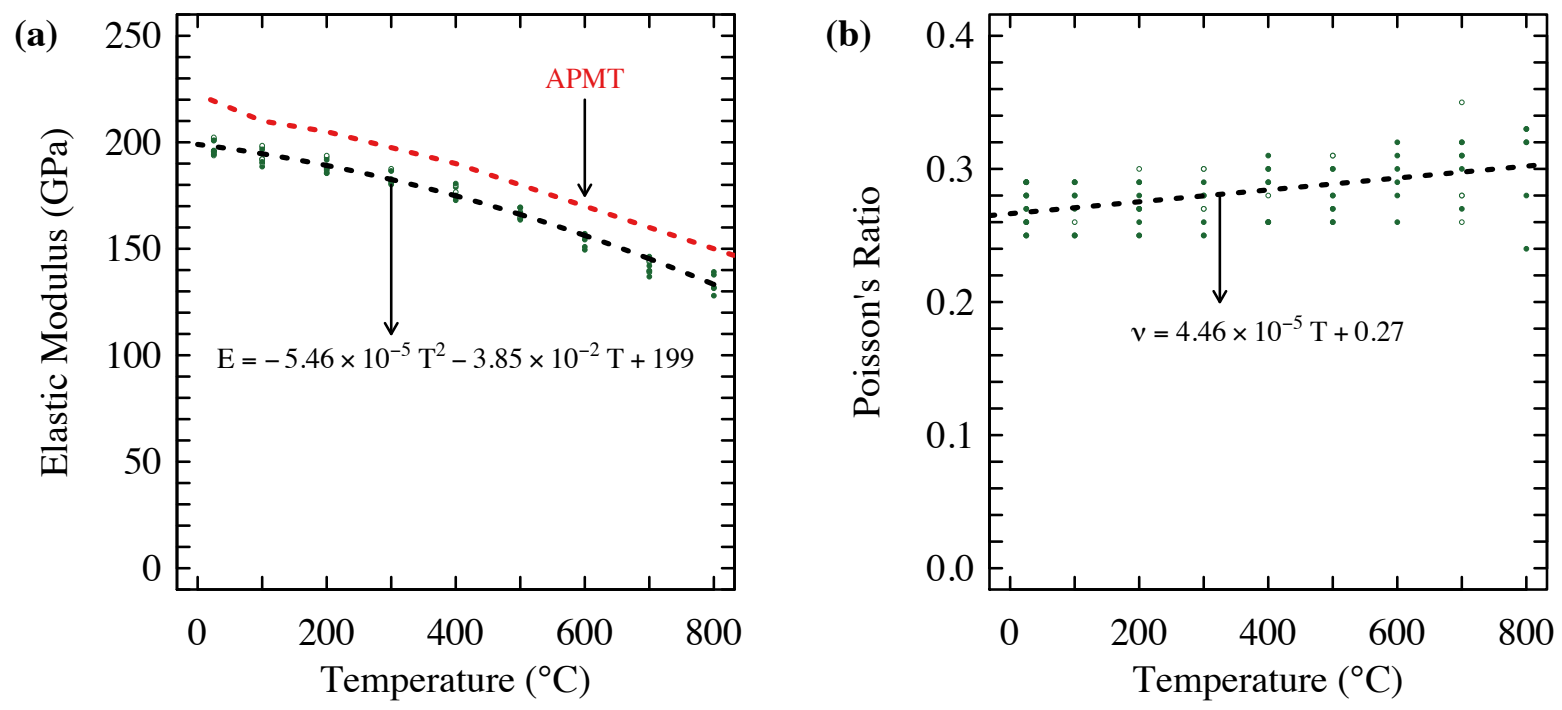

Figure 11: Elastic moduli (a) and Poisson's ratio (b) of various ORNL wrought FeCrAl alloys [68] and Kanthal APMT [70] as a function of temperature. Fits for wrought data provided within figure. 


\subsubsection{Creep Properties}

The published creep data [5,71-74] vary greatly depending on the alloy, temperature, and stress. Figure 12a provides a summary of the compiled data.

In general, all data follows the general power-law creep equation,

$$
\dot{\varepsilon}_{s}=A_{0} \sigma^{n} \exp (-Q / R T)
$$

where $\dot{\varepsilon}_{s}$ is the strain rate $\left(\mathrm{s}^{-1}\right), \mathrm{A}_{0}$ is a constant $\left(\mathrm{MPa}^{-\mathrm{n}} \mathrm{s}^{-1}\right), \sigma$ is the stress $(\mathrm{MPa}), \mathrm{n}$ is the creep exponent, $\mathrm{Q}$ is the activation energy $(\mathrm{J} / \mathrm{mol}), \mathrm{R}=8.314 \mathrm{~J} / \mathrm{K} \cdot \mathrm{mol}$, and $\mathrm{T}$ is the temperature $(\mathrm{K})$. Several authors have fitted subsets of the data presented in Figure 12a to determine the creep parameters for FeCrAl alloys within varying regimes. Table 4 summarizes creep parameters provided by different studies. Additionally, the data presented in Figure 12a was compiled and fitted across all stress and temperature regimes to provide a highly "generalized" - first order approximation - of the creep parameters for both wrought and Kanthal APMT FeCrAl alloys.

(a)

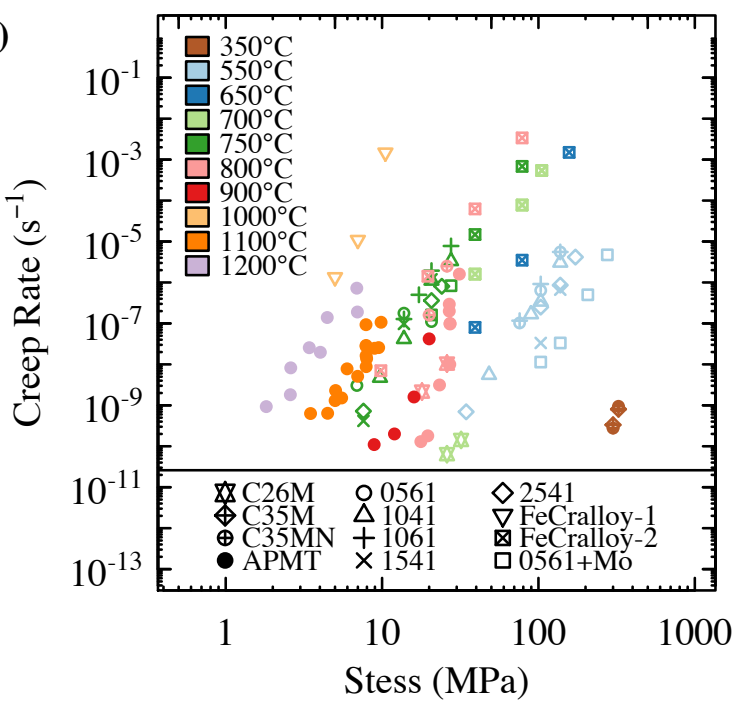

(b)

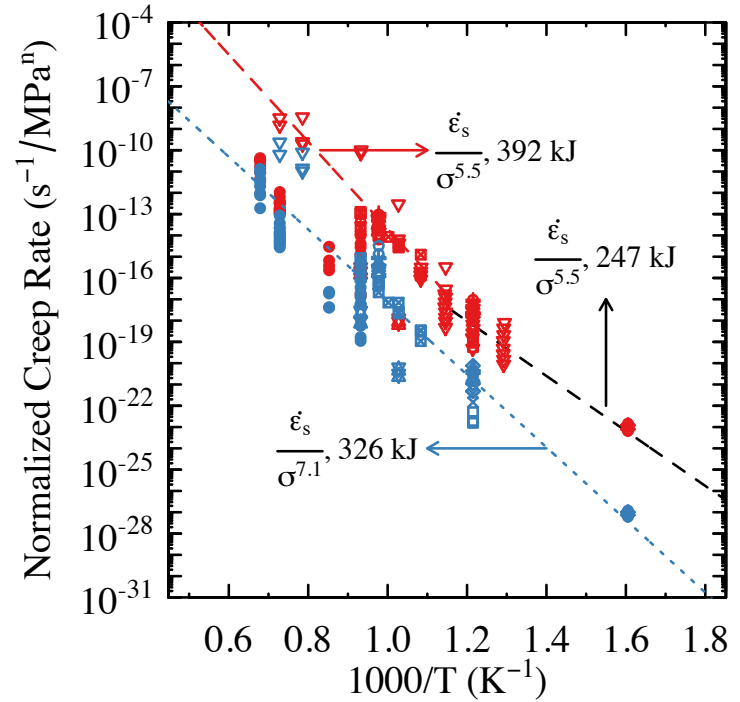

Figure 12: Creep rates versus applied stress for varying FeCrAl alloys (a) and Arrhenius plot of compiled creep data for given FeCrAl alloys where the ordinate axis is normalized to the creep exponent (b). Symbols for given alloys are identical in both plots [5,71-74].

The correlations of Saunders et al. [72], Terrani et al. [71], and the generalized correlation are plotted in Figure $12 \mathrm{~b}$. Note, the data is presented with the ordinate axis as the normalized creep rate or $\left(\dot{\varepsilon}_{s} / \sigma^{n}\right)$ for simplicity. The parameters in Terrani et al. are modifications to the Saunders values to provided better fitting within the low-temperature creep regime. Figure 12b shows that the Saunders et al. model fits well within the specified temperature regime except for the creep resistant Kanthal APMT. Extrapolation of the Terrani et al. model would result in gross underestimation for most wrought FeCrAl alloys at temperatures above $600^{\circ} \mathrm{C}$, and hence should only be used within the regime specified. The generalized model provides modest fits across all alloy types and temperature-stress regimes and appears a reasonable, if not oversimplified, model to determine the creep rate for $\mathrm{FeCrAl}$ alloys.

A large portion of the variation seen in the normalized creep rate for a given temperature and proposed model can be attributed to alloy-to-alloy variation. For example, at a temperature of $550^{\circ} \mathrm{C}$, the majority of 
the data is composed of GE model alloys where variations in the trends are seen in Figure 12a. The GE model alloys span a range of $20 \mathrm{wt} \% \mathrm{Cr}$ and $2 \mathrm{wt} . \% \mathrm{Al}$ [5]; it is not unreasonable to expect some alloy-toalloy variation based on compositional effects. At the time of this report, no systematic studies on the creep properties as a function of composition have been found. Caution is provided here to accurately determine the creep properties of a given alloy, fits to Eqn. 3.9 (or conversely different creep models) should be applied to only the alloy of interest within the temperature-stress regime(s) of interest.

Table 4: Estimated creep parameters for varying FeCrAl alloys based on Eqn. (3.9).

\begin{tabular}{|c|c|c|c|c|c|c|c|}
\hline $\operatorname{Alloy}(s)$ & $\begin{array}{l}\mathrm{Cr}, \mathrm{Al} \\
\text { (wt.\%) }\end{array}$ & $\begin{array}{c}\text { Valid } \\
\text { Temperature } \\
\text { Regime }\left({ }^{\circ} \mathrm{C}\right) \\
\end{array}$ & $\begin{array}{c}\text { Valid Stress } \\
\text { Regime } \\
\text { (MPa) } \\
\end{array}$ & $\begin{array}{c}\mathbf{A}_{0} \\
\left(\mathbf{M P a}^{-\mathrm{n}} \mathbf{s}^{-1}\right)\end{array}$ & $\mathbf{n}$ & $\begin{array}{c}\mathbf{Q} \\
(\mathrm{kJ} / \mathrm{mol})\end{array}$ & Ref. \\
\hline Fecralloy-1 & 22,5 & 500-1100 & UNS & $5.96 \times 10^{6}$ & 5.5 & 392 & {$[72]$} \\
\hline $\begin{array}{c}\mathrm{C} 35 \mathrm{M} \\
\mathrm{C} 35 \mathrm{MN} \\
\end{array}$ & $\begin{array}{l}13,5 \\
13,5 \\
\end{array}$ & $<600$ & UNS & $2.9 \times 10^{-3}$ & 5.5 & 247 & [71] \\
\hline Fecralloy-2 & $14,4.5$ & $>725$ & $<100$ & 1.72 & 5.5 & 277 & {$[75]$} \\
\hline Fecralloy-2 & $14,4.5$ & $<710$ & $<100$ & $1.65 \times 10^{-3}$ & 5.8 & 489 & {$[75]$} \\
\hline Fecralloy-2 & $14,4.5$ & $<710$ & $>100$ & 28.2 & 10.5 & 489 & {$[75]$} \\
\hline Fecralloy-3 & UNS & UNS & UNS & $8.68 \times 10^{16} \cdot(-0.0122 \mathrm{~T})$ & 5.29 & 486 & {$[74]$} \\
\hline $\mathrm{T} 35 \mathrm{Y}$ & 13,5 & UNS & UNS & $82-84$ & $3.7-3.9$ & $248-258$ & {$[76]$} \\
\hline Kanthal AF & 21,5 & UNS & UNS & $2.9 \times 10^{-6}$ & 4.5 & 143 & [76] \\
\hline $\begin{array}{l}\text { Generalized } \\
\text { for all alloys }\end{array}$ & - & $350-1200$ & $1-150$ & 0.83 & 7.1 & 326 & $\begin{array}{c}\text { This } \\
\text { report }\end{array}$ \\
\hline
\end{tabular}

*UNS: Unspecified ranges, $\mathrm{T}=$ Temperature in ${ }^{\circ} \mathrm{C}$

Creep rupture has also been investigated on a subset of FeCrAl alloys as shown in Figure 13. Wrought $\mathrm{FeCrAl}$ alloys tend to perform in a similar manner. At all temperatures and stress levels the total strain is greater than $35 \%$ with values closer to $60 \%$ being common. The PM based Kanthal APMT alloy exhibited excellent creep strength compared to the wrought $\mathrm{FeCrAl}$ alloys.

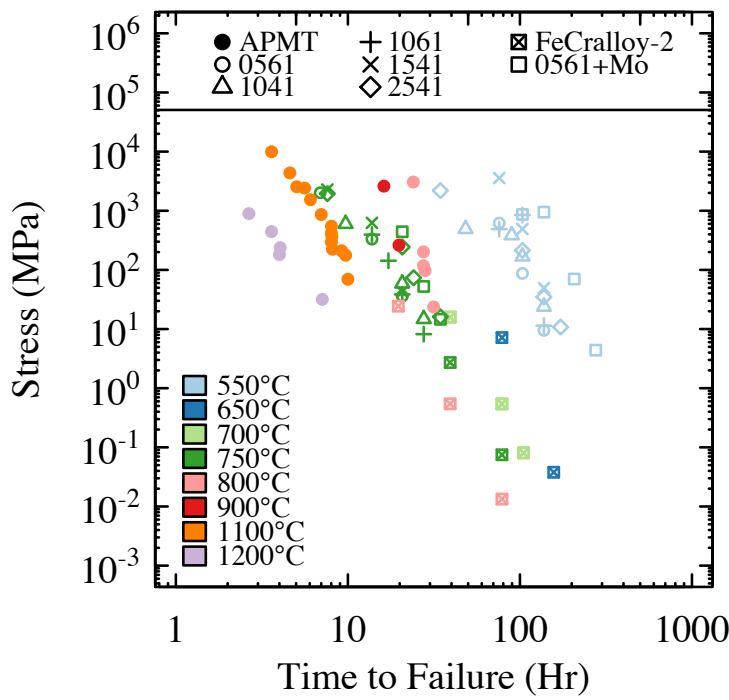

Figure 13: Creep rupture for varying FeCrAl alloys. Legend is identical to Figure 12a. 


\subsubsection{Fatigue}

Low cycle fatigue of a wrought $\mathrm{FeCrAl}$ alloy (Fe-23.85Cr-3.89Al in wt.\%) with a nominal grain size of $600 \mu \mathrm{m}$ was studied in a series of manuscripts by S.C. Tjong and colleagues [58,77-80]. Tests were performed in air under various strain amplitude and test temperatures with the resulting responses shown in Figure 14. The results show a three-stage behavior with the initial stage characterized by hardening, followed by a saturation stage, and then finally softening and eventual facture. The extent and magnitude for each stage was found to be dependent both on the strain amplitude and the test temperature as seen in Figure 14. Tjong and colleagues reported the observation of DSA in the temperature range of 400 to $600^{\circ} \mathrm{C}$ and that DSA played an important role in the cycle deformation within this temperature regime [58]. Further work also was conducted on a lower $\mathrm{Al}$ variant - Fe-25Cr-2Al, in wt. $\%$ - and showed variances in both the cyclic stress responses as a function of number reversals as well as the resulting dislocation structures in the two alloys [78]. The limited work completed by Tjong and colleagues indicates a potential composition dependency on the fatigue properties, but further studies are needed to confirm any dependency. It should also be noted that the fatigue results presented here are derived from very coarse grained, model FeCrAl alloys. No studies were found at the time of this report on additional wrought materials and/or finer grained $\mathrm{FeCrAl}$ alloys.
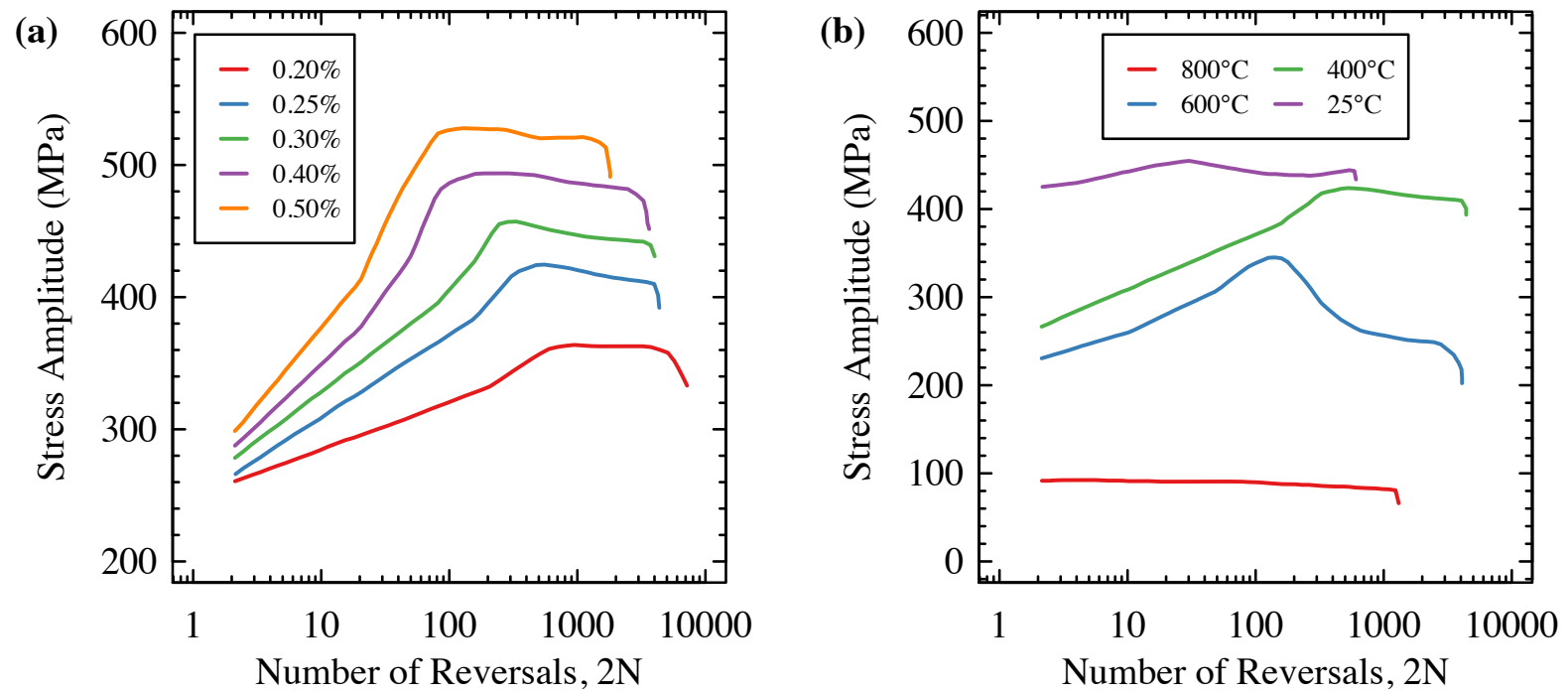

Figure 14: Cyclic stress response curves of a $\mathrm{Fe}-23.85 \mathrm{Cr}-3.89 \mathrm{Al}$ in wt.\% alloy tested (a) at $400^{\circ} \mathrm{C}$ at various strain amplitudes and (b) at a strain amplitude of $0.30 \%$ at various test temperatures. Reproduced from [58].

\subsubsection{Fretting and wear}

Fretting and wear properties of an unspecified FeCrAl alloy (Fe-21Cr-5.2Al in wt.\%) was studied by Lee and Byun [81] while more recently the study of Winter et al. has investigated the Kanthal APMT alloy [82]. The study of Lee and Byun focused on the grid-to-rod fretting (GTRF) mechanisms including FeCrAl$\mathrm{FeCrAl}$ interactions and FeCrAl-Zr interactions under unlubricated (air) and lubricated (water) conditions. In brief, it was found that $\mathrm{FeCrAl}$ to $\mathrm{Zr}$ mating leads to wear depths as high as $\sim 250 \mu \mathrm{m}$ in the unlubricated condition $(5-30 \mathrm{~Hz})$, but these values were reduced for the lower frequency conditions in a water lubricated state. For the case of FeCrAl-to-FeCrAl mating surfaces, wear depths were limited to below $150 \mu \mathrm{m}$ in the 
unlubricated and below $30 \mu \mathrm{m}$ in the lubricated state. The study by Winter et al. studied dry fretting conditions at $30 \mathrm{~Hz}$ at temperatures of $23^{\circ} \mathrm{C}, 300^{\circ} \mathrm{C}$, and $350^{\circ} \mathrm{C}$. The work of Winter et al. supports the earlier study of Lee and Byun and showed that APMT has more favorable wear characteristics in the conditions studied than that of the investigated Zr-based alloy. It can be concluded through these studies $[81,82]$ that Zr-based grids could be more susceptible to GTRF compared to a high-Cr FeCrAl-based grid when FeCrAl-based rods are used within a fuel assembly. Additional studies are needed to evaluate the fretting and wear characteristics of lower $\mathrm{Cr}(<20 \mathrm{wt}$.\% Cr) FeCrAl alloys.

\subsection{Oxidation, corrosion, and environmental cracking}

\subsubsection{Air and steam oxidation}

In general, FeCrAl alloys are known to exhibit excellent oxidation resistance [5,21,23,55,63,83-92]. The oxidation performance of $\mathrm{FeCrAl}$ alloys can be attributed to the formation of $\alpha-\mathrm{Al}_{2} \mathrm{O}_{3}$ (alumina) on the exposed surface(s) due to the preferential oxidation of Al within the alloy [20,23,55,63]. The addition of Cr has been shown to be beneficial towards the alumina scale formation, an effect referred to as the "third" element effect [22]. Yttrium has also been shown to have an effect on oxidation kinetics in both air and steam and hence careful control of the yttrium content in FeCrAl alloys is needed [4,23,93]. Only small differences between the oxidation kinetics of FeCrAl alloys exist for steam and air exposures [21,90-92,94]. For both conditions, alumina formation is promoted when sufficient $\mathrm{Cr}$ and $\mathrm{Al}$ are contained within the alloy $[63,86,88]$.

A significant amount of testing has been completed to determine the idealized $\mathrm{Cr}$ and $\mathrm{Al}$ content of model $\mathrm{FeCrAl}$ alloys to show high temperature oxidation resistance while working towards alloy contents which are not prone to $\alpha^{\prime}$ embrittlement [14,95]. Even more studies have been completed to evaluate different aspects of oxidation at elevated temperatures for varying model and commercial FeCrAl alloys. A brief summary of the effects of $\mathrm{Cr}$ and $\mathrm{Al}$ on the oxidation resistance of FeCrAl alloys is provided here. In particular, a focus on steam oxidation at temperatures of $1200^{\circ} \mathrm{C}$ and higher are the focus as the database has direct relevancy towards ATF cladding applications.

Figure 15 summarizes the effect of $\mathrm{Cr}$ and $\mathrm{Al}$ content on three separate factors: (1) protective alumina film formation in $\mathrm{Ar}-50 \% \mathrm{H}_{2} \mathrm{O}$ and $100 \% \mathrm{H}_{2} \mathrm{O}$ as a function of alloying at $1200^{\circ} \mathrm{C}$ for a four-hour exposure [88], Figure 15a, (2) the parabolic reaction rates of different alloy compositions scaled to the reported value for Kanthal APMT [21], Figure 15a, and (3) identification of the maximum use temperature for the formation of a protective alumina scale [89], Figure $15 \mathrm{~b}$.

As discussed in prior Sections, a matter of concern for FeCrAl alloys where the application temperature resides below $500^{\circ} \mathrm{C}$, such as LWR fuel cladding applications, is the formation of $\alpha^{\prime}$ which at significant number densities can lead to severe hardening and embrittlement of the alloy (See [96] and references within). This embrittlement mechanism for FeCrAl alloys has led to a focus on developing alloys which exhibit the typical oxidation resistance of the higher $\mathrm{Cr}(>18 \mathrm{wt} . \%$ - e.g. Kanthal APMT, PM2000, etc.) $\mathrm{FeCrAl}$ alloys but have significantly lower $\mathrm{Cr}$ compositions. To overcome the lack of $\mathrm{Cr}$ within the system, it is anticipated increased $\mathrm{Al}$ is needed.

Figure 15a represents the on-going oxidation testing to determine viable lean- $\mathrm{Cr} \mathrm{FeCrAl}$ alloys for normal operation below $500^{\circ} \mathrm{C}$ while still maintaining oxidation resistance at and above $1200^{\circ} \mathrm{C}$. Preliminary tests were completed using a Cahn thermogravimetric analyzer (TGA) in Ar-50\% $\mathrm{H}_{2} \mathrm{O}$ [83] while more recent results were obtained in $100 \% \mathrm{H}_{2} \mathrm{O}$ using a Rubotherm TGA [90]. A shift between the two datasets was observed - an indication on the role of steam content on the oxidation performance of FeCrAl alloys; the shifted dataset is presented in Figure 15a. The up-triangles are compositions which form a protective alumina scale for $4 \mathrm{hr}$ in steam, while down-triangle symbols are those that do not. The effect of $\mathrm{H}_{2} \mathrm{O}$ 
content on shifting the boundary is consistent with other studies such as the one performed on Fe-13Cr$\mathrm{XAl}$ model $\mathrm{FeCrAl}$ alloys with low $\mathrm{Al}$ variants ( $<2 \mathrm{wt} . \%)$. With these low $\mathrm{Al}$ variants, a continuous alumina scale is not formed, and they are therefore more susceptible to increasing water content than higher Al variants which do form the protective alumina scale [97]. Figure 15a shows that for lean-Cr variants, such as $12-13$ wt. $\% \mathrm{Cr}$, that $\mathrm{Al}$ content in the alloys needs to be $\geq 5 \mathrm{wt} . \%$ to be oxidation resistant in high temperature steam environments. The dashed line represents an arbitrary "kinetic" composition boundary for oxidation resistance in $\mathrm{FeCrAl}$ alloys in steam environments.
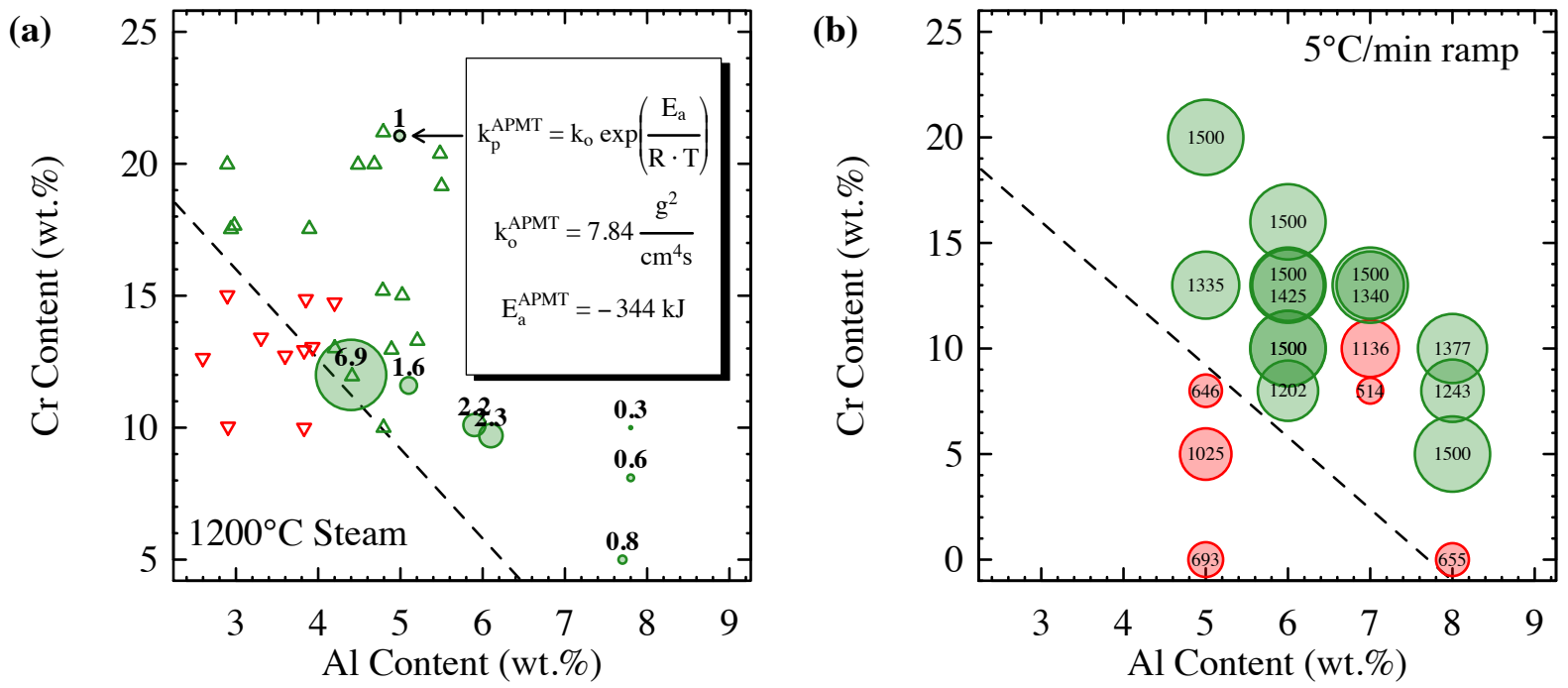

Figure 15: Effect of $\mathrm{Cr}$ and $\mathrm{Al}$ alloy content on steam oxidation resistance at $1200^{\circ} \mathrm{C}$ in $\mathrm{FeCrAl}$ alloys. (a) green, up-triangle symbols showing compositions which form a protective alumina scale and red, down-triangle symbols are those that are not protective [88], dashed line is arbitrary boundary separating the two regimes. Where kinetic data is available [21] circles are scaled with the scaling factor (S) presented to the Kanthal APMT parabolic oxidation rate as shown in inset, $k_{p}^{C r, A l}=S \cdot k_{p}^{A P M T: 1200^{\circ} C}$ ( (b) maximum use temperature determined via "ramp" testing, green circles are alloys with maximum use above $1200^{\circ} \mathrm{C}$ [89].

The "go, no-go" type of studies depicted by the triangle symbols in Figure 15a do not provide insight into the varying kinetics of oxidation in $\mathrm{FeCrAl}$ alloys. The progression of the alumina scale and oxidation resistance of $\mathrm{FeCrAl}$ alloys is needed for accurate modeling of different reactor scenarios such as off-normal condition(s) modeling. Several studies have provided the required data for the oxidation kinetics in varying FeCrAl alloys. These studies have shown the steam oxidation kinetic data of protective alloys can be fitted to an Arrhenius relationship (also shown in Figure 15a) [88],

$$
k_{p}=k_{o} \exp \left(\frac{-E_{a}}{R \cdot T}\right)
$$

where $k_{p}$ is the steady state parabolic rate constant in $\mathrm{g}^{2} / \mathrm{cm}^{4} \mathrm{~s}, k_{o}$ is a constant with the same units of $k_{p}$, $E_{a}$ is the activation energy in $\mathrm{J} / \mathrm{mol}, \mathrm{R}$ is the gas constant, and $\mathrm{T}$ is the temperature in Kelvin [21]. The steady state parabolic rate constant can be determined via mass gain data by,

$$
\Delta m=\Delta m_{o}+k_{p}^{1 / 2} t^{1 / 2}
$$


where $\Delta m$ is the mass gain, $\Delta m_{o}$ is a constant in $\mathrm{g} / \mathrm{cm}^{2}$ and $t$ is time [98]. Hence, a plot of $\Delta m$ vs. $t^{1 / 2}$ can be used to determine the parabolic rate constant as long as the plot does not include a transient period within it. This technique has been applied to the database on Kanthal APMT exposed at temperatures ranging from $1050^{\circ} \mathrm{C}$ to $1475^{\circ} \mathrm{C}$ and it was found that the activation energy is $344 \mathrm{~kJ}$ and the pre-exponential constant was $7.84 \mathrm{~g}^{2} / \mathrm{cm}^{2}$ s, Figure 15a [88]. Note, the activation energy has also been quoted at varying levels such as $273 \mathrm{~kJ} / \mathrm{mol}$, but the fitting range is smaller in those studies [21] compared to the referenced study.

Kanthal APMT is a typical high $\mathrm{Cr}(21 \mathrm{wt} . \%) \mathrm{FeCrAl}$ alloy and hence shows excellent oxidation kinetics. Several other alloys have been investigated at $1200^{\circ} \mathrm{C}$ to determine the change in the parabolic rate constant as application of the Kanthal APMT parabolic oxidation rates does not provide good agreeance with expected mass gains under simulated station black out (SBO) experimental simulation tests [99]. Figure $15 \mathrm{a}$ shows a bubble plot overlay where the size of the circular symbols are scaled against $k_{p}^{A P M T: 1200^{\circ} \mathrm{C} \text { for }}$ model alloys with varying $\mathrm{Cr}$ and $\mathrm{Al}$ content (triangles are unscaled symbols). Decreasing the $\mathrm{Cr}$ content from the Kanthal APMT composition to leaner Cr compositions while maintaining the Al content relatively the same ( 4-6 wt.\%) results in increased oxidation kinetics in steam. Alloys which reside very close to the arbitrary line for protective oxidation show a significant increase $(6.9 \times)$ in the oxidation rate while those which reside farther away show similar oxidation kinetics (1.6-2.3 $\times$ faster) to Kanthal APMT. These results are consistent with the range of scaling factors considered for $13 \mathrm{wt} \% \mathrm{Cr}, 6 \mathrm{wt} \% \mathrm{Al} \mathrm{FeCrAl}$ alloys by Robb et al. based on accident scenario benchmark testing [99]. The composition dependence for steam oxidation is also consistent with composition dependencies in air $[63,86]$.

Note the scaling factors for lean-Cr FeCrAl alloys (1.5-10×) are still considerably lower than the $\sim 100$ $1000 \times$ faster oxidation kinetics of Zr-based alloys [15]. Interestingly, alloys with Al contents greater than 7 wt.\% show marked improvement over Kanthal APMT regardless of Cr content - but, these alloys have been shown to exhibit poor fabricability and joining. The results in Figure 15a highlight the significant benefit of $\mathrm{Al}$ additions on the oxidation resistance to $\mathrm{FeCrAl}$ alloys.

The data generated in Figure 15a is produced using isothermal testing which are inefficient for screening a large number of different alloy compositions, and even as a first-order approximation, does not simulate typical accident type scenarios for LWRs. A simple "ramp" testing experiment has been completed to supplement the isothermal tests. Within the "ramp" tests, the specimens are heated in Ar to $600^{\circ} \mathrm{C}$ then steam is introduced at $5^{\circ} \mathrm{C} / \mathrm{min}$ up to $1500^{\circ} \mathrm{C}$ while continuously monitoring the mass gain. The maximum use temperature is determined when the specimen mass grain exceeds $2 \mathrm{mg} / \mathrm{cm}^{2}$, essentially the onset of break-away oxidation.

Figure 15b provides a bubble plot of the ORNL model alloys and Kanthal APMT tested in this manner, the dashed line is the same boundary plotted in the sister Figure 15a plot. Kanthal APMT is again used as the litmus test as the alloy's max use temperature is $1500^{\circ} \mathrm{C}$, which is nearly the typical melting point for $\mathrm{FeCrAl}$ alloys [100]. The tests show alloys which have $\mathrm{Cr}$ and $\mathrm{Al}$ contents below the arbitrary line for protective oxidation, derived from the data in Figure 15a, tend to show poor performance with maximum use temperatures at or greatly below $1200^{\circ} \mathrm{C}$. In general, increasing the $\mathrm{Cr}$ and $\mathrm{Al}$ content to push away from the boundary significantly increases the maximum use temperature. Thus, even lean-Cr FeCrAl alloys (10-13 wt.\%) exhibit maximum use temperatures at $1500^{\circ} \mathrm{C}$. Again, it should be noted in comparison to other material systems such as Zr-based alloys and austenitic stainless steels the oxidation resistance of $\mathrm{FeCrAl}$ alloys, as long as sufficient $\mathrm{Cr}$ and $\mathrm{Al}$ are provided, far exceed the performance of the other material classes. In short summary, Figure 15 provides the experimental verification for the use of lean-Cr FeCrAl alloys for applications where high temperature oxidation resistance is of importance.

Additional oxidation studies have also been targeted to specifically determine the ability of FeCrAl alloys to form $\alpha-\mathrm{Al}_{2} \mathrm{O}_{3}$ in the low temperature $\left(<1000^{\circ} \mathrm{C}\right)$ regime $[87,101,102]$. These studies have primarily been focused in the low temperature regime as $\alpha-\mathrm{Al}_{2} \mathrm{O}_{3}$ has been proposed as a tritium barrier (see Section 3.5) but the formation of $\alpha-\mathrm{Al}_{2} \mathrm{O}_{3}$ produced under a final high temperature oxidation process could affect the 
final microstructure and performance of a $\mathrm{FeCrAl}$ alloy. The resulting conclusion of these low temperature oxidation studies is that the oxidation kinetics at low temperatures is sufficiently low that it prevents the production of a tritium-resistant $\alpha-\mathrm{Al}_{2} \mathrm{O}_{3}$ barrier. At the present, the only method that has been found capable of producing a continous an $\alpha-\mathrm{Al}_{2} \mathrm{O}_{3}$ tritium barrier is a high temperature oxidation process [101].

\subsubsection{Hydrothermal corrosion}

Autoclave immersion tests were performed on ORNL model alloys and commercial Kanthal APMT in pressurized water reactor (PWR), boiling water reactor hydrogen water chemistry (BWR-HWC), and normal water chemistry (NWC) conditions. For details on the conditions for each autoclave test the reader is referred to the original work by Terrani et al. [103]. Alloy chemistry was varied in the ORNL model alloys to determine any composition effects on the corrosion behaviors of wrought FeCrAl alloys. Alloys exposed to hydrogen water chemistry conditions experienced mass loss as a function of time while those in oxygenated water tests experienced mass gain. X-ray diffraction of the different oxides revealed spineltype oxides to form during hydrogen water chemistry exposures while those alloys exposed to oxygenated water formed hematite-type oxides. The corrosion process was empirically found to follow parabolic kinetics,

$$
\Delta \omega_{T}=\left(k_{1}-k_{2}\right) \sqrt{t}
$$

where $\Delta \omega_{T}$ is the total mass change in the specimen, $k_{l}$ is the rate constant for oxide layer growth, $k_{2}$ is the rate constant for Fe dissolution and $t$ is the exposure time [103]. The parameters for varying alloys and conditions were provided by Terrani et al. [103] and reproduced here in Table 5. It should be noted that $k_{2}$ is not valid for exposures in BWR-NWC as no mass loss was determined.

Table 5: Parabolic oxidation $\left(k_{1}\right)$ and dissolution $\left(k_{2}\right)$ rate constants for various FeCrAl alloys [103].

\begin{tabular}{|c|c|c|c|c|c|c|}
\hline \multirow{2}{*}{ Alloy } & \multirow{2}{*}{$\begin{array}{c}\text { Cr, Al } \\
(\mathbf{w t .} \%)\end{array}$} & \multicolumn{2}{|c|}{ PWR $^{\mathbf{1}}$} & \multicolumn{2}{|c|}{ BWR-HWC $^{\mathbf{2}}$} & $\begin{array}{c}\text { BWR- } \\
\text { NWC }^{\mathbf{3}}\end{array}$ \\
\cline { 3 - 7 } & & $\boldsymbol{k}_{\mathbf{1}}\left(\times \mathbf{1 0}^{-\mathbf{3}}\right)^{*}$ & $\boldsymbol{k}_{\mathbf{2}}\left(\times \mathbf{1 0}^{-\mathbf{3}}\right) *$ & $\boldsymbol{k}_{\mathbf{1}}\left(\times \mathbf{1 0}^{-\mathbf{3}}\right) *$ & $\boldsymbol{k}_{\mathbf{2}}\left(\times \mathbf{1 0}^{-\mathbf{3}}\right)^{*}$ & $\boldsymbol{k}_{\mathbf{1}}\left(\times \mathbf{1 0}^{-4}\right)^{*}$ \\
\hline F1C5AY & 10,5 & $2.05 \pm 0.30$ & $7.09 \pm 0.42$ & $1.38 \pm 0.06$ & $4.41 \pm 0.26$ & $3.63 \pm 0.46$ \\
\hline B125Y & 12,5 & & & & & $2.66 \pm 0.60$ \\
\hline $\begin{array}{c}\text { Fe-13Cr- } \\
\text { 4Al }\end{array}$ & 13,4 & 3.96 & $7.49 \pm 1.93$ & 2.20 & $6.70 \pm 0.31$ & $4.51 \pm 0.50$ \\
\hline $\begin{array}{c}\text { Fe-13Cr- } \\
\text { 4A1 SG }\end{array}$ & 13,4 & & & & & $1.60 \pm 0.35$ \\
\hline B154Y & 15,4 & & & & & $5.34 \pm 0.92$ \\
\hline B183Y & 18,3 & $4.45 \pm 3.02$ & $7.83 \pm 0.28$ & $3.28 \pm 0.26$ & $6.04 \pm 0.16$ & $2.97 \pm 0.55$ \\
\hline Average & N/A & 3.49 & 7.47 & 2.29 & 5.72 & $3.45 \times 10^{-4}$ \\
\hline
\end{tabular}

*Units: $\mathrm{mg}^{-\mathrm{cm}^{-2} \mathrm{~h}^{-1 / 2}}$

${ }^{1} 3.57 \mathrm{ppm} \mathrm{H}_{2}, 330^{\circ} \mathrm{C}, 7.2 \mathrm{ph}, 15 \mathrm{MPa},-820 \mathrm{mV}$ vs SHE

${ }^{2} 0.3 \mathrm{ppm} \mathrm{H}_{2}, 290^{\circ} \mathrm{C}, 5.6 \mathrm{ph}, 7 \mathrm{MPa},-540 \mathrm{mV}$ vs SHE

${ }^{3} 1.0 \mathrm{ppm} \mathrm{O}_{2}, 290^{\circ} \mathrm{C}, 5.6 \mathrm{ph}, 7 \mathrm{MPa}, 350 \mathrm{mV}$ vs SHE 
No significant effects on composition was observed for the BWR-NWC condition while oxidation rates increased with increasing chromium content in the BWR-HWC condition. Given this, corrosion rates still remain low for all alloys regardless of water chemistry and hence alloy composition is not considered a major contributing factor based on hydrothermal corrosion.

\subsubsection{Stress corrosion cracking}

Stress corrosion cracking (SCC) is a primary concern for many core internal components including those composed of Fe-based stainless steels such as the 300 -series of austenitic stainless steels. As such, a wealth of data on the mechanisms and susceptibility of austenitic stainless steels has been generated (for instance see Ref. [104,105] and those within). For high-Cr ferritic steels, including FeCrAl alloys, limited studies have been completed. Currently, the only known work on SCC of FeCrAl alloys has been completed on Kanthal APMT by Andresen et al./Rebak [106,107] and by Ahmedabadi and Was [108]. The study of Ahmedabadi and Was used constant extension rate tensile (CERT) experiments to evaluate crack initiation while those of Andresen et al. and Rebak used standard 0.5T compact type fracture mechanics specimens to evaluate crack growth rates. All studies were focused on BWR water chemistries. Both research groups indicate that Kanthal APMT, compared to reference austenitic stainless steels, is extremely resistant to SCC at BWR or aggressive-BWR conditions in the non-irradiated state.

\subsection{Hydrogen and tritium permeation}

Tritium permeation is a primary concern with cladding based applications as the reactor inventory of tritium is produced by ternary fission in the fuel rods. The high mobility of tritium results in the ability for it to permeate from the fuel through the cladding causing safety issues during plant operation including increased radiation exposure to plant personnel. Tritium permeation has been investigated for a range of different $\mathrm{FeCrAl}$ alloys to determine specific alloys permeability and possible mitigation strategies. For many studies, hydrogen is used in lieu of radioactive tritium resulting in decreased safety concerns during the experiment.

The hydrogen permeability of FeCrAl alloys has been measured by several authors [109-114] in the range of $200^{\circ} \mathrm{C}$ to $700^{\circ} \mathrm{C}$. Figure 16 plots the data as a function of temperature. In general, the higher $\mathrm{Cr}$ content FeCrAl alloys (1605 (16 wt.\%), Kanthal APMT (21 wt.\%), and Thermacore (22 wt.\%)) show lower permeability than the lower $\mathrm{Cr}$ content model alloys. Additionally, a significant difference in the permeability between non-oxidized and oxidized specimens is apparent. $\mathrm{Al}_{2} \mathrm{O}_{3}$ has been shown to have nearly one order of magnitude lower permeability than typical bare $\mathrm{FeCrAl}$ alloys $[110,112]$. Oxidation via a $730^{\circ} \mathrm{C}$ for $\sim 3 \mathrm{~h}$ treatment in air, which promotes $\mathrm{Al}_{2} \mathrm{O}_{3}$ formation on $\mathrm{FeCrAl}$ alloys - see Section 3.4.1, led to a large reduction in the permeability of hydrogen through the specimen(s). These results confirm the expectations for oxidation detailed by $\mathrm{Hu}$ et al. [109] and the predicted permeation impedance factor of $1000 \times$ provided within Bell and Redman [112].

The permeability of hydrogen, deuterium, and tritium in FeCrAl alloys can be empirically described by

$$
\phi=\phi_{0} \exp \left(-E_{a} / R T\right)
$$

where $\phi_{0}$ is the permeability constant and $E_{a}$ is the effective activation energy for permeation [115]. The permeability constant and activation energies were determined empirically by $\mathrm{Hu}$ et al. [109] using a nonlinear least-squares method for Kanthal APMT, T54Y, and T35Y in Figure 16. The same method was applied for the remaining alloys in Figure 16 here; the permeability parameters for all alloys is summarized in Table 6 fits are provided in Figure 16 shows for those tests where the testing conditions are identical that 
the activation energy $\left(\mathrm{E}_{\mathrm{a}}\right)$ increases with increasing $\mathrm{Cr}$ content within the FeCrAl alloys. These findings would suggest higher-Cr content $\mathrm{FeCrAl}$ alloys are more desirable if tritium permeation is of significant concern for reactor operation using $\mathrm{FeCrAl}$ cladding.

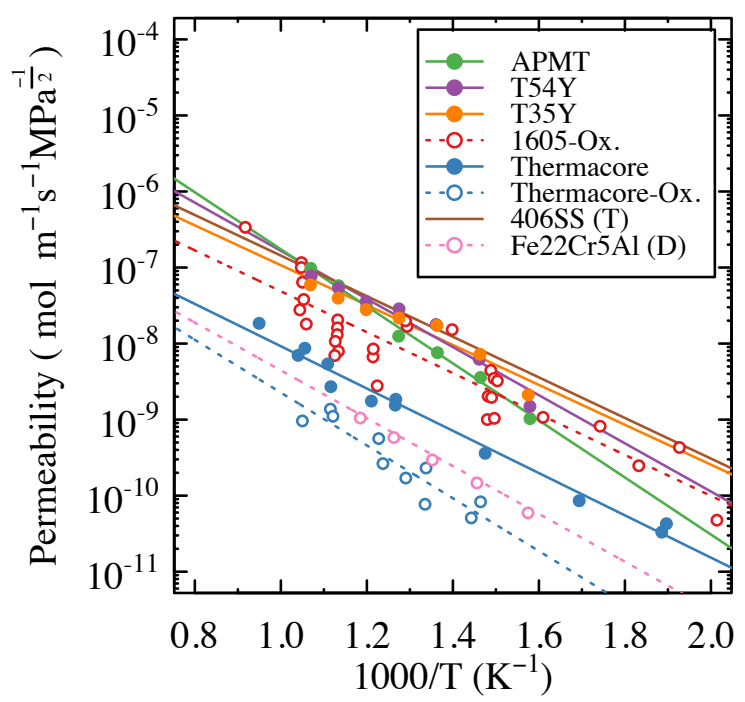

Figure 16: Arrhenius plot of the fitted hydrogen permeability for several FeCrAl alloys [109-114]. Closed symbols are for samples with limited to no oxidation, open symbols are for oxidized specimens, (D): deuterium permeability, (T): tritium permeability.

Several studies have also been completed on deuterium and tritium permeation in select FeCrAl alloys. Deuterium permeation studies were performed by Xu et al. [109] on a Fe-20Cr-5Al (in wt.\%) FeCrAl alloy that was preoxidized prior to permeability measurements. Measurements are plotted with the data on hydrogen permeability in Figure 16 and parameters presented in Table 6. Xu et al.'s study shows similar results to those in Van Deventer et al. [110]; the permeability between the two alloys and species are within the same order of magnitude.

Tritium permeation was performed by Bell et al. [111] on a range of structural alloys, including a 13 wt.\% $\mathrm{Cr}-4$ wt.\% Al FeCrAl alloy (Alloy 406SS). Permeability parameters from the study of Bell et al. are also reproduced in Table 6 and Figure 16. Additional, preliminary work has been completed [116] to investigate the permeability of deuterium and tritium directly on alloy T54Y to provide direct comparison to the results on the same alloy provided by $\mathrm{Hu}$ et al. Given this, due to reported concerns on the leak-tightness of the fitting apparatuses used the values are not reported here. The relationship used by San Marchi et al. [115] is proposed for adoption to determine the permeability of deuterium and tritium based on the hydrogen permeability for a given alloy, where,

$$
\phi_{H}=\sqrt{2} \phi_{D}=\sqrt{3} \phi_{T} .
$$

From this relationship, values in Table 6 for hydrogen permeability can be used to predict the permeability of tritium. Note, no additional microstructural effects are taken into account in Table 6, Figure 16, or the above equation. 
Table 6: Estimated permeability parameters for varying FeCrAl alloys.

\begin{tabular}{|c|c|c|c|c|c|}
\hline Alloy(s) & $\begin{array}{c}\mathbf{C r}, \mathbf{A l} \\
\mathbf{( w t . \% )}\end{array}$ & State & $\begin{array}{c}\boldsymbol{\phi}_{\mathbf{0}} \\
\left(\mathbf{m o l} \mathbf{~ m}^{-1} \mathbf{s}^{-1} \mathbf{M P a}\right. \\
\mathbf{1}\end{array}$ & $\begin{array}{c}\mathbf{E} \\
\mathbf{( k J / m o l})\end{array}$ & Reference \\
\hline $\begin{array}{c}\text { Kanthal } \\
\text { APMT }\end{array}$ & 21,5 & bare & $9.8 \pm 2.2 \times 10^{-4}$ & $71.8 \pm 5.8$ & {$[109]$} \\
\hline T54Y & 15,4 & bare & $2.4 \pm 0.6 \times 10^{-4}$ & $60.6 \pm 0.6$ & {$[109]$} \\
\hline T35Y & 13,5 & bare & $4.5 \pm 2.4 \times 10^{-5}$ & $50.2 \pm 6.0$ & {$[109]$} \\
\hline 1605 & $16,5.0$ & oxidized & $6.7 \times 10^{-6}$ & 66.5 & {$[114]$} \\
\hline Thermacore & 18,2 & bare & $5.6 \times 10^{-6}$ & 53.2 & {$[110]$} \\
\hline Thermacore & 18,2 & oxidized & $2.4 \times 10^{-5}$ & 51.5 & {$[110]$} \\
\hline 406SS** & 13,4 & bare & $6.7 \times 10^{-5}$ & 51.1 & {$[111]$} \\
\hline Fe22Cr5A1* & 22,5 & oxidized & $6.2 \times 10^{-6}$ & 60.2 & {$[113]$} \\
\hline
\end{tabular}

*Permeability parameters for deuterium, **Permeability parameters for tritium

\section{IRRADIATION OF FeCrAI ALLOYS}

\subsection{Irradiation induced microstructure}

\subsubsection{Cavities and swelling}

The primary swelling study for FeCrAl alloys was completed by Little and Stow on a $14.5 \mathrm{wt} . \% \mathrm{Cr}-4.18$ wt. $\% \mathrm{Al} \mathrm{FeCrAl}$ alloy with an initial grain size of $\sim 100 \mu \mathrm{m}$. The alloy was irradiated up to 23 displacements per atom (dpa) in the temperature range of $380-615^{\circ} \mathrm{C}$ within the Dounreay Fast Reactor [11]. Within this experiment, temperatures were monitored continuously using thermocouples. The void swelling for all irradiation conditions were shown to be within the detection limit $(0.1 \%)$ of the technique. More recent work on commercial FeCrAl alloys (Kanthal APMT and Alkrothal 720) and ORNL model alloys irradiated in the temperature range of $334-382^{\circ} \mathrm{C}$ up to $1.8 \mathrm{dpa}$ have shown similar swelling resistance with no observations of voids or cavities in the microstructure as examined using electron microscopy based techniques $[24,117,118]$. Additional heavy ion and proton irradiations on ORNL model alloys match the neutron irradiation responses with no observed void swelling in the alloys of interest $[119,120]$. These results are in line with the well-known swelling resistance of high-Cr ferritic alloys and thus common incubation regime dpa swelling rates can be used for typical LWR fuel clad applications for first order modeling applications.

\subsubsection{Dislocation loop morphologies}

Preliminary studies on neutron irradiated model FeCrAl alloys using materials test reactors have linked the observed radiation and hardening in the alloys to both dislocation loop formation and precipitation. The production of these defects is the direct result of the neutron damage within the material resulting in a range of damage processes including radiation-enhanced diffusion and defect agglomeration. Studies have evaluated different aspects for dislocation loop formation and precipitation in a variety of $\mathrm{FeCrAl}$ alloys including the influence of damage dose, alloy content, and local microstructure. In brief, the observed effects are consistent with classical effects in $\mathrm{Fe}$ and high-Cr Fe-Cr ferritic alloys. 
Neutron and ion irradiation in the temperature range of $334^{\circ} \mathrm{C}$ to $384^{\circ} \mathrm{C}$ up to 2.5 dpa have been shown to produce a mixed population of dislocation loops with either a Burgers vector of $a / 2\langle 111\rangle$ which can be either interstitial or vacancy in nature or $a\langle 100\rangle$ with interstitial nature [24,117,121]. Determination of the Burgers vectors of the dislocation loops is of high importance for irradiated FeCrAl alloys. Application of the dispersed barrier hardening models have shown $a\langle 100\rangle$ loops to be strong barriers to dislocation motion compared to $a / 2\langle 111\rangle$ loops [24]. The result is the ratio of the loops can have a strong effect on the mechanical properties of $\mathrm{FeCrAl}$ alloys, and thus should be reported.

Burgers vectors have been determined via both classical tilt-series characterization [122] and using morphology-based determination from on-zone scanning transmission electron microscopy (STEM) bright field (BF) imaging [123] (for more details on each technique see the cited references and those within). The on-zone STEM-BF technique was initially used for characterizing the ORNL model alloys due to the inherent simplicity of the technique, but no systematic study was completed to determine the difference or similarities in the quantitative ability of each technique to characterize the dislocation loop populations in irradiated FeCrAl. Recent studies by E. Aydogan et al. completed characterization on the same alloys using both techniques with the results reproduced in Table 7 [120]. The results shown in Table 7 indicate that the data obtained from the STEM-BF technique and from the classical tilt-series characterization produce identical results when counting and statistical errors are taken into account. This result means data produced from one technique can be directly compared to that of the other technique and vice versa.

Table 7: Comparison of two electron microscopy approaches to quantify the dislocation loop population in $\mathrm{C} 06 \mathrm{M} 2$ and $\mathrm{C} 36 \mathrm{M} 3$ after heavy ion irradiations at $300^{\circ} \mathrm{C}$. Reproduced from [120].

\begin{tabular}{|c|c|c|c|c|c|c|c|c|}
\cline { 2 - 9 } \multicolumn{1}{c|}{} & \multicolumn{4}{|c|}{ C06M2 } & \multicolumn{4}{c|}{ C36M3 } \\
\cline { 2 - 9 } & \multicolumn{2}{|c|}{$\mathbf{0 . 7}$ dpa } & \multicolumn{2}{c|}{$\mathbf{1 6}$ dpa } & \multicolumn{2}{c|}{ 0.7 dpa } & \multicolumn{2}{c|}{ 16 dpa } \\
\cline { 2 - 9 } & BFTEM & STEM & BFTEM & STEM & BFTEM & STEM & BFTEM & STEM \\
\hline $\mathbf{d}_{\text {avg }}(\mathbf{n m})$ & $10.2 \pm 3.8$ & $10.3 \pm 4.7$ & $10.8 \pm 4.5$ & $8.1 \pm 2.9$ & $11.0 \pm 3.1$ & $12.9 \pm 4.9$ & $10.6 \pm 4.1$ & $8.6 \pm 3.2$ \\
\hline & 1.7 & 1.2 & 1.7 & 2.4 & 1.0 & 3.6 & 2.1 & 9.2 \\
$\boldsymbol{\rho}_{<\mathbf{1 0 0}>}$ & \pm & \pm & \pm & \pm & \pm & \pm & \pm & \pm \\
$\left(\mathbf{m}^{-3}\right)$ & $0.9 \times 10^{21}$ & $0.1 \times 10^{21}$ & $1.3 \times 10^{22}$ & $0.03 \times 10^{22}$ & $0.5 \times 10^{21}$ & $0.4 \times 10^{20}$ & $6.3 \times 10^{21}$ & $0.2 \times 10^{21}$ \\
\hline & 1.3 & 1.2 & 2.0 & 3.0 & 1.7 & 6.4 & 3.0 & 2.8 \\
$\boldsymbol{\rho}_{<\mathbf{1 1 1}>}$ & \pm & \pm & \pm & \pm & \pm & \pm & \pm & \pm \\
$\left.\mathbf{( m}^{-3}\right)$ & $0.7 \times 10^{21}$ & $0.1 \times 10^{21}$ & $0.9 \times 10^{22}$ & $0.03 \times 10^{22}$ & $0.2 \times 10^{21}$ & $0.6 \times 10^{20}$ & $0.5 \times 10^{22}$ & $0.5 \times 10^{22}$ \\
\hline & 3.0 & 2.4 & 3.7 & 5.4 & 2.7 & 1.0 & 3.2 & 3.7 \\
$\boldsymbol{\rho}_{\text {total }}\left(\mathbf{m}^{-\mathbf{3}}\right)$ & \pm & \pm & \pm & \pm & \pm & \pm & \pm & \pm \\
& $1.6 \times 10^{21}$ & $0.2 \times 10^{21}$ & $2.2 \times 10^{22}$ & $0.06 \times 10^{22}$ & $0.7 \times 10^{21}$ & $0.1 \times 10^{21}$ & $1.1 \times 10^{22}$ & $0.7 \times 10^{22}$ \\
\hline $\mathbf{f}_{<\mathbf{1 0 0}>}$ & 0.56 & 0.50 & 0.47 & 0.44 & 0.38 & 0.36 & 0.07 & 0.25 \\
\hline
\end{tabular}

The various dislocation loop structures in several FeCrAl alloys after neutron irradiation are shown in Figure 17 [24,117]. Although all studied alloys have shown both $a / 2\langle 111\rangle$ and $a\langle 100\rangle$ dislocation loops, the size and number vary based on alloy and local microstructure. For example, studies on cold-worked ORNL model alloys and Alkrothal 720 irradiated to identical conditions have shown that high sink density regions, including dislocation networks and grain boundaries, promotes larger loops with lower densities [117]. Local sink density was also shown to influence the ratio of $a / 2\langle 111\rangle$ to $a\langle 100\rangle$ loops within the same study. An additional study on Kanthal APMT also showed that refractory inclusions can have a similar effect to that of grain boundaries with an increased size and number density near refractory inclusions compared to regions far from defect sinks [118]. 

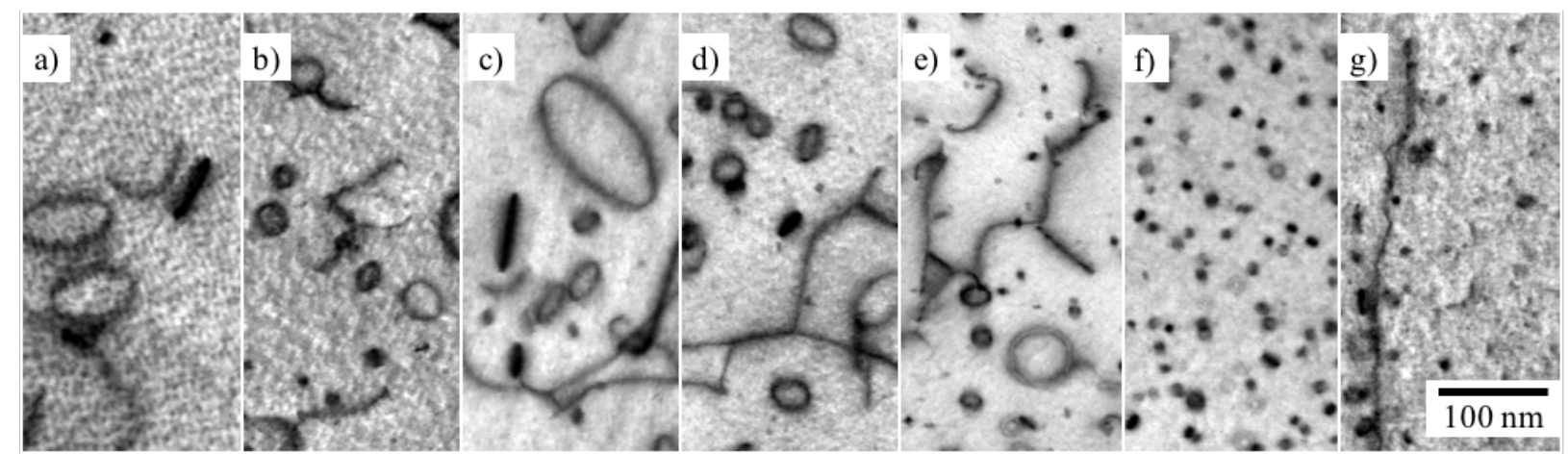

Figure 17: On-[100] zone STEM-BF images showing dislocation loops in ORNL model and commercial FeCrAl alloys irradiated to 1.8 dpa at $364-382^{\circ} \mathrm{C}$. (a) F1C5AY [24], (b) B125Y [24], (c) B154Y-2 [24], (d) B183Y-2 [24], (e) C35M, (f) Alkrothal 720 [117], (g) Kanthal APMT [118].

Composition also plays a role on the evolution of dislocation loops under irradiation. In-situ ion irradiations at $320^{\circ} \mathrm{C}$ and heavy ion irradiations at $300^{\circ} \mathrm{C}$ - data shown in Table 7 - have shown that dislocation loop densities are higher in low-Cr (10-12 wt.\%) FeCrAl alloys compared to higher Cr variants [120,121]. Additionally, the ratio of $a / 2\langle 111\rangle$ to $a\langle 100\rangle$ dislocation loops also increased with increasing $\mathrm{Cr}$ content. Trends that are consistent with low dose neutron irradiations [124]. The role of Al-content remains an open question as all previous studies have had both the $\mathrm{Cr}$ content and $\mathrm{Al}$ content vary. Al remains in solution during irradiation [96] and hence could have an additional effect on the morphology and nature of the dislocation loops in FeCrAl alloys. Further studies are needed to determine the effect of $\mathrm{Al}$, if any. Additionally, many variants in Appendix A use Mo and/or other alloying elements for increased benefits in high temperature strength or material performance factors. The role of minor alloying elements on the dislocation loop formation and growth remains unknown to date. The same in-situ ion irradiation reference earlier showed dose dependencies where the growth rate of $a\langle 100\rangle$ remains higher than that of $a / 2\langle 111\rangle$ dislocation loops and the nucleation rate approaches saturation around $1 \mathrm{dpa}$ at $320^{\circ} \mathrm{C}$ suggesting the onset of a coarsening regime at higher doses. Similar results have for ORNL model alloys neutron irradiated

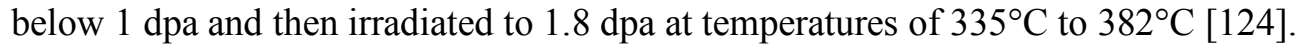

\subsubsection{Precipitation}

The primary focus of precipitation studies in irradiated $\mathrm{FeCrAl}$ alloys is on the precipitation of the $\alpha$ ' phase within the $\alpha$ matrix. No studies have focused on other phases under irradiation, primarily due to the phases such as $\mathrm{YFe}_{9}$ having not been linked to severe hardening or embrittlement after irradiation. Cr-rich $\alpha^{\prime}$ formation in irradiated $\mathrm{FeCrAl}$ has been studied using a range of techniques including small angle neutron scattering (SANS) [24,96,125,126], atom probe tomography (APT) [96,125,127,128], and high-efficiency STEM-EDS (Energy Dispersive Spectroscopy) [125,128]. All three techniques have been demonstrated to detect and quantify $\alpha^{\prime}$ within irradiated FeCrAl alloys. Given this, the techniques typically show disagreements in absolute magnitudes for factors such as size and number density but do present similar trends. Variances between the different techniques are expected due to contrasting simplifying assumptions and experimental uncertainties inherent in each technique [96]. We present this here as care should be taken when comparing datasets from different analytical techniques.

Additional care should also be taken when evaluating ion irradiations or other high dose irradiations as a method to screen for $\alpha^{\prime}$ precipitation in alloys $\left(>10^{-4} \mathrm{dpa} / \mathrm{s}\right)$. For example, recent work on a Fe-18Cr model alloy has shown strong dependencies on the Cr-clustering in the alloys as a function of dose rate $[129,130]$. Similarly, ferritic alloys that formed $\alpha^{\prime}$ under neutron irradiation at $300^{\circ} \mathrm{C}$ have been found not to form $\alpha^{\prime}$ 
under self-ion irradiations with dose rates of $10^{-3}$ to $10^{-2} \mathrm{dpa} / \mathrm{s}[131,132]$. The result is ion irradiations with high dose rates results in the ballistic resolution effect becoming significant which in turns effectively mitigates $\alpha^{\prime}$ formation in $\mathrm{Fe}-\mathrm{Cr}$ alloys. This can also be observed for $\mathrm{FeCrAl}$ alloy systems. For instance, $\alpha^{\prime}$ was not found in $\mathrm{C} 06 \mathrm{M} 2$ and $\mathrm{C} 36 \mathrm{M} 3$ alloys self-ion irradiated at $300^{\circ} \mathrm{C}$ up to $16 \mathrm{dpa}$ with a dose rate of $\sim 10^{-2} \mathrm{dpa} / \mathrm{s}$ while unpublished data completed using both APT and SANS has confirmed $\alpha^{\prime}$ formation in $\mathrm{C} 36 \mathrm{M}$ at doses as low as $2 \mathrm{dpa}$ at an irradiation temperature of $357^{\circ} \mathrm{C}$ using neutrons and a dose rate near $10^{-7} \mathrm{dpa} / \mathrm{s}$.

All neutron irradiation studies have focused on irradiations completed between $320^{\circ} \mathrm{C}$ and $382^{\circ} \mathrm{C}$. The highest dose characterized at the time of this report was $7.0 \mathrm{dpa}$. The remaining discussion is valid only within this dose and temperature regime. Both dose and composition trends have been established. In general, FeCrAl alloys that exist within the phase regime for $\alpha-\alpha^{\prime}$ will have a fine dispersion of high density $\alpha$ ' precipitates at low doses which progresses towards a coarser dispersion of larger precipitates with increasing damage dose (dpa). Increased starting $\mathrm{Cr}$ content of the alloys leads to higher number densities and volume fractions of $\alpha^{\prime}$ for a given irradiation condition. These effects can be seen in the APT based atom maps in Figure 18 [96]. Both the time (or irradiation dose) and composition trends are consistent with aging studies on $\mathrm{FeCrAl}$ alloys.

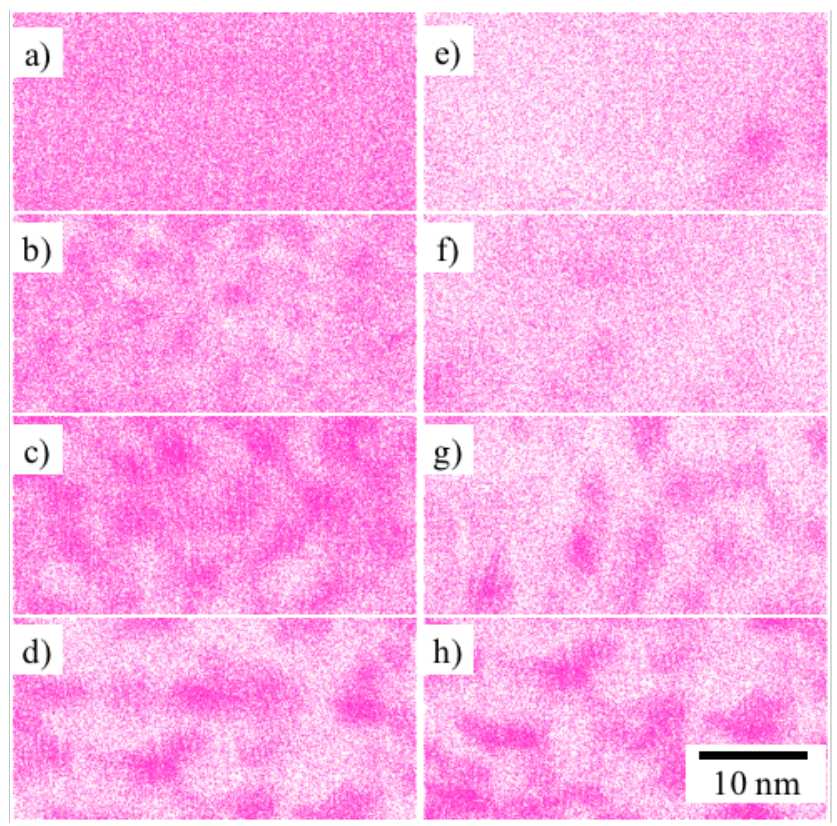

Figure 18: Atom probe tomography $\mathrm{Cr}$ atom maps showing precipitation of $\alpha^{\prime}$ after neutron irradiation [96]. B183Y-2 as-received, $0.8 \mathrm{dpa}$ at $355^{\circ} \mathrm{C}, 1.8 \mathrm{dpa}$ at $382^{\circ} \mathrm{C}$, and $7.0 \mathrm{dpa}$ at $320^{\circ} \mathrm{C}$, (ad) respectively. FeCrAl alloys irradiated to 7.0 dpa at $320^{\circ} \mathrm{C}$, (e) F1C5AY, (f) B125Y, (g) B154Y-2, (h) B183Y-2. All maps taken with a $20 \mathrm{~nm}$ z-axis (in-page) slice.

To a limited degree, the temperature dependence of $\alpha^{\prime}$ precipitation has been explored and established [27,126]. For instance, Ejenstam et al. [27] showed that at lower temperatures $\left(<400^{\circ} \mathrm{C}\right)$, less $\mathrm{Cr}$ content FeCrAl alloys can be susceptible to $\alpha^{\prime}$ precipitation. Care should be taken when considering alloys close to the phases boundaries proposed at $475^{\circ} \mathrm{C}$ - routinely considered the peak aging temperature - as irradiations and thermal aging experiments performed at lower temperatures can see this boundary shift.

For $\mathrm{FeCrAl}$ alloys with $\mathrm{Cr}$ contents below $\sim 21 \mathrm{wt} . \%$ and $\mathrm{Al}$ contents greater than $\sim 4$ wt.\%, $\alpha$ ' progresses via a diffusion limited nucleation and growth mechanisms. As seen in Figure 18 the precipitates remain as 
isolated near-spherical clusters in the matrix; the percolated microstructures of spinodally decomposed $\alpha^{\prime}$ typical for high $\mathrm{Cr} F e-C r$ alloys is not observed. The precipitation of $\alpha^{\prime}$ has been modeled for various ORNL model alloys using the Umantsev-Olson-Kuehmann-Voorhees (UOKV) model which is a diffusion limited coarsening model for ternary alloys [133]. The temporal evolution follows a time (or dose) to the one-third power which is consistent with diffusion limited coarsening. Additionally, it was shown that the rate of coarsening increases with $\mathrm{Cr}$ content suggesting a stronger driving force for higher-Cr FeCrAl alloys, a result consistent with studies on Fe-Cr alloys under similar irradiation conditions [134-136]. Given this, the temporal trends for number density do not fully align with the UOKV model suggesting similar precipitation behavior to that found by Novy et al. [137] where there are overlaps between the nucleation, growth, and coarsening regimes.

The current understanding on the precipitation of $\alpha^{\prime}$ thus indicates several factors including that precipitation is composition dependent, it remains a diffusion limited process under irradiation although radiation-enhanced diffusion ensures faster kinetics than purely thermal processes, and that in general, $\mathrm{FeCrAl} \alpha^{\prime}$ precipitation behavior follows the same trends as those of the larger database on $\mathrm{Fe}-\mathrm{Cr}$ alloys under irradiation [96].

\subsection{Thermal properties}

\subsubsection{Heat content}

No reports or databases on heat content in $\mathrm{FeCrAl}$ alloys were found at the time of this report.

\subsubsection{Thermal conductivity}

No reports or databases on thermal conductivity in $\mathrm{FeCrAl}$ alloys were found at the time of this report.

\subsubsection{Thermal expansion}

No reports or databases on thermal expansion in $\mathrm{FeCrAl}$ alloys were found at the time of this report.

\subsection{Electrical properties}

The study on the GE Model alloy, 1541, is the only know study on the effect of irradiation on the electrical properties in irradiated $\mathrm{FeCrAl}$ alloys [4]. The 1541 alloy $(15 \mathrm{wt} \% \mathrm{Cr}-4 \mathrm{wt} \% \mathrm{Al}$ ) was irradiated at ambient temperatures to a fluence of $9.25 \times 10^{19} \mathrm{n} / \mathrm{cm}^{2}$ (E > $1 \mathrm{MeV}-$ dpa not reported) in the Engineering Test Reactor (ETR). The incremental change in resistivey was found to change signficantly between $200^{\circ} \mathrm{C}$ to $300^{\circ} \mathrm{C}$ indicating removal of irradiation induced defects within the alloy. A signficant slope change was found at $\sim 450^{\circ} \mathrm{C}$ which was atrtirbuted to the dissolution of the $\alpha^{\prime}$ phase within the irradiated matrix [4]. Further details regarding the study were not provided.

\subsection{Mechanical properties}

\subsubsection{Tensile properties}

Tensile tests after neutron irradiation have been performed on ORNL model alloys, GE's 1541, and Kanthal APMT. Preliminary work was completed on Generation I ORNL model alloys and Kanthal APMT that were neutron irradiated up to $13.8 \mathrm{dpa}$ in the temperature range of $320^{\circ} \mathrm{C}$ to $382^{\circ} \mathrm{C}[24,62]$, while additional follow on irradiations were completed on Generation II ORNL model alloys in the non-welded and welded state at 1.8-1.9 dpa in the temperature range of $215^{\circ} \mathrm{C}$ to $557^{\circ} \mathrm{C}$ [138]. Finally, GE's model alloy, 1541, was irradiated at $700^{\circ} \mathrm{C}$ up to $3.4 \times 10^{20} \mathrm{n} / \mathrm{cm}^{2}$ (E>1 MeV - dpa not reported) [5]. The high temperature irradiation of 1541 led to radiation-induced softening when tensile tested at $600^{\circ} \mathrm{C}$ and $700^{\circ} \mathrm{C}$. The 
irradiation temperature resides well outside the $\alpha-\alpha^{\prime}$ region of the FeCrAl phase diagram, Figure 1. No microstructural characterization was completed on the alloys, but based on the softening and the irradiation existing not in the $\alpha$-regime of the phase diagram, it can be assumed limited dislocation loop formation and $\alpha^{\prime}$ formation occurred in the material.

The ORNL-based irradiations did show significant hardening and reduction of ductility after neutron irradiation below nominally $500^{\circ} \mathrm{C}$. Note, all of the ORNL data is generated using either the SS-J2 subsized tensile specimen geometry for the Generation I irradiations or SS-J2 sub-sized and SS-2E sub-sized specimen geometries for the Generation II irradiations which can produce varied mechanical property results compared to ASTM sub-sized specimen geometries [139,140]. The overall dose dependence on the mechanical performance was studied for the Generation I alloys and was shown to mimic that of other high $\mathrm{Cr} \mathrm{Fe}-\mathrm{Cr}$ alloys [62]. FeCrAl alloys demonstrated increased yield strengths up to $\sim 7 \mathrm{dpa}$ and then saturation of the hardening above this value. Additionally, uniform elongations were found to saturate at $\sim 0.5 \%$ and total elongations near $10 \%$ at and above $7.0 \mathrm{dpa}$. Tensile properties for the investigated alloys after irradiation can be found in detail elsewhere [62], only generalized trends are presented in the remainder of this section.

Of particular interest is the performance of alloys with varied composition. Figure 19 (reproduced from [62]) shows a bubble plot to demonstrate the role of $\mathrm{Cr}$ content on the change in yield strength with increasing radiation dose. The $\mathrm{Cr}$ composition dependence is apparent when tensile tests are performed at both room temperature and $320^{\circ} \mathrm{C}$, especially at damage doses below 2 dpa. At higher doses, the composition dependence becomes insignificant. The result is the mechanical properties data for $\mathrm{FeCrAl}$ alloys can be divided in two regimes (1) a low dose regime where $\mathrm{Cr}$ content plays a significant role in the mechanical properties and (2) a moderate/high dose regime where mechanical properties saturate, and composition dependencies are less prevalent.

(a)

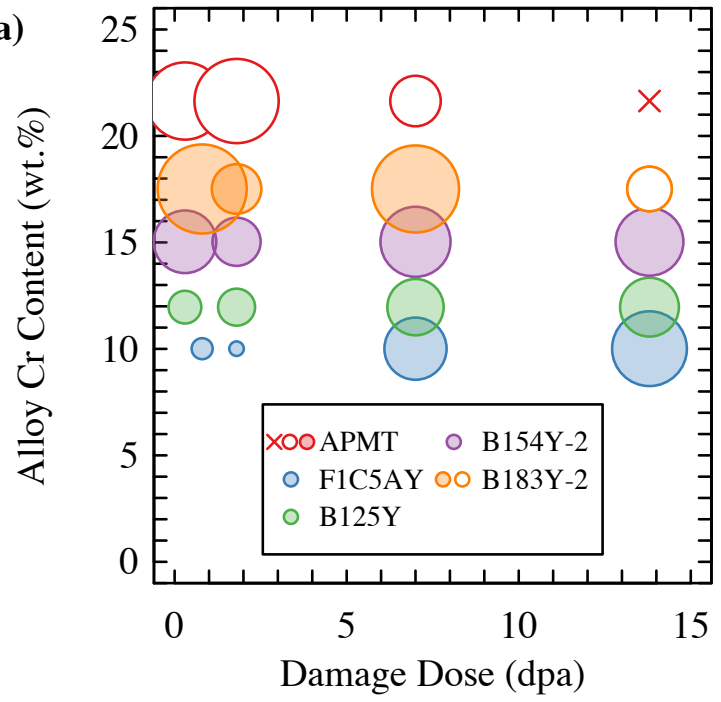

(b)

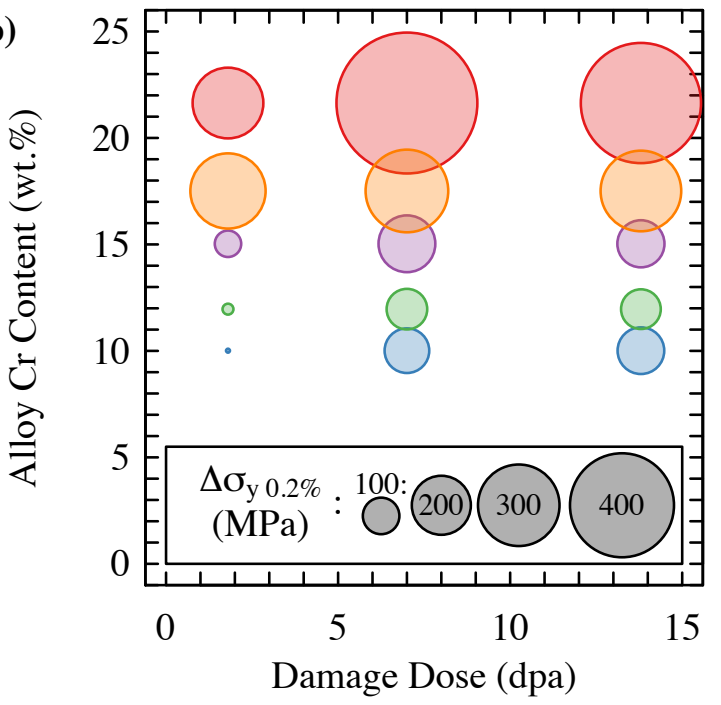

Figure 19: Bubble plot indicating change in $0.2 \%$ offset yield strength $\left(\Delta \sigma_{y 0.2 \%}\right)$ as a function of damage dose (dpa) and alloy $\mathrm{Cr}$ content for tensile tests performed at (a) room temperature $\left(T_{\text {test }}=24^{\circ} \mathrm{C}\right)$ and (b) elevated temperature $\left(T_{\text {test }}=320^{\circ} \mathrm{C}\right)$. Open symbols for Kanthal APMT and B183Y-2 represent tests that failed in a brittle manner. Symbol " $x$ " represents data points where the brittle failure stress occurred below the unirradiated yield stress. Legends in (a) and (b) are valid for both plots. Reproduced from [62]. 
The temperature dependence on the change in mechanical properties was studied in the low dose ( $<2 \mathrm{dpa})$ regime on Generation II ORNL model alloys. Figure 20 summarizes the general trend for all alloys but only shows that for the C35M alloy [138]. All non-welded alloys irradiated in the vicinity of $200^{\circ} \mathrm{C}$ showed limited to no uniform elongation but did show pronounced necking. The response of non-welded specimens varied compared to that of the welded specimens which showed failure to have a high probability of failing in the elastic regime of the engineering stress strain curve. The irradiations performed on non-welded alloys near $330^{\circ} \mathrm{C}$ showed similar responses to those provided on Generation I ORNL model alloys presented in Figure 19 where hardening in conjunction with ductility loss was observed. Welded specimens fared worse, with samples irradiated near $330^{\circ} \mathrm{C}$ having severe degradation of the ductility of the specimens. Irradiations conducted above $500^{\circ} \mathrm{C}$ showed no significant degradation of mechanical properties compared to the unirradiated counterpart specimens for any specimen or configuration studied.
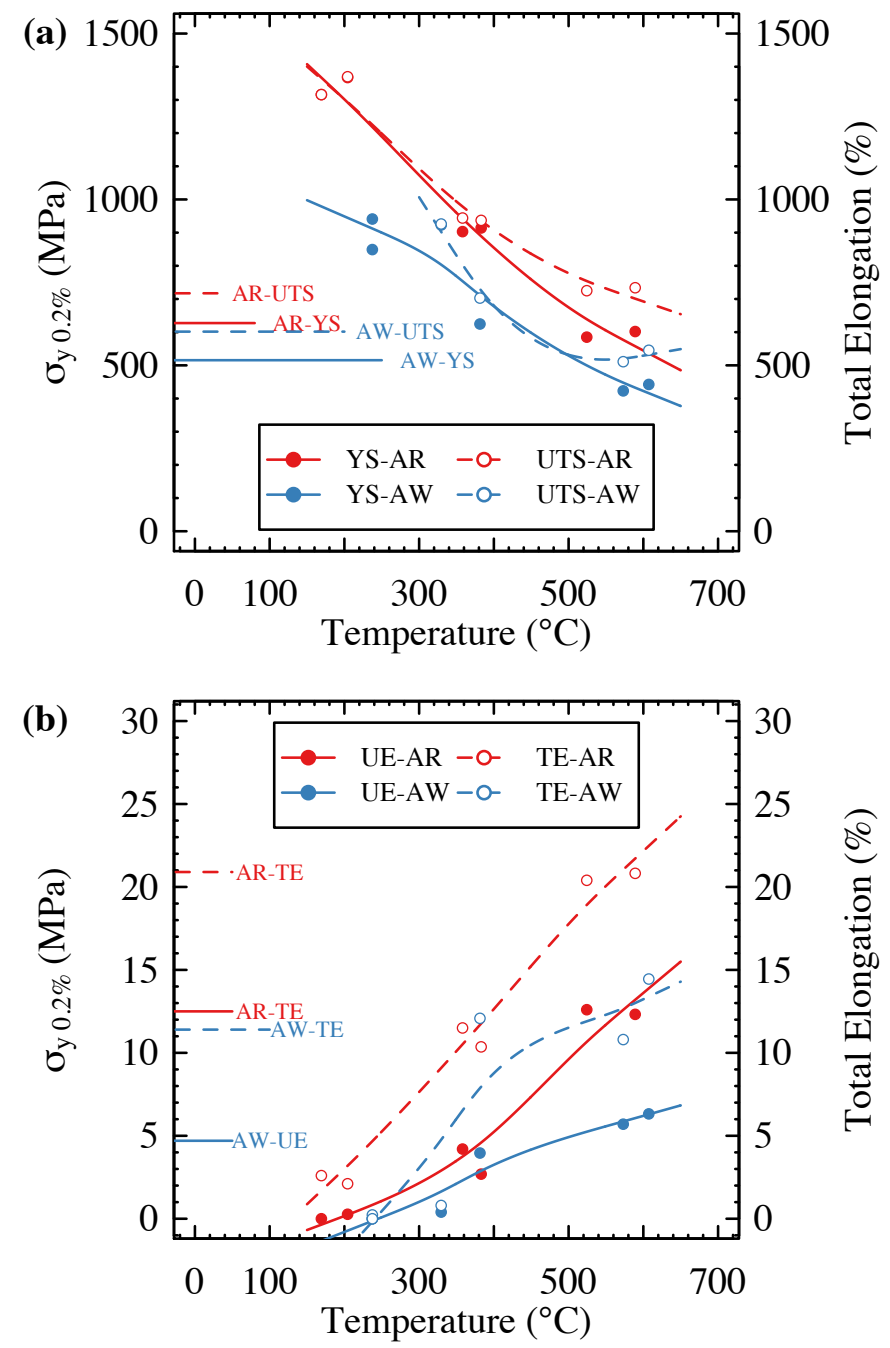

Figure 20: Mechanical properties - yield (YS) and ultimate tensile (UTS) strength, uniform (UE) and total (TE) elongation of C35M SS-J and SS-2E type specimens in the as-received (AR, e.g. nonwelded) and the as-welded (AW) states irradiated at varying temperatures in the dose range of 1.8 dpa to 1.9 dpa. Baseline data shown on the left portion of each plot for comparison. Reproduced from [138]. 


\section{Handbook on the Material Properties of FeCrAl Alloys for}

Nuclear Power Production Applications

The low dose regime for FeCrAl alloys mechanical performance was studied in detail for the ORNL model alloys. Microstructural investigations, such as those presented in Section 4.1, showed that dislocation loop formation and $\alpha^{\prime}$ precipitation could be directly linked to the observed radiation induced hardening in Figure 19 and Figure 20 using a dispersed barrier hardening model. As summarized in Section 4.1, the precipitation of $\alpha^{\prime}$ is strongly dependent on $\mathrm{FeCrAl}$ alloy $\mathrm{Cr}$ content and temperature leading to the compositiondependent hardening response being sensitive to the $\mathrm{Cr}$ content of an alloy and the temperature-dependent hardening response being sensitive to the irradiation temperature. The $\mathrm{Cr}$ composition- $\alpha$-hardening correlation is similar to those observed in high $\mathrm{Cr} F \mathrm{Fer}$ alloys after low dose irradiations at similar conditions [141].

Limited work has been completed to determine the controlling mechanisms within the high dose regime to date. Extrapolation of the low dose regime correlations does not hold within the high dose regime suggesting different mechanisms in the overall hardening response of FeCrAl alloys above 2 dpa at LWRlike irradiation conditions. It is speculated the difference is a transition in the deformation mode from dislocation channeling to twinning within the alloys, similar to that proposed by Park et al. [142] or Triki et al. [143] on aged FeCr alloys. Significantly more work is required to determine the validity of the proposed transition in the deformation mechanics of $\mathrm{FeCrAl}$ alloys in the moderate/high dose regime.

Furthermore, within the high dose regime it has been shown that high-Cr content $\mathrm{FeCrAl}$ alloys are more readily susceptible to embrittlement (defined here as $0 \%$ total elongation) compared to lower-Cr alloys. This would suggest although hardening has no composition effect at higher doses, embrittlement effects could still exist. The low dose hardening and the speculated high dose embrittlement effects on $\mathrm{Cr}$ content are the driving factors for examining lean-Cr FeCrAl alloys for nuclear power production.

\subsubsection{Hardness}

GE model alloys were irradiated to a fluence of $9.25 \times 10^{19} \mathrm{n} / \mathrm{cm}^{2}(\mathrm{E}>1 \mathrm{MeV}-$ dpa not reported) in the Engineering Test Reactor (ETR) in ambient temperature conditions. Samples were annealed at $250^{\circ} \mathrm{C}$ and $300^{\circ} \mathrm{C}$ and showed a decrease in the hardness after $\sim 0.5 \mathrm{hr}$ of annealing at both temperatures. The total change in hardness was higher in the $300^{\circ} \mathrm{C}$ compared to the $250^{\circ} \mathrm{C}$ [4]. No indication of the alloy(s) studied were provided.

Preliminary studies were completed using nanohardness measurements on several ORNL developed alloys and commericial alloys to supplement the previous GE model alloy work. Seven alloys including ORNL A, ORNL B, and ORNL PII, assumed to be B155Y, B183Y, and C35M respectively based on composition were ion irradiated using $1.5 \mathrm{MeV}$ protons to a nominal damage dose of $0.5 \mathrm{dpa}$ [144]. The results indicate irradiation hardening to exist with the hardening ranging from 0.4 to $1.5 \mathrm{GPa}$ depending on alloy studied. No trend based on composition was presented. The hardening observed was attributed to the fomraiton of dislocaiton loops based on preliminary TEM analysis of selected alloys.

A more recent study by E. Aydogan and colleagues used nanoindentation tests via the continous stiff measurement (CSM) technique on C06M2 (Fe-10Cr-6Al-2Mo-0.2Si-0.05Y, wt.\%) and C36M3 alloys (Fe13Cr-6Al-2Mo-0.2Si-0.05Y, wt.\%) [120]. The tube samples were ion irradiated using $5 \mathrm{MeV} \mathrm{Fe}^{++}$ions at damage does between 0.25 and $16.2 \mathrm{dpa}$ at a temperature of $300 \pm 10^{\circ} \mathrm{C}$. The resulting hardness versus damage dose for both alloys is reproduced in Figure 21.

Figure 21 shows nearly identical results to those reported for tensile tests after neutron irradiated in terms of dose and composition trends. In Figure 21, saturation is observed between 3.4 and 16 dpa which is within the sample dose regigme ( $\sim 7 \mathrm{dpa})$ of the tensile tests reported eariler. Furthermore, the alloy C36M3 with higher $\mathrm{Cr}$ content shows a higher increase in hardening compared to the lower-Cr C06M2 variant. Microstructural investigations on the same alloy did not show the formation of the Cr-rich $\alpha$ ' phase or void formation but did show the formation of both $a / 2\langle 111\rangle$ and $a\langle 100\rangle$ dislocation loops. The resulting 
hardening trends in Figure 21 were attributed to the observed dislocation loop formation in the alloys after heavy ion irradiations.

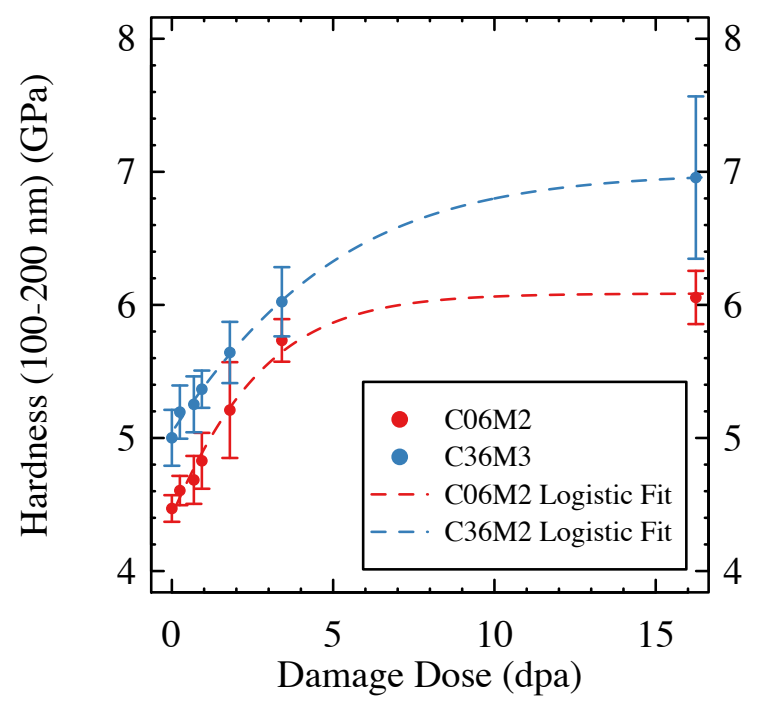

Figure 21: Scatter plot indicating change in nanohardness as a function of damage dose (dpa) and alloy for nanohardness tests performed at room temperature $\left(T_{\text {test }}=24^{\circ} \mathrm{C}\right)$. Averages and standard deviations (error bars) come from a total of 8-27 tests for each data point. Reproduced from [120].

\subsubsection{Fracture toughness}

No fracture toughness or Charpy impact tests have been completed on neutron irradiated FeCrAl alloys at the time of this report. The only available data is based on bend tests conducted around a $2 \mathrm{~T}$ thickness on GE model alloys [4]. Results indicated the high $\mathrm{Cr}$ variants $(>10 \mathrm{wt} \% \mathrm{Cr})$ had a shift in the transition temperature of $\sim 25^{\circ} \mathrm{C}$ while the lower $\mathrm{Cr}$ variants showed no range in the transition temperature.

\subsubsection{Irradiation creep}

Irradiation creep has been investigated in the low dose ( $<1 \mathrm{dpa})$ regime for GE Model alloy 1541 [5] and ORNL Model alloy C35M [71]. The 1541 data was derived from creep and tensile test results while the C35M data was generated using an in-situ irradiation capsule. Results of both alloys are shown in Figure 22 using the Zenner-Holloman parameter to normalize the data against test temperature. Both studies indicate that irradiation reduces the creep rate but not within a significant manner. The minimal change in the shape of the spline fits between the unirradiated and neutron irradiated 1541 sample indicates that irradiation does not significantly alter the stress component. Further high dose (dpa) irradiation creep data is needed to accurately determine the irradiation creep parameters such as those provided by Garner et al. for BCC-FeCr alloys [145]. 


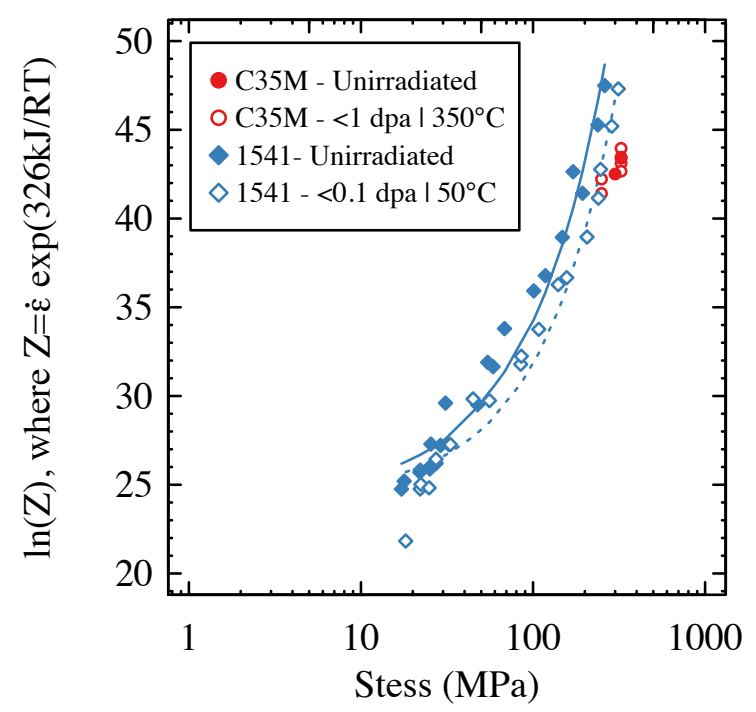

Figure 22: Normalized creep data using the Zenner-Holloman parameter for 1541 [5] and C35M alloys [71] irradiated to low dose $(<1 \mathrm{dpa})$ at temperatures of $50^{\circ} \mathrm{C}$ and $350^{\circ} \mathrm{C}$, respectively.

\subsection{Oxidation, corrosion, and compatibility}

Very limited data exists on environmental effects during or after irradiation for $\mathrm{FeCrAl}$ alloys - significantly more studies are needed on integral and environmental effects for FeCrAl alloys. Only one study has been completed to explore irradiation assisted stress corrosion cracking (IASCC) [108]. Kanthal APMT was irradiated to $5 \mathrm{dpa}$ at $360^{\circ} \mathrm{C}$ using protons and then CERT tested in BWR water chemistry - the same configuration as described in Section 3.4.3. Dislocation channeling, which has been indicated as a dominate factor in IASCC for austenitic alloys [146,147], was observed on the irradiated surface of the Kanthal APMT sample. However, the authors did not observe any stress corrosion cracks within the irradiated specimen up to $10 \%$ strain. This preliminary study suggests a marked decrease in IASCC susceptibility compared to austenitic stainless steels.

Only one study has been initiated to investigate the corrosion of candidate FeCrAl cladding under irradiation in a pressurized water loop facility. This study, known as the ORNL Hybrid Composites Loop ATF Irradiation or the COATI, was completed in the Massachusetts Institute of Technology (MIT) Nuclear Reactor Laboratory' Research Reactor (MITR) [148,149]. The COATI study operated in the MITR for two cycles with the temperature maintained near $300^{\circ} \mathrm{C}$ with the pressure maintained at $10.3 \mathrm{MPa}$ with a target hydrogen concentration of $50 \mathrm{cc} / \mathrm{kg} \mathrm{H}_{2} \mathrm{O}$ [148]. The total accumulated peak fluence was estimated at $1.21 \times 10^{21} \mathrm{n} / \mathrm{cm} 2(\mathrm{E}>0.1 \mathrm{MeV}-$ dpa was not reported) [149]. The irradiation contained a various array of coated and uncoated $\mathrm{SiC}$-based components but also included commercially available Kanthal AF, and the ORNL model alloys of C06M and C36M3; all FeCrAl samples were in an as-processed (e.g. non-coated) state. Images were taken of the samples post irradiation, with a subset of the FeCrAl specimens shown in Figure 23. Surface scratching can be observed on the samples due to post-irradiation sample handling. The general condition in Figure 23 suggests minimal corrosion effects on the samples for the given conditions but further post-irradiation examination has not been completed at the time of this report.

Another preliminary study has been performed to observe the interaction of $\mathrm{UO}_{2}$ fuel with $\mathrm{FeCrAl}$ claddings under irradiation [5]. Agglomerated $\mathrm{UO}_{2}$ was contained within a $\mathrm{Fe}$ matrix or fully $\mathrm{UO}_{2}$ fuel was clad in varying $\mathrm{GE}$ model $\mathrm{FeCrAl}$ alloys. In-pile exposures of $2400 \mathrm{hr}$ at $950^{\circ} \mathrm{C}$ showed no deterioration of the 
clad or fission product release. Similar out-of-pile tests were performed at $750^{\circ} \mathrm{C}$ and $950^{\circ} \mathrm{C}$ and showed good thermal stability. Alumina was observed at the $\mathrm{UO}_{2}-\mathrm{FeCrAl}$ interface, but not enough sufficient detail is provided to determine if the oxide was formed prior to or during the high temperature exposures. High temperature exposures showed uranium diffusion through the clad to only occur at temperatures of $1000^{\circ} \mathrm{C}$ and higher. Furthermore, $\mathrm{Al}$ was found to reduce the $\mathrm{UO}_{2}$ fuels starting at the temperature range of $1000^{\circ} \mathrm{C}$ to $1200^{\circ} \mathrm{C}$. In this temperature range, the $\mathrm{Al}$ generates free $\mathrm{U}$ which then diffuses through the $\mathrm{FeCrAl}$ cladding. Further reduction of $\mathrm{UO}_{2}$ leads to the formation of alumina at the $\mathrm{FeCrAl}-\mathrm{UO}_{2}$ interface which forms an effective barrier to further diffusion of $\mathrm{Al}$ into the $\mathrm{UO}_{2}$ fuel. Further details are presented elsewhere [5].

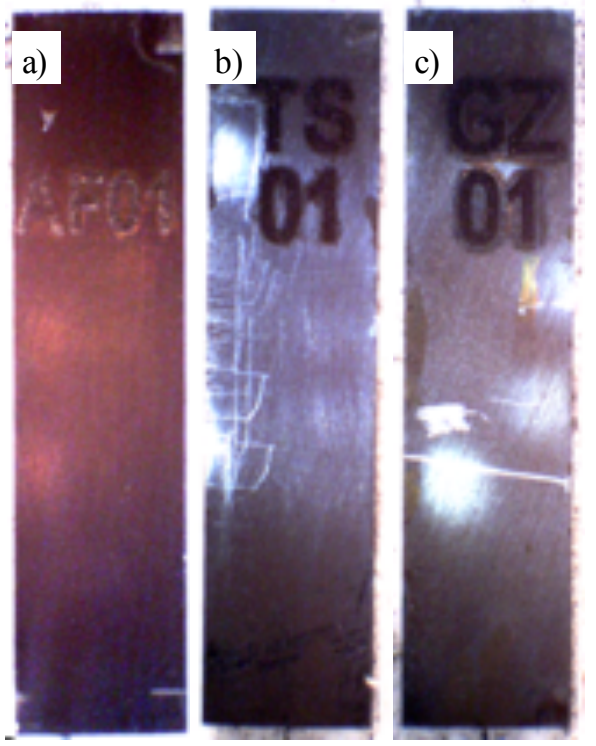

Figure 23: Optical images of FeCrAl specimens after peak irradiation fluence of $1.21 \times 10^{21} \mathrm{n} / \mathrm{cm}^{2}$ (E>0.1 MeV - dpa was not reported) in PWR-like water conditions; (a) Kanthal AF, (b) C36M3, and (c) C06M. Images courtesy of Y. Katoh (ORNL).

\subsection{Fueled rod tests}

To date, two primary tests have been conducted using fueled rods or rodlet tests in a materials test reactor. The first test being deemed "ATF-1" which encompasses neutron irradiations of dry (no coolant contact) FeCrAl rodlets containing prototypical $\mathrm{UO}_{2}$ in Idaho National Laboratories (INL) Advanced Test Reactor (ATR). The second is the Instrumented Fuel Assembly (IFA) 796 which is experiments carried out in the Halden Boiling Water Reactor using FeCrAl rodlets containing prototypical $\mathrm{UO}_{2}$. A summary of both irradiation campaigns and of available results are provided in the following discussion.

The ATF-1 experiments for an ORNL model FeCrAl alloy was a series of $\mathrm{UO}_{2}$ fueled $\mathrm{FeCrAl}$ clad rodlets which targeted peak burn-ups of $10 \mathrm{MWd} / \mathrm{kg} \mathrm{UO}_{2}, 30 \mathrm{MWd} / \mathrm{kg} \mathrm{UO}$, and $50 \mathrm{MWd} / \mathrm{kg} \mathrm{UO}_{2}$. Additional ATF-1 experiments included APMT and Alloy 33 as cladding materials submitted by GE [150]. The APMT and Alloy 33 clad rodlets targeted peak burn-ups of $20 \mathrm{MWd} / \mathrm{kg} \mathrm{UO}_{2}$ and $60 \mathrm{MWd} / \mathrm{kg} \mathrm{UO} \mathrm{UO}_{2}$ [151]. The

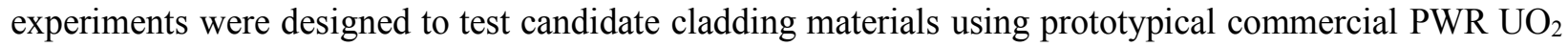
fuel to test the cladding structural stability and weldment performance. The assembly design was a drop-in capsule design based on the mixed-oxide (MOX) fuel irradiation design previously used within the DOE Fissile Materials Disposition Program (FMDP) [152]. The design does not incorporate any coolant, removing the ability to assess coolant-clad interactions and limiting possible clad creep down under 
irradiation. Further details regarding the design and fabrication of the ATF-1 rodlets can be found in $[151,153]$. At the time of this report, non-destructive PIE including radiography and visual inspection has been performed on the rodlet fabricated using the ORNL C35MN FeCrAl alloy reaching a nominal peak burn-up of $10 \mathrm{MWd} / \mathrm{kg} \mathrm{UO}_{2}$ [154]. This rodlet is known as the ATF-1 LOCA FCA-L3 rodlet coming from the ATF-18 capsule in published reporting [154]. Post-irradiation examination results for the GE concept rodlets (APMT and Alloy 33) were not publicly available at the time of this report.

Figure 24a shows the ATF-1 LOCA FCA-L3 rodlet assembly and outer housing prior to removal from the protective outer capsule housing while Figure $24 \mathrm{~b}$ shows the corresponding neutron radiography. Prior to full disassembly, the outer housing was punctured to analyze the isotopic content of the gas contained within the outer housing. The Assay, Sample, and Recharge (GASR) system at the Hot Fuel Examination Facility (HFEF) determined the gas to contain ${ }^{85} \mathrm{Kr}$ using gamma spectrometry indicating a possible breech and fission gas release from the rodlet into the capsule cavity [154]. Visual inspection and neutron radiography showed no signs of cladding breech with the outer housing remaining intact after neutron irradiation in the ATR. Figure $24 \mathrm{c}$ shows visual inspection of the rodlet after removal from the ATF-18 capsule. The rodlet appeared to be in good form, with no visible defects on the cladding or the welds. Further PIE to confirm the viability of a breech in the ATF-1 LOCA FCA-L3 rodlet have not performed at the time of this report.

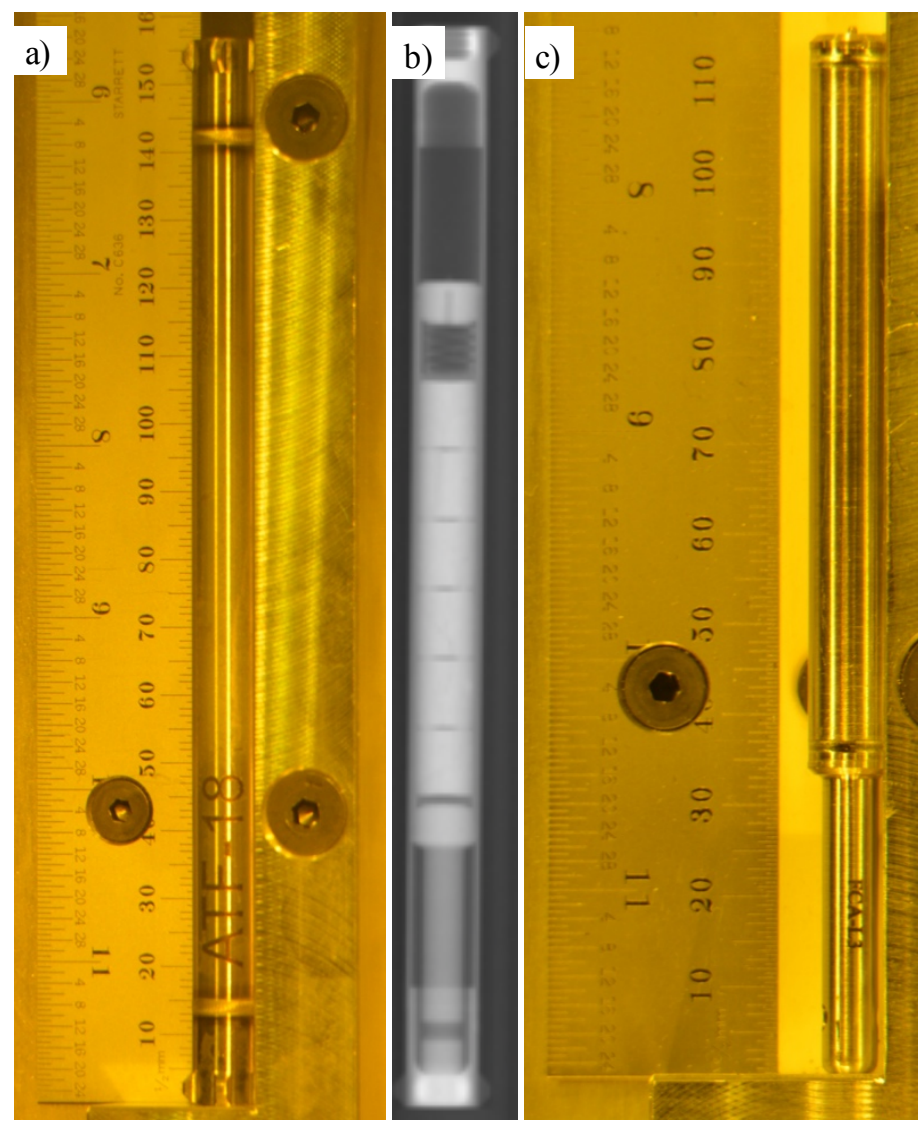

Figure 24: Images of capsule and rodlet assembly for FCA-L3 rodlet from the ATF-1 irradiation in the ATR. (a) optical image of capsule assembly, (b) neutron radiography of capsule and rodlet assemblies, (c) optical image of rodlet assembly. Reproduced from [154].

IFA-796 was a $\mathrm{UO}_{2}$ fueled FeCrAl clad assembly which operated for two cycles in the Halden Boiling Water Reactor up to a peak burnup of $4.5 \mathrm{MWd} / \mathrm{kg} \mathrm{UO}$. The irradiation initially had a target burn-up of 
$\sim 40 \mathrm{MWd} / \mathrm{kg} \mathrm{UO}_{2}$ but the experiment was cancelled early due to the Institutes for Energy Technology's (IFE) board of directors deciding to permanently close the Halden Reactor in the summer of 2018 [155]. The design incorporated six radial positions with five of those positions containing four segmented rods with a length of $\sim 117 \mathrm{~mm}$ with $\sim 100 \mathrm{~mm}$ active fuel stacks. The segments were interconnected with $50 \mathrm{~mm}$ plug sections. The sixth position contained a full-length rod connected to a cladding elongation sensor to continuously monitor for pellet-cladding mechanical interaction (PCMI). Additional instrumentation included three inlet, three outlet, and three down comer thermocouples and three Rh neutron detectors at varying axial locations. Water chemistry was controlled to simulate PWR conditions with $4.6 \mathrm{ppm}$ Li with boron additions aimed at maintaining a $\mathrm{pH}_{300}$ of $~ 7.3$. Inlet and outlet temperatures of the experimental rig was maintained near $300^{\circ} \mathrm{C}$. Further details regarding the IFA-796 configuration can be found in [156].

IFA-796 contained multiple ATF concepts with the full length rodlet cladding being C06M2 FeCrAl tubing and two of the shortened rods being of C06M2 and C36M3 FeCrAl tubing [156]. The cladding elongation sensor was used for the full length C06M2 rodlet with the data from the two cycles shown in Figure 25. The data in Figure 25 shows thermal expansion of the cladding at reactor operation and power ramp but no contact between the fuel and cladding has been made up to the thermal peak burnup of $4.5 \mathrm{MWd} / \mathrm{kg} \mathrm{UO}_{2}$.

Visual inspection of the full length and shorten rodlets of C06M2 and C36M3 were performed after the first cycle (blue data in Figure 25) to determine if any significant defects or other damage occurred to the rodlets under operation. Figure 26 shows an excerpt from the visual inspections and shows no major defects or failure occurred under operation in PWR conditions in the Halden Reactor after 1 cycle of operation. Further post-irradiation examination was not completed at the time of this report.

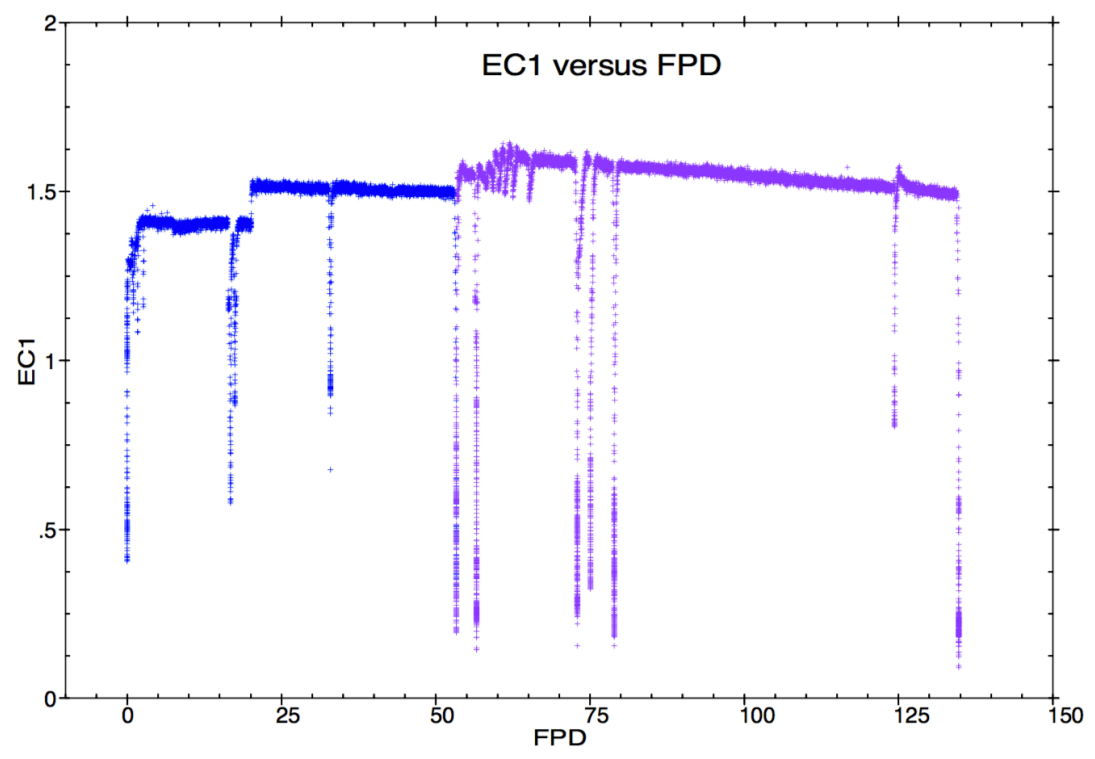

Figure 25: Cladding elongation (EC, in $\mathrm{mm}$ ) in C06M2 after two cycles of neutron irradiation near $300^{\circ} \mathrm{C}$ in the Halden Reactor as a function of full power days (FPD). Results provided courtesy of K. Terrani (ORNL), first cycle data (blue) presented in [156]. 


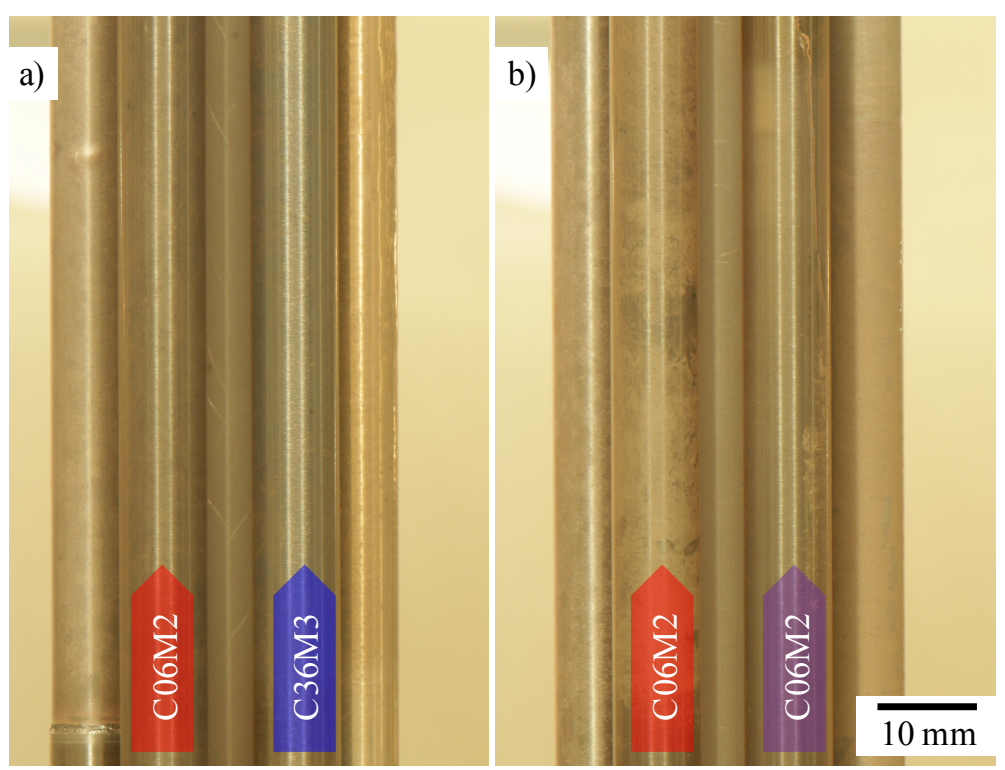

Figure 26: Fueled rodlets for a full length rodlet (red label) and segmented rods (blue and purple labels) for $\mathrm{C06M2}$ and $\mathrm{C36 \textrm {M } 3}$ after one cycle $\left(1.4 \mathrm{MWd} / \mathrm{kgUO}_{2}\right)$ in the IFA-796 experiment. Results provided courtesy of K. Terrani (ORNL).

\subsection{Lead test rod evaluations}

GE/GNF have deployed the first FeCrAl cladding prototypes into Southern Nuclear's Plant Hatch, Unit 1 during the Cycle 29 refueling outage. Four Lead Test Assemblies (LTAs) of the conventional GNF2 design were used to house unfueled FeCrAl clad test rods in standard fuel rod positions [157]. The outside diameter of the rods is the same as prototypical GNF2 fuel rods [158]. Initial plans for the segmented rods called for insertion of the ORNL derived C26M alloy and the commercially available APMT alloy - at the time of this report the exact number of rods and alloy variant combinations are not publicly available. The overarching objectives of the FeCrAl containing LTAs are (1) confirm fundamental Fuel-Cladding-Reactor environment compatibility, (2) confirm cladding creep characteristics in commercial reactor environments, and (3) enable the specimens to be used for subsequent tests [159]. Further details regarding the GE/GNF inserted into Plant Hatch, Unit 1 on February 13 ${ }^{\text {th }}, 2018$ [160] were not available at the time of this report.

\section{CONCLUSIONS}

The enclosed databases highlight that $\mathrm{FeCrAl}$ alloys must be treated as an alloy class. FeCrAl alloys with varying composition, microstructure, and processing will behave differently for a given parameter/experiment and thus data from one $\mathrm{FeCrAl}$ alloy may not be applicable to others. In some cases, the alloys perform in similar manners, and these cases have been specifically highlighted. The provided information highlights the marked benefits for $\mathrm{FeCrAl}$ alloys for nuclear power use including their inherent corrosion resistance, stress corrosion cracking resistance, radiation-induced swelling resistance, and high temperature oxidation resistance - especially in comparison to other nuclear grade materials such as $\mathrm{Zr}$ based alloys and austenitic stainless steels. Given this, the provided information also shows significant knowledge gaps especially in regard to radiation effects including both single variable and integral tests. These knowledge gaps necessitate continued efforts into researching and developing FeCrAl alloys for nuclear power applications. 


\section{REFERENCES}

[1] Y. Yamamoto, M.A. Snead, K.G. Field, K.A. Terrani, Handbook of the Materials Properties of FeCrAl Alloys For Nuclear Power Production Applications, ORNL/TM-2017/186. (2017). doi: $10.2172 / 1400207$.

[2] Sixth annual report -High Temperature materials program, GEMP-475A. (1967) 1-305.

[3] Fourth Annual Report- High temparature materials and reactor component development programs, GEMP-334A. (1965) 1-238.

[4] Fifth annual report on high temperature materials programs - Part A, GEMP-400A. (1966) 294.

[5] Seventh annual report - AEC Fuels and Materials Development program, GEMP-1004. (1968) 368.

[6] High-Temperature Materials Program Progess Report No. 59, Part A, GEMP-59A. (1966).

[7] High-Temperature Materials Program Progress Report No. 55, Part A, GEMP-55A. (1966).

[8] Fourth Annual Report - High-Temperature Materials and Reactor Component Development Programs, GEMP-334A. (1965) 1-238.

[9] J.F. Collins, F.C. Robertshaw, Advanced Long-Life Reactor Fuel Cladding and Structural Materials Development, Sixth Annu. Rep. - High Temp. Mater. Programs Part A - GEMP-475A. (1967) 143-174.

[10] G.R. VanHouten, M.R. Broz, Advanced Log-Life Reactor Fuel Element, Moderator, Control, and Shield Materials Development, Sixth Annu. Rep. - High Temp. Mater. Programs Part B - GEMP475B. (1967).

[11] E.A. Little, D.A. Stow, Void-swelling in irons and ferritic steels - II An experimental survey of materials irradiated in fast reactor, J. Nucl. Mater. 87 (1979) 25-39.

[12] F.G. Wilson, B.R. Knott, C.D. Desforges, Preparation and properties of some ODS Fe-Cr-Al alloys, Metall. Trans. A. 9 (1978) 275-282. doi:10.1007/BF02646711.

[13] M. Kangilaski, R.E.I. Center, The Effects of Neutron Radiation on Structural Materials, REIC Rep. No. 45. (1967) 94-103.

[14] Y. Yamamoto, B.A. Pint, K.A. Terrani, K.G. Field, Y. Yang, L.L. Snead, Development and property evaluation of nuclear grade wrought $\mathrm{FeCrAl}$ fuel cladding for light water reactors, J. Nucl. Mater. 467 (2015) 703-716. doi:10.1016/j.jnucmat.2015.10.019.

[15] K.A. Terrani, S.J. Zinkle, L.L. Snead, Advanced oxidation-resistant iron-based alloys for LWR fuel cladding, J. Nucl. Mater. 448 (2014) 420-435. doi:10.1016/j.jnucmat.2013.06.041.

[16] S.J.J. Zinkle, K.A.A. Terrani, J.C.C. Gehin, L.J.J. Ott, L.L.L. Snead, Accident tolerant fuels for LWRs: A perspective, J. Nucl. Mater. 448 (2014) 374-379. doi:10.1016/j.jnucmat.2013.12.005.

[17] K. Terrani, Accident tolerant fuel cladding development: Promise, status, and challenges, J. Nucl. Mater. (2018). doi:10.1016/j.jnucmat.2017.12.043.

[18] B.A. Pint, K.A. Terrani, M.P. Brady, T. Cheng, J.R. Keiser, High temperature oxidation of fuel cladding candidate materials in steam-hydrogen environments, J. Nucl. Mater. 440 (2013) 420 427. doi:10.1016/j.jnucmat.2013.05.047.

[19] L. Colombier, J. Hochmann, Stainless and Heat Resisting Steels, St. Martin's Press, New York, 
NY, 1968.

[20] E. a. Gulbransen, K.F. Andrew, Oxidation Studies on the Iron-Chromium-Aluminum Heater Alloys, J. Electrochem. Soc. 106 (1959) 294. doi:10.1149/1.2427333.

[21] K.A. Unocic, Y. Yamamoto, B.A. Pint, Effect of Al and Cr Content on Air and Steam Oxidation of FeCrAl Alloys and Commercial APMT Alloy, Oxid. Met. 87 (2017) 431-441. doi:10.1007/s11085-017-9745-1.

[22] F.H. Stott, G.C. Wood, J. Stringer, The influence of alloying elements on the development and maintenance of protective scales, Oxid. Met. 44 (1995) 113-145. doi:10.1007/BF01046725.

[23] C.S. Wukusick, The physical metallurgy and oxidation behavior of Fe-Cr-Al-Y alloys, Cincinnati, Ohio, 1966.

[24] K.G. Field, X. Hu, K.C. Littrell, Y. Yamamoto, L.L. Snead, Radiation tolerance of neutronirradiated model Fe-Cr-Al alloys, J. Nucl. Mater. 465 (2015) 746-755. doi:10.1016/j.jnucmat.2015.06.023.

[25] G. Bonny, D. Terentyev, L. Malerba, On the $\alpha-\alpha^{\prime}$ miscibility gap of Fe-Cr alloys, Scr. Mater. 59 (2008) 1193-1196. doi:10.1016/j.scriptamat.2008.08.008.

[26] S. Kobayashi, T. Takasugi, Mapping of $475^{\circ} \mathrm{C}$ embrittlement in ferritic $\mathrm{Fe}-\mathrm{Cr}-\mathrm{Al}$ alloys, Scr. Mater. 63 (2010) 1104-1107. doi:10.1016/j.scriptamat.2010.08.015.

[27] J. Ejenstam, M. Thuvander, P. Olsson, F. Rave, P. Szakalos, Microstructural stability of Fe-Cr-Al alloys at $450-550{ }^{\circ} \mathrm{C}$, J. Nucl. Mater. (2014). doi:10.1016/j.jnucmat.2014.11.101.

[28] W. Li, S. Lu, Q.-M. Hu, H. Mao, B. Johansson, L. Vitos, The effect of Al on the $475^{\circ} \mathrm{C}$ embrittlement of Fe-Cr alloys, Comput. Mater. Sci. 74 (2013) 101-106. doi:10.1016/j.commatsci.2013.03.021.

[29] B.A. Pint, Experimental observations in support of the dynamic-segregation theory to explain the reactive-element effect, Oxid. Met. 45 (1995) 1-37.

[30] B.A. Pint, Optimization of reactive-element additions to improve oxidation performance of alumina-forming alloys, J. Am. Ceram. Soc. 86 (2003) 686-695.

[31] J.P. Shingledecker, P.J. Maziasz, N.D. Evans, M.J. Pollard, J.P. Shingledecker, P.J. Maziasz, N.D. Evans, and M.J. Pollard, Proc. Symp. Sponsored by Materials Science \& Technology 2005, R.S. Mishra, J.C. Earthman, S.V. Raj, and R. Viswanathan, eds., The Minerals, Metals and Materials Society, Pittsburgh, PA, Sept., in: Proc. Symp. Spons. by Mater. Sci. Technol. 2005, R.S. Mishra, J.C. Earthman, S.V. Raj, R. Viswanathan, Eds., Miner. Met. Mater. Soc., Pittsburgh, PA, 2005: pp. $25-28$.

[32] M.S. El-Genk, J.-M. Tournier, Mechanically Alloyed-Oxide Dispersion Strengthened Steels for Use in Space Nuclear Power Systems, Sp. Technol. Appl. 699 (2004) 829-844. doi:10.1063/1.1649648.

[33] Z. Sun, P.D. Edmondson, Y. Yamamoto, Effects of Laves phase particles on recovery and recrystallization behaviors of Nb-containing FeCrAl alloys, Acta Mater. 144 (2018) 716-727. doi:10.1016/j.actamat.2017.11.027.

[34] W. Chubb, S. Alfant, A.A. Bauer, E.J. Jablonowski, F.R. Shober, R.F. Dickerson, Constitution, metallurgy, and oxidation resistance of iron-chromium-aluminum alloys: BMI-1298, 1958.

[35] Y. Yamamoto, Z. Sun, Quality optimization of commercial FeCrAl tube production, ORNL/TM2017/338. (2017). 
[36] Y. Yamamoto, Development and Quality Assessments of Commercial Heat Production of ATF FeCrAl Tubes, ORNL/TM-2015/478. (2015) 1-40.

[37] Z. Sun, Y. Yamamoto, Processability evaluation of a Mo-containing FeCrAl alloy for seamless thin-wall tube fabrication, Mater. Sci. Eng. A. 700 (2017) 554-561. doi:10.1016/j.msea.2017.06.036.

[38] Y. Yamamoto, M.N. Gussev, B.K. Kim, T.S. Byun, Optimized properties on base metal and thinwalled tube of Generation II ATF FeCrAl, ORNL/TM-2015/414. (2015) 1-63.

[39] J.R. Regina, J.N. Dupont, A.R. Marder, The effect of chromium on the weldability and microstructure of Fe-Cr-Al weld cladding, Weld. J. 86 (2007) 170-178.

[40] J.N. Dupont, J.R. Regina, K. Adams, Improving the weldability of fecral weld overlay coatings, Foss. Energy Mater. Conf. (2007) 131-137.

[41] K.G. Field, M.N. Gussev, Y. Yamamoto, L.L. Snead, Deformation behavior of laser welds in high temperature oxidation resistant Fe-Cr-Al alloys for fuel cladding applications, J. Nucl. Mater. 454 (2014) 352-358. doi:10.1016/j.jnucmat.2014.08.013.

[42] M.N. Gussev, K.G. Field, Y. Yamamoto, Design, Properties, and Weldability of Advanced Oxidation-Resistant FeCrAl Alloys, Mater. Des. 129 (2017) 227-238.

doi:10.1016/j.matdes.2017.05.009.

[43] J. Tusek, A. Kosmac, U. Nartnik, A. Dejan, Welding of heat-resistant $20 \%$ Cr - 5\% Al steels, Z. Met. 93 (2002) 310-314.

[44] N.A. McPherson, H. Samson, T.N. Baker, N. Suarez-Fernandez, Steel microstructures in autogenous laser welds, J. Laser Appl. 15 (2003) 200-210.

[45] H. El Kadiri, Y. Bienvenu, K. Solanki, M.F. Horstemeyer, P.T. Wang, Creep and tensile behaviors of $\mathrm{Fe}-\mathrm{Cr}-\mathrm{Al}$ foils and laser microwelds at high temperature, Mater. Sci. Eng. A. 421 (2006) 168181. doi:10.1016/j.msea.2005.11.048.

[46] J. Gan, E. Perez, D.C. Haggard, C. Nichol, N. Jered, Report on the Development of Weld Techniques for Thin Walled Tubing Fuel Cycle Research \& Development Advanced Fuels Campaign, Inl/Ltd-15-34684. (2015).

[47] J. Gan, E. Perez, D.C. Haggard, N. Jerred, Status Report on Thin-Walled Cladding Weld Development and Test Fuel Cycle Research \& Development Advanced Fuels Campaign, INL/LTD-16-39760. (2016).

[48] A. Sittiho, V. Tungala, I. Charit, R.S. Mishra, Microstructure, mechanical properties and strengthening mechanisms of friction stir welded Kanthal APMT ${ }^{\mathrm{TM}}$ steel, J. Nucl. Mater. (2018). doi:10.1016/j.jnucmat.2018.07.001.

[49] R.B. Rebak, Iron-chrome-aluminum alloy cladding for increasing safety in nuclear power plants, EPJ Nucl. Sci. Technol. 3 (2017). doi:10.1051/epjn/2017029.

[50] K. Mergia, N. Boukos, Structural, thermal, electrical and magnetic properties of Eurofer 97 steel, J. Nucl. Mater. 373 (2008) 1-8. doi:10.1016/j.jnucmat.2007.03.267.

[51] S. Raju, B. Jeya Ganesh, A.K. Rai, R. Mythili, S. Saroja, E. Mohandas, M. Vijayalakshmi, K.B.S. Rao, B. Raj, Measurement of transformation temperatures and specific heat capacity of tungsten added reduced activation ferritic-martensitic steel, J. Nucl. Mater. 389 (2009) 385-393. doi:10.1016/j.jnucmat.2009.02.030.

[52] Q. Chen, B. Sundman, Modeling of thermodynamic properties for Bcc, Fcc, liquid, and 
amorphous iron, J. Phase Equilibria. 22 (2001) 631-644. doi:10.1007/s11669-001-0027-9.

[53] L. Leibowitz, R.A. Blomquist, Thermal conductivity and thermal expansion of stainless steels D9 and HT9, Int. J. Thermophys. 9 (1988) 873-883. doi:10.1007/BF00503252.

[54] N. Yamanouchi, M. Tamura, H. Hayakawa, A. Hishinuma, T. Kondo, Accumulation of engineering data for practical use of reduced activation ferritic steel: $8 \% \mathrm{Cr}-2 \% \mathrm{~W}-0.2 \% \mathrm{~V}$ 0.04\%Ta-Fe, J. Nucl. Mater. 191-194 (1992) 822-826. doi:10.1016/0022-3115(92)90587-B.

[55] A.G. Metcalfe, The Stability of Strain Gage Alloy Wires, in: Symp. Elev. Temp. Strain Gages, ASTM International, 100 Barr Harbor Drive, PO Box C700, West Conshohocken, PA 194282959, 1958: pp. 109-109-4. doi:10.1520/STP45040S.

[56] J.E.S. D.C. Drennen, C.M. Jackson, N. Crites, LMFBR Instrumentation - Strain gagues Phase I High Temperature strain gage development, 1970.

[57] Y. Yamamoto, B.A. Pint, K.A. Terrani, K.G. Field, Y. Yang, L.L. Snead, Development and property evaluation of nuclear grade wrought $\mathrm{FeCrAl}$ fuel cladding for light water reactors, J. Nucl. Mater. 467 (2015) 703-716. doi:10.1016/j.jnucmat.2015.10.019.

[58] S.C. Tjong, S.M. Zhu, Creep and Low-Cycle Fatigue Behavior of Ferritic Fe-24Cr-4Al Alloy in the Dynamic Strain Aging Regime: Effect of Aluminum Addition, 28 (1997). https://link.springer.com/content/pdf/10.1007/s11661-997-0271-7.pdf (accessed July 24, 2018).

[59] Z. Deng, J. Liu, B. Yan, Y. He, Monotonous deformation behavior of ferritic FeCrAl alloy in the dynamic strain aging regime, J. Alloys Compd. 749 (2018) 664-671. doi:10.1016/J.JALLCOM.2018.03.193.

[60] A. Guria, I. Charit, Observation of serrated flow in $\mathrm{APMT}^{\mathrm{TM}}$ steel, Mater. Lett. 160 (2015) 55-57. doi:10.1016/j.matlet.2015.07.072.

[61] A. Guria, I. Charit, Tensile properties of accident-tolerant aluminum-bearing ferritic steels, Ann. Nucl. Energy. 100 (2017) 82-88. doi:10.1016/j.anucene.2016.09.018.

[62] K.G. Field, S.A. Briggs, K. Sridharan, R.H. Howard, Y. Yamamoto, Mechanical Properties of Neutron-Irradaited Model and Commercial FeCrAl Alloys, J. Nucl. Mater. 489 (2017) 118-128.

[63] I. Kornilov, Alloys of Iron-Chromium-Aluminum, Vol 1, Academy of Sciences, Moscow, 1945.

[64] J.T. Busby, M.C. Hash, G.S. Was, The relationship between hardness and yield stress in irradiated austenitic and ferritic steels, J. Nucl. Mater. 336 (2005) 267-278. doi:10.1016/j.jnucmat.2004.09.024.

[65] R.J. Perkins, C.S. Wukusick, Long Time Oxidation Resistance of Iron-Chromium-AluminumYttrium Alloys at Temperatures of $450^{\circ}$ to $1100^{\circ} \mathrm{C}$, TM 67-2-3. (1966).

[66] J.L. Bartos, The Nature of Aging of Fe-Cr-Al-Y Alloys at $450^{\circ} \mathrm{C}$, GEMP-708. (1969).

[67] Z. Sun, Y. Yamamoto, X. Chen, Impact toughness of commercial and model FeCrAl alloys, Mater. Sci. Eng. A. (2018). doi:10.1016/J.MSEA.2018.07.074.

[68] Z.T. Thompson, K.A. Terrani, Y. Yamamoto, Elastic Modulus Measurement of ORNL ATF FeCrAl Alloys, ORNL/TM-2015/632. (2015) 1-17.

[69] J. Weaver, E. Aydogan, N.A. Mara, S.A. Maloy, Nanoindentation of Electropolished FeCrAl Alloy Welds, LA-UR-17-20914. (2017). http://permalink.lanl.gov/object/tr?what=info:lanlrepo/lareport/LA-UR-17-20914 (accessed July 24, 2018).

[70] Kanthal, Kanthal APMT Tube datasheet, (2017) 1-4. 
http://www.kanthal.com/en/products/material-datasheets/tube/kanthal-apmt/ (accessed July 26, 2017).

[71] K.A. Terrani, T.M. Karlsen, Y. Yamamoto, Input Correlations for Irradiation Creep of FeCrAl and SiC Based on In-Pile Halden Test Results, ORNL/TM-2016/191. (2016) 1-32. http://info.ornl.gov/sites/publications/files/Pub62748.pdf.

[72] S.R.J. Saunders, H.E. Evans, M. Li, D.D. Gohil, S. Osgerby, Oxidation growth stresses in an alumina-forming ferritic steel measured by creep deflection, Oxid. Met. 48 (1997) 189-200. doi:10.1007/BF01670498.

[73] R.C. Lobb, R.B. Jones, Creep-rupture properties of Fecralloy stainless steel between 650 and $800^{\circ} \mathrm{C}$, J. Nucl. Mater. 91 (1980) 257-264. doi:10.1016/0022-3115(80)90225-1.

[74] P. Seiler, M. Bäker, J. Rösler, Influence of creep and cyclic oxidation in thermal barrier coatings, Int. J. Mater. Res. 103 (2012) 50-56. doi:10.3139/146.110629.

[75] R.C. Lobb, R.B. Jones, Creep-rupture properties of fecralloy stainless steel between 650 and $800^{\circ} \mathrm{c}$, J. Nucl. Mater. 91 (1980) 257-264. doi:10.1016/0022-3115(80)90225-1.

[76] M.N. Gussev, T.S. Byun, Y. Yamamoto, S.A. Maloy, K.A. Terrani, In-situ tube burst testing and high-temperature deformation behavior of candidate materials for accident tolerant fuel cladding, J. Nucl. Mater. 466 (2015) 417-425. doi:10.1016/j.jnucmat.2015.08.030.

[77] S.C. Tjong, J.S. Zhang, Low cycle fatigue behavior of ferritic Fe-24Cr-4Al alloy at high temperatures, Scr. Metall. Mater. 32 (1995) 1589-1593. doi:10.1016/0956-716X(95)00241-M.

[78] S.C. Tjong, Transmission electron microscope observations of the dislocation substructures induced by cyclic deformation of the ferritic $\mathrm{Fe} \quad 25 \mathrm{Cr} \quad(2-4) \mathrm{Al}$ and $\mathrm{Fe} \quad 19 \mathrm{Cr}$ 4Ni 2Al alloys, Mater. Charact. 26 (1991) 109-121. doi:10.1016/1044-5803(91)90071-B.

[79] S.C. Tjong, J.S. Zhang, Low cycle fatigue behavior of ferritic Fe-24Cr-4Al alloy at high temperatures, Scr. Metall. Mater. 32 (1995) 1589-1593. doi:10.1016/0956-716X(95)00241-M.

[80] S.C. Tjong, L.T. Wu, N.J. Ho, Some aspects of the dislocation microstructures in fatigued Fe-CrAl alloys, Mater. Sci. Eng. 100 (1988) 79-84. doi:10.1016/0025-5416(88)90241-8.

[81] Y.-H. Lee, T.S. Byun, A comparative study on the wear behaviors of cladding candidates for accident-tolerant fuel, J. Nucl. Mater. 465 (2015) 857-865. doi:10.1016/j.jnucmat.2015.05.017.

[82] T.C. Winter, R.W. Neu, P.M. Singh, L.E. Kolaya, C.S. Deo, Fretting wear comparison of cladding materials for reactor fuel cladding application, J. Nucl. Mater. 508 (2018) 505-515. doi:10.1016/J.JNUCMAT.2018.05.069.

[83] B.A. Pint, K.A. Terrani, J.R. Keiser, M.P. Brady, Y. Yamamoto, L.L. Snead, Material selection for fuel cladding resistant to severe accident scenarios, in: NACE (Ed.), 16th Environ. Degrad. Conf., Asheville, NC, USA, 2013.

[84] C. Tang, M. Steinbrueck, M. Grosse, A. Jianu, A. Weisenburger, H.J. Seifert, High-Temperature Oxidation Behavior of Kanthal APM and D Alloys in Steam, in: Int. Congr. Adv. Nucl. Power Plants, 2016.

[85] D.J. Park, H.G. Kim, J.Y. Park, Y. Il Jung, J.H. Park, Y.H. Koo, A study of the oxidation of $\mathrm{FeCrAl}$ alloy in pressurized water and high-temperature steam environment, Corros. Sci. 94 (2015) 459-465. doi:10.1016/j.corsci.2015.02.027.

[86] S.L. Case, K.R. Van Horn, Aluminum in iron and steel, Chapman \& Hall for the Engineering Foundation, New York, 1953. 
http://trove.nla.gov.au/work/16374169? selectedversion=NBD28520665 (accessed July 26, 2017).

[87] S.E. Sadique, A.H. Mollah, M.S. Islam, M.M. Ali, M.H.H. Megat, S. Basri, High-Temperature Oxidation Behavior of Iron-Chromium-Aluminum Alloys, Oxid. Met. 54 (2000) 385-400. doi:10.1023/A:1004682316408.

[88] B.A. Pint, K.A. Terrani, Y. Yamamoto, L.L. Snead, Material Selection for Accident Tolerant Fuel Cladding, Metall. Mater. Trans. E. 2 (2015) 190-196. doi:10.1007/s40553-015-0056-7.

[89] B.A. Pint, K.A. Unocic, K.A. Terrani, Steam Oxidation of FeCrAl and SiC in the SATS, ORNL/TM-2015/417. (2015).

[90] B.A. Pint, K.A. Unocic, K.A. Terrani, Effect of steam on high temperature oxidation behaviour of alumina-forming alloys, Mater. High Temp. 32 (2015) 28-35. doi:10.1179/0960340914Z.00000000058.

[91] B.A. Pint, S. Dryepondt, K.A. Unocic, D.T. Hoelzer, Development of ODS FeCrAl for compatibility in fusion and fission energy applications, Jom. 66 (2014) 2458-2466. doi:10.1007/s11837-014-1200-z.

[92] K.A. Unocic, D.T. Hoelzer, B.A. Pint, Microstructure and environmental resistance of low Cr ODS FeCrAl, Mater. High Temp. 32 (2015) 123-132. doi:10.1179/0960340914Z.00000000088.

[93] E.J. Felten, High-Temperature Oxidation of Fe-Cr Base Alloys with Particular Reference to Fe-CrY Alloys, J. Electrochem. Soc. 108 (1961) 490. doi:10.1149/1.2428122.

[94] R.B. Rebak, V.K. Gupta, M. Larsen, Oxidation Characteristics of Two FeCrAl Alloys in Air and Steam from $800^{\circ} \mathrm{C}$ to $1300^{\circ} \mathrm{C}$, Jom. (2018). doi:10.1007/s11837-018-2979-9.

[95] M. Snead, L.L. Snead, K.A. Terrani, K.G. Field, A. Worrall, K.R. Robb, Y. Yamamoto, J. Powers, S. Dryepondt, B.A. Pint, X. HU, Technology Implementation Plan ATF FeCrAl Cladding for LWR Application, ORNL/TM-2014/353. (2015).

[96] S.A. Briggs, P.D. Edmondson, K.C. Littrell, Y. Yamamoto, R.H. Howard, C.R. Daily, K.A. Terrani, K. Sridharan, K.G. Field, A combined APT and SANS investigation of $\alpha$ ' phase precipitation in neutron-irradiated model FeCrAl alloys, Acta Mater. 129 (2017) 217-228. doi:10.1016/j.actamat.2017.02.077.

[97] I. Kvernes, M. Oliveira, P. Kofstad, High temperature oxidation of Fe $13 \mathrm{Cr}$ xAl alloys in vapour mixtures, Corros. Sci. 17 (1977) 237-252. doi:10.1016/0010-938X(77)90049-X.

[98] B. Pieraggi, Calculations of parabolic reaction rate constants, Oxid. Met. 27 (1987) 177-185. doi:10.1007/BF00667057.

[99] K. Robb, M. Howell, L.J. Ott, Parametric and experimentally informed BWR Severe Accident Analysis Utilizing FeCrAl, ORNL/TM-2017/373. (2017).

[100] J.W. McMurray, R. Hu, S.V. Ushakov, D. Shin, B.A. Pint, K.A. Terrani, A. Navrotsky, Solidliquid phase equilibria of Fe-Cr-Al alloys and spinels, J. Nucl. Mater. 492 (2017) 128-133. doi:10.1016/j.jnucmat.2017.05.016.

[101] N. Li, S.S. Parker, E.S. Wood, A.T. Nelson, Oxide Morphology of a FeCrAl Alloy, Kanthal APMT, Following Extended Aging in Air at $300^{\circ} \mathrm{C}$ to $600{ }^{\circ} \mathrm{C}$, Metall. Mater. Trans. A Phys. Metall. Mater. Sci. 49 (2018) 1-11. doi:10.1007/s11661-018-4649-5.

[102] F. Liu, H. Josefsson, J.-E. Svensson, L.-G. Johansson, M. Halvarsson, TEM investigation of the oxide scales formed on a FeCrAlRE alloy (Kanthal AF) at $900^{\circ} \mathrm{C}$ in dry $\mathrm{O} 2$ and $\mathrm{O} 2$ with $40 \%$ H2O, Mater. High Temp. 22 (2005) 521-526. 
doi:10.1179/mht.2005.062org/10.1179/mht.2005.062.

[103] K.A. Terrani, B.A. Pint, Y.J. Kim, K.A. Unocic, Y. Yang, C.M. Silva, H.M. Meyer, R.B. Rebak, Uniform corrosion of FeCrAl alloys in LWR coolant environments, J. Nucl. Mater. 479 (2016) 36-47. doi:10.1016/j.jnucmat.2016.06.047.

[104] P. Scott, A review of irradiation assisted stress corrosion cracking, J. Nucl. Mater. 211 (1994) 101-122. doi:10.1016/0022-3115(94)90360-3.

[105] G.S. Was, P.L. Andersen, Stress Corrosion Cracking Behavior of Alloys in Aggressive Nuclear Reactor Core Enviroments, Corrosion. 63 (1997) 19-45.

[106] R.B. Rebak, Alloy Selection for Accident Tolerant Fuel Cladding in Commercial Light Water Reactors, Metall. Mater. Trans. E. 2 (2015) 197-207. doi:10.1007/s40553-015-0057-6.

[107] P.L. Andresen, R.B. Rebak, E. Dolley, SCC Resistance of Irradiated and Unirradiated High Cr Ferritic Steels, in: Corros. 2014, NACE International, 2014.

[108] P.M. Ahmedabadi, G.S. Was, Stress corrosion cracking of ferritic-maretensitic steels in simulated boiling water reactor environment, Corrosion. 72 (2015) 66-77.

[109] X. Hu, K.A. Terrani, B.D. Wirth, L.L. Snead, Hydrogen permeation in FeCrAl alloys for LWR cladding application, J. Nucl. Mater. 461 (2015) 282-291. doi:10.1016/j.jnucmat.2015.02.040.

[110] E.H. Van Deventer, V.A. MacLaren, V.A. Maroni, Hydrogen permeation characteristics of aluminum-coated and aluminum-modified steels, J. Nucl. Mater. 88 (1980) 168-173. doi:10.1016/0022-3115(80)90397-9.

[111] J.T. Bell, J.D. Redman, H.F. Bittner, Tritium permeation through clean construction alloys, J. Mater. Energy Syst. 1 (1979) 55-59. doi:10.1007/BF02833332.

[112] J.T. Bell, J.D. Redman, Tritium permeation through steam generator materials, in: No. CONF790803-38, Oak Ridge National Laboratory, 1979.

[113] Y.-P. Xu, S.-X. Zhao, F. Liu, X.-C. Li, M.-Z. Zhao, J. Wang, T. Lu, S.-H. Hong, H.-S. Zhou, G.N. Luo, Studies on oxidation and deuterium permeation behavior of a low temperature $\alpha$-Al2O3forming FeCrAl ferritic steel, J. Nucl. Mater. 477 (2016) 257-262. doi:10.1016/j.jnucmat.2016.04.054.

[114] B.G. Ashdown, Alloy Development for Irradiation Performance, DOE/ER-0045/2. (1980).

[115] C.S. Marchi, B.P. Somerday, S.L. Robinson, Permeability, solubility and diffusivity of hydrogen isotopes in stainless steels at high gas pressures, Int. J. Hydrogen Energy. 32 (2007) 100-116. doi:10.1016/j.ijhydene.2006.05.008.

[116] J.R. Wermer, Initial Results from Deuterium Diffusion Experiments on FeCrAl Tubing, 2015.

[117] K.G. Field, S.A. Briggs, X. Hu, Y. Yamamoto, R.H. Howard, K. Sridharan, Heterogeneous dislocation loop formation near grain boundaries in a neutron-irradiated commercial FeCrAl alloy, J. Nucl. Mater. 483 (2017) 54-61. doi:10.1016/j.jnucmat.2016.10.050.

[118] D. Zhang, S.A. Briggs, K.G. Field, Role of refractory inclusions in the radiation-induced microstructure of APMT, J. Nucl. Mater. 505 (2018). doi:10.1016/j.jnucmat.2018.04.017.

[119] O. Anderoglu, E. Aydogan, S.A. Maloy, Y. Wang, Ion Irradiation Testing and Characterization of FeCrAl Candidate Alloys, (2014).

[120] E. Aydogan, J.S. Weaver, S.A. Maloy, O. El-Atwani, Y.Q. Wang, N.A. Mara, Microstructure and mechanical properties of $\mathrm{FeCrAl}$ alloys under heavy ion irradiations, J. Nucl. Mater. 503 (2018) 
250-262. doi:10.1016/j.jnucmat.2018.03.002.

[121] J. Haley, S.A. Briggs, P.D. Edmondson, K. Sridharan, S. Roberts, S. Lozano-Perez, K.G. Field, Dislocation loop evolution during in-situ ion irradiation of model FeCrAl alloys, Acta Mater. (2017). doi:10.1016/j.actamat.2017.07.011.

[122] M.L. Jenkins, Kirk, Characterization of Radiation Damage by Transmission Electron Microscopy, Taylor \& Francis, 2000.

[123] C.M. Parish, K.G. Field, A.G. Certain, J.P. Wharry, Application of STEM characterization for investigating radiation effects in BCC Fe-based alloys, J. Mater. Res. 30 (2015) 1246-1274. doi:10.1557/jmr.2015.32.

[124] K.G. Field, S.A. Briggs, K. Sridharan, Y. Yamamoto, R.H. Howard, Dislocation Loop Formation in Model FeCrAl Alloys After Neutron Irradiation Below 1 dpa, J. Nucl. Mater. 495 (2017).

[125] S.A. Briggs, Correlative Microscopy of $\alpha$ ' Precipitation in Neutron-Irradiated Fe-Cr-Al Alloys, University of Wisconsin - Madison, 2016.

[126] K.G. Field, K.C. Littrell, S.A. Briggs, Precipitation of $\alpha^{\prime}$ in neutron irradiated commercial FeCrAl alloys, Scr. Mater. 142 (2018) 41-45. doi:10.1016/j.scriptamat.2017.08.022.

[127] P.D. Edmondson, S.A. Briggs, Y.Yamamoto, R.H. Howard, K. Sridharan, K.A. Terrani, K.G. Field, Irradiation-enhanced $\alpha$ ' precipitation in model FeCrAl alloys, Scr. Mater. 116 (2016) 112116. doi:10.1016/j.scriptamat.2016.02.002.

[128] S.A. Briggs, K. Sridharan, K.G. Field, Correlative Microscopy of Neutron-Irradiated Materials, Adv. Mater. Process. 174 (2016) 16-21.

[129] E.R. Anderson, G.R. Odette, N. Almirall, S. Tumey, E.A. Marquis, On the Dose Rate Dependence of Cr Clustering in Ion-Irradiated Fe-18Cr Alloys, Microsc. Microanal. 23 (2017) 690-691. doi:10.1017/s1431927617004111.

[130] E.R. Reese, N. Almirall, T. Yamamoto, S. Tumey, G. Robert Odette, E.A. Marquis, Dose rate dependence of Cr precipitation in an ion-irradiated Fe18Cr alloy, Scr. Mater. 146 (2018) 213-217. doi:10.1016/J.SCRIPTAMAT.2017.11.040.

[131] C. Pareige, V. Kuksenko, P. Pareige, Behaviour of P, Si, Ni impurities and $\mathrm{Cr}$ in self ion irradiated $\mathrm{Fe}-\mathrm{Cr}$ alloys - Comparison to neutron irradiation, (2015). doi:10.1016/j.jnucmat.2014.10.024.

[132] E. Marquis, B. Wirth, G. Was, Characterization and Modeling of Grain Boundary Chemistry Evolution in Ferritic Steels under Irradiation, (2016). doi:10.2172/1248953.

[133] A. Umantsev, G.B. Olson, Ostwald ripening in multicomponent alloys, Scr. Metall. Mater. 29 (1993) 1135-1140.

[134] M. Bachhav, G. Robert Odette, E.A. Marquis, $\alpha^{\prime}$ precipitation in neutron-irradiated Fe-Cr alloys, Scr. Mater. 74 (2014) 48-51. doi:10.1016/j.scriptamat.2013.10.001.

[135] M. Bachhav, L. Yao, G. Robert Odette, E.A. Marquis, Microstructural changes in a neutronirradiated Fe-6at.\%Cr alloy, J. Nucl. Mater. 453 (2014) 334-339. doi:10.1016/j.jnucmat.2014.06.050.

[136] M. Bachhav, G. Robert Odette, E.A. Marquis, Microstructural changes in a neutron-irradiated Fe15at.\%Cr alloy, J. Nucl. Mater. 454 (2014) 381-386. doi:10.1016/j.jnucmat.2014.08.026.

[137] S. Novy, P. Pareige, C. Pareige, Atomic scale analysis and phase separation understanding in a thermally aged Fe-20at.\%Cr alloy, J. Nucl. Mater. 384 (2009) 96-102. doi:10.1016/j.jnucmat.2008.10.008. 
[138] M.N. Gussev, E. Cakmak, K.G. Field, Impact of neutron irradiation on mechanical performance of FeCrAl alloy laser-beam weldments, J. Nucl. Mater. 504 (2018). doi:10.1016/j.jnucmat.2018.03.036.

[139] M.N. Gussev, J.T. Busby, K.G. Field, M.A. Sokolov, S.E. Gray, Role of Scale Factor During Tensile Testing of Small Specimens, (2014) 1-19. doi:10.1520/stp157620140013.

[140] M.N. Gussev, R.H. Howard, K.A. Terrani, K.G. Field, Sub-size tensile specimen design for inreactor irradiation and post-irradiation testing, Nucl. Eng. Des. 320 (2017) 298-308. doi:10.1016/j.nucengdes.2017.06.008.

[141] F. Bergner, C. Pareige, M. Hernández-Mayoral, L. Malerba, C. Heintze, Application of a threefeature dispersed-barrier hardening model to neutron-irradiated $\mathrm{Fe}-\mathrm{Cr}$ model alloys, J. Nucl. Mater. 448 (2014) 96-102. doi:10.1016/j.jnucmat.2014.01.024.

[142] K.-H. Park, J.C. LaSalle, L.H. Schwartz, M. Kato, Mechanical properties of spinodally decomposed Fe-30 wt\% Cr alloys: Yield strength and aging embrittlement, Acta Metall. 34 (1986) 1853-1865. doi:10.1016/0001-6160(86)90130-6.

[143] A. Triki, F. Bley, Y. Brechet, F. Louchet, On the origin of hardening in aged FeCr alloys: relation between unmixing and mechanical properties, in: U. Messerschmidt, F. Appel, J. Heydenreich, V. Schmidt (Eds.), Electron Microsc. Plast. Fract. Res. Mater., Akademie-Verlag, Berlin, 1989: pp. 139-147.

[144] O. Anderoglu, E. Aydogan, S.A. Maloy, Y. Wang, Ion Irradiation Testing and Characterization of FeCrAl Candidate Alloys, LA-UR-14-27194. 13 (2014).

[145] F.A. Garner, M.B. Toloczko, B.H. Sencer, Comparison of swelling and irradiation creep behavior of fcc-austenitic and bcc-ferritic/martensitic alloys at high neutron exposure, J. Nucl. Mater. 276 (2000) 123-142. doi:10.1016/S0022-3115(99)00225-1.

[146] G.S. Was, D. Farkas, I.M. Robertson, Micromechanics of dislocation channeling in intergranular stress corrosion crack nucleation, Curr. Opin. Solid State Mater. Sci. 16 (2012) 134-142. doi:10.1016/j.cossms.2012.03.003.

[147] M.N. Gussev, K.G. Field, J.T.J. Busby, Deformation localization and dislocation channel dynamics in neutron-irradiated austenitic stainless steels, J. Nucl. Mater. 460 (2015) 139-152. doi:10.1016/j.jnucmat.2015.02.008.

[148] D. Carpenter, Irradiation History Report, No Rep. Number Provid. (2017) 1-7.

[149] D. Carpenter, G. Kohse, Final Report ORNL Hybrid Composites Loop ATF Irradiation Design and Analysis Report, No Rep. Number Provid. (2018).

[150] S. Hayes, DOE and Industry Testing of Accident Tolerant Fuels, (2018).

[151] G. Core, Fuel Cycle Research and Development Accident Tolerant Fuels Series 1 ( ATF-1 ) Irradiation Testing FY 2016 Status Report Fuel Cycle Research \& Development Advanced Fuels Campaign, INL/EXT-16-39804. (2016).

[152] L. Ott, Personal communication on MOX fuels irradiation test plan, 2013.

[153] S. Hayes, K. Barrett, I.N. Laboratory, Irradiation Testing of Accident Tolerant Fuels in the ATR (The ATF-1 Test Series), INL/PNL-4444. (2013).

[154] K.G. Field, J.M. Harp, G. Core, K. Linton, Status of Wrought FeCrAl-UO 2 Capsules Irradiated in the Advanced Test Reactor, ORNL/TM-2017/366. (2017).

[155] S.A. Hole, IFE decides to close the Halden Reactor, but continues nuclear research activities - 
IFE, (2018). https://www.ife.no/en/ife/ife_news/2018/haldenreaktoren-stenges-men-ife-satservidere-i-halden (accessed July 16, 2018).

[156] R. Szoke, M.A. McGrath, P. Bennett, Dimensional Behaviour Testing of Accident Tolerant Fuel (ATF) in the Halden Reactor, in: 2017 Water React. Fuel Perform. Meet., 2017: pp. 1-9.

[157] J.T. Wheat, Edwin I. Hatch Nuclear Plant, Unit 1 - Information Reports for Lead Test Assemblies., NL-18-0026. (2018). https://www.nrc.gov/docs/ML1801/ML18012A057.pdf (accessed July 24, 2018).

[158] Global Nuclear Fuel, GNF FeCrAl ATF Lead Test Assembly for Edwin I. Hatch Nuclear Plant, Unit 1, NEDO-33884 Revis. 0. (2017). https:/www.nrc.gov/docs/ML1801/ML18012A058.pdf (accessed July 24, 2018).

[159] R. Stachowski, R. Fawcett, R.B. Rebak, W. Gassmann, J.B. Williams, K.A. Terrani, Progress of GE Development of Accident Tolerant Fuel FeCrAl Cladding, in: 2017 Water React. Fuel Perform. Meet., Jeju Island, Korea, 2017: pp. 1-11.

[160] D. Bost, NRC Briefing Accident Tolerant Fuel, (2018). https://www.nrc.gov/reading-rm/doccollections/commission/slides/2018/20180412/bost-20180412.pdf (accessed July 24, 2018).

[161] K.G. Field, M.N. Gussev, R. Howard, Y. Yamamoto, R. Howard, S. Briggs, First Annual Progress Report on Radiation Tolerance of Controlled Fusion Welds in High Temperature Oxidation Resistant FeCrAl Alloys, ORNL/TM-2015/770. (2015). http://www.ntis.gov/help/ordermethods.aspx (accessed July 16, 2017).

[162] K.G. Field, M.N. Gussev, Y. Yamamoto, R. Howard, S. Briggs, Second Annual Progress Report on Radiation Tolerance of Controlled Fusion Welds in High Temperature Oxidation Resistant FeCrAl Alloys, ORNL/TM-2016/770. (2016). http://www.ntis.gov/help/ordermethods.aspx (accessed July 16, 2017).

[163] K.G. Field, M.N. Gussev, X. Hu, Y. Yamamoto, Preliminary Results on FeCrAl Alloys in the Asreceived and Welded State Designed to Have Enhanced Weldability and Radiation Tolerance, ORNL/TM-2015/579. (2015).

[164] Y. Yamamoto, M.N. Gussev, B.A. Pint, K.A. Terrani, Examination of Compressive Deformation Routes for Production of ATF FeCrAl Tubes, ORNL/TM-2016/509. (2016).

[165] Z. Sun, H. Bei, Y. Yamamoto, Microstructural control of FeCrAl alloys using Mo and Nb additions, Mater. Charact. 132 (2017) 126-131. doi:10.1016/j.matchar.2017.08.008.

[166] J. Ejenstam, B. Jönsson, P. Szakalos, Optimizing the Oxidation Properties of FeCrAl Alloys at Low Temperatures, Oxid. Met. 88 (2017) 361-370. doi:10.1007/s11085-017-9718-4.

[167] Y. Yan, J.R. Keiser, K.A. Terrani, G.L. Bell, L.L. Snead, Post-quench ductility evaluation of Zircaloy-4 and select iron alloys under design basis and extended LOCA conditions, J. Nucl. Mater. 448 (2014) 436-440. doi:10.1016/j.jnucmat.2013.05.071.

[168] R.B. Rebak, M. Larsen, Y.J. Kim, Characterization of oxides formed on iron-chromiumAluminum alloy in simulated light water reactor environments, Corros. Rev. 35 (2017) 177-188. doi:10.1515/corrrev-2017-0011.

[169] Kanthal, Kanthal APM Tube datasheet, (2017). http://www.kanthal.com/en/products/materialdatasheets/tube/kanthal-apm (accessed January 1, 2017).

[170] Kanthal, Kanthal Alkrothal-720 strip datasheet, (2017). http://www.kanthal.com/en/products/material-datasheets/strip/alkrothal-720/ (accessed January 1, 2017). 
[171] Kanthal, Kanthal Kanthal A-1 strip datasheet, (2017).

[172] Kanthal, Kanthal Kanthal-D strip datasheet, (2017). http:/www.kanthal.com/en/products/materialdatasheets/strip/kanthal-d/ (accessed January 1, 2017). 


\section{Handbook on the Material Properties of FeCrAl Alloys for Nuclear Power Production Applications}

\section{APPENDIX A}

Table A: Candidate FeCrAl alloys for nuclear applications.

\begin{tabular}{|c|c|c|c|c|}
\hline Alloy Designation & Originator & Known Heat Numbers & $\begin{array}{c}\text { Nominal } \\
\text { Composition, wt.\% }\end{array}$ & Reference \\
\hline 561 & GE & M-237, M-236, MS-59 & Fe-5Cr-6Al-1Y & {$[2,4,5]$} \\
\hline 0561+Mo & GE & M-237, MS-64 & Fe-5Cr-6Al-1Y-3Mo & {$[2,4,5]$} \\
\hline 1041 & GE & M-239, MS-60 & Fe-10Cr-4Al-1Y & {$[2,4,5]$} \\
\hline 1061 & GE & MS-61 & Fe-10Cr-6Al-1Y & [5] \\
\hline 1540 & GE & M-230, MS-49 & $\mathrm{Fe}-15 \mathrm{Cr}-4 \mathrm{Al}$ & {$[4]$} \\
\hline 1541 & GE & MS-38, MS,41, MS-47, MS-50, MS-51, M-231 & Fe-15Cr-4Al-1Y & {$[2,4,5]$} \\
\hline $254(0.35)$ & GE & MS-13 & $\mathrm{Fe}-25 \mathrm{Cr}-4 \mathrm{Al}-0.35 \mathrm{Y}$ & {$[4]$} \\
\hline $253(0.5)$ & $\mathrm{GE}$ & MS-10 & $\mathrm{Fe}-25 \mathrm{Cr}-3 \mathrm{Al}-0.5 \mathrm{Y}$ & [4] \\
\hline 2540 & GE & & $\mathrm{Fe}-25 \mathrm{Cr}-4 \mathrm{Al}$ & \\
\hline $2541+1 \mathrm{Nb}$ & GE & MS-33 & $\mathrm{Fe}-25 \mathrm{Cr}-4 \mathrm{Al}-1 \mathrm{Y}-1 \mathrm{Nb}$ & {$[4]$} \\
\hline 2541 & $\mathrm{GE}$ & MS-32, MS-36, MS-46, MS-62 & Fe-25Cr-4Al-1Y & {$[2,4,5]$} \\
\hline $0561+\mathrm{Nb}$ & GE & M-238, M-233 & $\mathrm{Fe}-5 \mathrm{Cr}-6 \mathrm{Al}-1 \mathrm{Nb}$ & {$[4]$} \\
\hline 563 & GE & MS-44 & Fe-5Cr-6Al-3Y & [4] \\
\hline $057(1.5)$ & GE & FM-65278 & Fe-5Cr-7Al-1.5Y & [4] \\
\hline $136(1.5)$ & GE & FM-65277 & $\mathrm{Fe}-13 \mathrm{Cr}-6 \mathrm{Al}-1.5 \mathrm{Y}$ & [4] \\
\hline $\mathrm{B} 055 \mathrm{Y}$ & ORNL & $\mathrm{B} 055 \mathrm{Y}$ & $\mathrm{Fe}-5 \mathrm{Cr}-5 \mathrm{Al}-0.05 \mathrm{Y}$ & \\
\hline B058Y & ORNL & B058Y & $\mathrm{Fe}-5 \mathrm{Cr}-8 \mathrm{Al}-0.05 \mathrm{Y}$ & [21] \\
\hline $\mathrm{B} 085 \mathrm{Y}$ & ORNL & $\mathrm{B} 085 \mathrm{Y}$ & $\mathrm{Fe}-8 \mathrm{Cr}-5 \mathrm{Al}-0.05 \mathrm{Y}$ & \\
\hline B086Y & ORNL & B086Y & $\mathrm{Fe}-8 \mathrm{Cr}-6 \mathrm{Al}-0.05 \mathrm{Y}$ & \\
\hline $\mathrm{B} 087 \mathrm{Y}$ & ORNL & $\mathrm{B} 087 \mathrm{Y}$ & $\mathrm{Fe}-8 \mathrm{Cr}-7 \mathrm{Al}-0.05 \mathrm{Y}$ & [21] \\
\hline B088Y & ORNL & B088Y & Fe-8Cr-8Al-0.05Y & [21] \\
\hline $\mathrm{B} 105 \mathrm{Y}$ & ORNL & $\mathrm{B} 105 \mathrm{Y}$ & $\mathrm{Fe}-10 \mathrm{Cr}-5 \mathrm{~A} ;-0.05 \mathrm{Y}$ & [21] \\
\hline B106Y & ORNL & B106Y, B106Y2 (MH*) & $\mathrm{Fe}-10 \mathrm{Cr}-6 \mathrm{Al}-0.05 \mathrm{Y}$ & [21] \\
\hline $\mathrm{B} 107 \mathrm{Y}$ & ORNL & $\mathrm{B} 107 \mathrm{Y}$ & $\mathrm{Fe}-10 \mathrm{Cr}-7 \mathrm{Al}-0.05 \mathrm{Y}$ & \\
\hline B108Y & ORNL & B108Y & $\mathrm{Fe}-10 \mathrm{Cr}-8 \mathrm{Al}-0.05 \mathrm{Y}$ & {$[21]$} \\
\hline $\mathrm{B} 125 \mathrm{Y}$ & ORNL & $\mathrm{B} 125 \mathrm{Y}, \mathrm{B} 125 \mathrm{Y} 2\left(\mathrm{MH}^{*}\right)$ & Fe-12Cr-4.5Al-0.05Y & {$[14,21,24,96,121,125,127]$} \\
\hline $\mathrm{B} 126 \mathrm{Y}$ & ORNL & B126Y & $\mathrm{Fe}-12 \mathrm{Cr}-6 \mathrm{Al}-0.05 \mathrm{Y}$ & \\
\hline B134Y & ORNL & $\mathrm{B} 134 \mathrm{Y}$ & Fe-13Cr-4Al-0.05Y & \\
\hline $\mathrm{T} 35 \mathrm{Y}$ & ORNL & $\mathrm{T} 35 \mathrm{Y}$ & Fe-13Cr-4.5Al-0.15Y & [109] \\
\hline $\mathrm{T} 35 \mathrm{Y} 2$ & SAI* & T35Y2 (\#13054147-1) & Fe-13Cr-4.5Al-0.15Y & \\
\hline $\mathrm{B} 135 \mathrm{Y}$ & ORNL & B135Y, B135Y2, B135Y3 (MH*) & $\mathrm{Fe}-13 \mathrm{Cr}-5 \mathrm{Al}-0.05 \mathrm{Y}$ & \\
\hline $\mathrm{B} 136 \mathrm{Y}$ & ORNL & B136Y, B136Y2, B136Y3 (MH*) & $\mathrm{Fe}-13 \mathrm{Cr}-6 \mathrm{Al}-0.05 \mathrm{Y}$ & \\
\hline $\mathrm{B} 137 \mathrm{Y}$ & ORNL & B137Y & $\mathrm{Fe}-13 \mathrm{Cr}-7 \mathrm{Al}-0.05 \mathrm{Y}$ & \\
\hline $\mathrm{T} 54 \mathrm{Y}$ & ORNL & $\mathrm{T} 54 \mathrm{Y}$ & $\mathrm{Fe}-15 \mathrm{Cr}-4 \mathrm{Al}-0.15 \mathrm{Y}$ & \\
\hline T54Y2 & $\mathrm{SAI}^{* *}$ & T54Y2 (13054147-2) & $\mathrm{Fe}-15 \mathrm{Cr}-4 \mathrm{Al}-0.15 \mathrm{Y}$ & \\
\hline $\mathrm{B} 154 \mathrm{Y}$ & ORNL & $\mathrm{B} 154 \mathrm{Y}, \mathrm{B} 154 \mathrm{Y} 2\left(\mathrm{MH}^{*}\right)$ & $\mathrm{Fe}-15 \mathrm{Cr}-4 \mathrm{Al}-0.05 \mathrm{Y}$ & {$[14,24,41,96,121,125,127]$} \\
\hline $\mathrm{B} 155 \mathrm{Y}$ & ORNL & $\mathrm{B} 155 \mathrm{Y}$ & $\mathrm{Fe}-15 \mathrm{Cr}-5 \mathrm{Al}-0.05 \mathrm{Y}$ & \\
\hline F5C5AY & ORNL & F5C5AY & $\mathrm{Fe}-15 \mathrm{Cr}-5 \mathrm{Al}-0.15 \mathrm{Y}$ & \\
\hline $\mathrm{B} 166 \mathrm{Y}$ & ORNL & B166Y & Fe-16Cr-6Al-0.05Y & \\
\hline B183Y & ORNL & B183Y, B183Y2 (MH*) & $\mathrm{Fe}-17.5 \mathrm{Cr}-3 \mathrm{Al}-0.05 \mathrm{Y}$ & {$[14,24,41,96,121,125,127]$} \\
\hline $\mathrm{B} 184 \mathrm{Y}$ & ORNL & $\mathrm{B} 184 \mathrm{Y}$ & Fe-17.5Cr-4Al-0.05Y & \\
\hline $\mathrm{B} 105 \mathrm{~N}$ & ORNL & $\mathrm{B} 105 \mathrm{~N}$ & $\mathrm{Fe}-10 \mathrm{Cr}-5 \mathrm{Al}$ & \\
\hline B203N & ORNL & B203N & $\mathrm{Fe}-20 \mathrm{Cr}-3 \mathrm{Al}$ & \\
\hline
\end{tabular}




\begin{tabular}{|c|c|c|c|c|}
\hline Alloy Designation & Originator & Known Heat Numbers & $\begin{array}{c}\text { Nominal } \\
\text { Composition, wt.\% } \\
\end{array}$ & Reference \\
\hline $\mathrm{C} 35 \mathrm{M}$ & ORNL & C35M, C35M2, C35M3, C35M4-1, C35M4-2 & $\begin{array}{c}\mathrm{Fe}-13 \mathrm{Cr}-5 \mathrm{Al}-2 \mathrm{Mo} \\
-0.2 \mathrm{Si}-0.05 \mathrm{Y} \\
\end{array}$ & {$[14,37,42]$} \\
\hline $\mathrm{C} 35 \mathrm{MN}$ & ORNL, SAI** & $\begin{array}{c}\text { C35MN, C35MN2 (by ORNL), } \\
\text { C35MN6B (by ORNL), } \\
\text { C35MN5 (\#13114246-1, by SAI**) }\end{array}$ & $\begin{array}{l}\mathrm{Fe}-13 \mathrm{Cr}-5 \mathrm{Al}-2 \mathrm{Mo} \\
-1 \mathrm{Nb}-0.2 \mathrm{Si}-0.05 \mathrm{Y}\end{array}$ & {$[14,42]$} \\
\hline $\mathrm{C} 37 \mathrm{M}$ & $\begin{array}{l}\text { ORNL, } \\
\text { SAI** }\end{array}$ & $\begin{array}{c}\mathrm{C} 37 \mathrm{M}(\mathrm{ORNL}) \\
\mathrm{C} 37 \mathrm{M}(\# 14084401-\mathrm{C} 37 \mathrm{M}) \\
\end{array}$ & $\begin{array}{c}\mathrm{Fe}-13 \mathrm{Cr}-7 \mathrm{Al}-2 \mathrm{Mo} \\
-0.2 \mathrm{Si}-0.05 \mathrm{Y} \\
\end{array}$ & {$[14,42]$} \\
\hline $\mathrm{C} 06 \mathrm{M}$ & ORNL & $\mathrm{C} 06 \mathrm{M}, \mathrm{C} 06 \mathrm{M} 2$ & $\begin{array}{c}\mathrm{Fe}-10 \mathrm{Cr}-6 \mathrm{Al}-2 \mathrm{Mo} \\
-0.2 \mathrm{Si}-0.05 \mathrm{Y} \\
\end{array}$ & {$[120]$} \\
\hline $\mathrm{C} 36 \mathrm{M}$ & ORNL & $\mathrm{C} 36 \mathrm{M} 2, \mathrm{C} 36 \mathrm{M} 3$ & $\begin{array}{c}\mathrm{Fe}-13 \mathrm{Cr}-6 \mathrm{Al}-2 \mathrm{Mo} \\
-0.2 \mathrm{Si}-0.05 \mathrm{Y} \\
\end{array}$ & {$[120]$} \\
\hline C35M01TC & ORNL & C35M01TC (\#20766) & $\begin{array}{c}\mathrm{Fe}-10 \mathrm{Cr}-5 \mathrm{Al}-2 \mathrm{Mo} \\
-0.2 \mathrm{Si}-0.05 \mathrm{Y}+0.1 \mathrm{TiC} \\
\end{array}$ & {$[42,161-164]$} \\
\hline $\mathrm{C} 35 \mathrm{M} 03 \mathrm{TC}$ & ORNL & C35M01TC (\#20767) & $\begin{array}{c}\text { Fe-10Cr-5 Al-2Mo } \\
-0.2 \mathrm{Si}-0.05 \mathrm{Y}+0.3 \mathrm{TiC} \\
\end{array}$ & {$[42]$} \\
\hline C35M10TC & ORNL & C35M01TC (\#20768) & $\begin{array}{c}\mathrm{Fe}-10 \mathrm{Cr}-5 \mathrm{Al}-2 \mathrm{Mo} \\
-0.2 \mathrm{Si}-0.05 \mathrm{Y}+1.0 \mathrm{TiC}\end{array}$ & {$[42]$} \\
\hline $\mathrm{C} 26 \mathrm{M}$ & ORNL & $\mathrm{C} 26 \mathrm{M}, \mathrm{C} 26 \mathrm{M} 2$ & $\begin{array}{c}\mathrm{Fe}-12 \mathrm{Cr}-6 \mathrm{Al} \\
-2 \mathrm{Mo}-0.2 \mathrm{Si}-0.05 \mathrm{Y} \\
\end{array}$ & [94] \\
\hline FeCrAl-2Mo & ORNL & NS*** & $\begin{array}{c}\text { Fe-13Cr-6Al-2Mo } \\
-0.2 \mathrm{Si}-0.05 \mathrm{Y} \\
\end{array}$ & {$[33,165]$} \\
\hline $\mathrm{FeCrAl}-0.7 \mathrm{Nb}$ & ORNL & NS*** & $\begin{array}{c}\mathrm{Fe}-13 \mathrm{Cr}-6 \mathrm{Al}-0.7 \mathrm{Nb} \\
-0.2 \mathrm{Si}-0.05 \mathrm{Y} \\
\end{array}$ & {$[33,165]$} \\
\hline FeCrAl-1Nb & ORNL & NS*** & $\begin{array}{c}\mathrm{Fe}-13 \mathrm{Cr}-6 \mathrm{Al}-1 \mathrm{Nb} \\
-0.2 \mathrm{Si}-0.05 \mathrm{Y} \\
\end{array}$ & {$[33]$} \\
\hline $\mathrm{FeCrAl}-2 \mathrm{Nb}$ & ORNL & $\mathrm{NS} * * *$ & $\begin{array}{c}\mathrm{Fe}-13 \mathrm{Cr}-6 \mathrm{Al}-2 \mathrm{Nb} \\
-0.2 \mathrm{Si}-0.05 \mathrm{Y} \\
\end{array}$ & {$[33]$} \\
\hline Fe-10Cr-4Al-Zr-0.1 & KTH & NS*** & $\mathrm{Fe}-10 \mathrm{Cr}-4 \mathrm{Al}-0.1 \mathrm{Zr}$ & [166] \\
\hline Fe-10Cr-4Al-Zr-0.2 & $\mathrm{KTH}$ & NS*** & $\mathrm{Fe}-10 \mathrm{Cr}-4 \mathrm{Al}-0.2 \mathrm{Zr}$ & [166] \\
\hline Fe-10Cr-4Al-Zr-0.4 & $\mathrm{KTH}$ & NS*** & $\mathrm{Fe}-10 \mathrm{Cr}-4 \mathrm{Al}-0.4 \mathrm{Zr}$ & [166] \\
\hline Fe-10Cr-4Al-Y-0.02 & $\mathrm{KTH}$ & NS*** & Fe-10Cr-4Al-0.02Y & {$[166]$} \\
\hline Fe-10Cr-4Al-Y-0.1 & KTH & NS*** & $\mathrm{Fe}-10 \mathrm{Cr}-4 \mathrm{Al}-0.1 \mathrm{Y}$ & [166] \\
\hline Fe-10Cr-4Al-Y-0.2 & KTH & NS*** & $\mathrm{Fe}-10 \mathrm{Cr}-4 \mathrm{Al}-0.2 \mathrm{Y}$ & [166] \\
\hline $10 \mathrm{Cr}-4 \mathrm{Al}$ & KTH/Sandvik & NS*** & $\mathrm{Fe}-10 \mathrm{Cr}-4 \mathrm{Al}-0.1 \mathrm{Zr}$ & {$[27]$} \\
\hline $10 \mathrm{Cr}-6 \mathrm{Al}$ & KTH/Sandvik & NS*** & $\mathrm{Fe}-10 \mathrm{Cr}-6 \mathrm{Al}-0.1 \mathrm{Zr}$ & {$[27]$} \\
\hline $10 \mathrm{Cr}-8 \mathrm{Al}$ & KTH/Sandvik & $\mathrm{NS}^{* * *}$ & $\mathrm{Fe}-10 \mathrm{Cr}-8 \mathrm{Al}-0.1 \mathrm{Zr}$ & {$[27]$} \\
\hline $21 \mathrm{Cr}-5 \mathrm{Al}$ & KTH/Sandvik & $\mathrm{NS}^{* * *}$ & $\mathrm{Fe}-21 \mathrm{Cr}-5 \mathrm{Al}-0.1 \mathrm{Zr}$ & {$[27]$} \\
\hline APMT & Kanthal & NS*** & $\mathrm{Fe}-21 \mathrm{Cr}-5 \mathrm{Al}-3 \mathrm{Mo}$ & {$[21,48,61,62,70,101,126,167,168]$} \\
\hline APM & Kanthal & NS*** & $\mathrm{Fe}-21 \mathrm{Cr}-5.8 \mathrm{Al}$ & {$[169]$} \\
\hline Alkothal 720 & Kanthal & NS*** & $\mathrm{Fe}-13 \mathrm{Cr}-4 \mathrm{Al}$ & {$[117,126,170]$} \\
\hline Kanthal A-1 & Kanthal & $\mathrm{NS}^{* * *}$ & $\mathrm{Fe}-21 \mathrm{Cr}-5.8 \mathrm{Al}$ & {$[171]$} \\
\hline Kanthal D & Kanthal & NS*** & $\mathrm{Fe}-21 \mathrm{Cr}-4.8 \mathrm{Al}$ & {$[172]$} \\
\hline $\mathrm{Fe} 20 \mathrm{Cr} 5 \mathrm{Al}$ & $\begin{array}{c}\text { Dongbei } \\
\text { Special Steel } \\
\end{array}$ & NS*** & $\mathrm{Fe}-20 \mathrm{Cr}-5 \mathrm{Al}$ & {$[59]$} \\
\hline
\end{tabular}

*MH: multi heats, **SAI: Sophisticated Alloys, Inc., ***Not specified 